University of Louisville

ThinkIR: The University of Louisville's Institutional Repository

Electronic Theses and Dissertations

$12-2006$

\title{
The effect of modular tapered fluted stems on proximal stress shielding in the human femur.
}

Justin Steve Conway

University of Louisville

Follow this and additional works at: https://ir.library.louisville.edu/etd

\section{Recommended Citation}

Conway, Justin Steve, "The effect of modular tapered fluted stems on proximal stress shielding in the human femur." (2006). Electronic Theses and Dissertations. Paper 273.

https://doi.org/10.18297/etd/273

This Master's Thesis is brought to you for free and open access by ThinkIR: The University of Louisville's Institutional Repository. It has been accepted for inclusion in Electronic Theses and Dissertations by an authorized administrator of ThinkIR: The University of Louisville's Institutional Repository. This title appears here courtesy of the author, who has retained all other copyrights. For more information, please contact thinkir@louisville.edu. 
THE EFFECT OF MODULAR TAPERED FLUTED STEMS ON PROXIMAL STRESS SHIELDING IN THE HUMAN FEMUR

\author{
By \\ Justin Steve Conway \\ B.S., University of Louisville, 2005

\begin{abstract}
A Thesis
Submitted to the Faculty of the

University of Louisville

J.B. Speed School of Engineering

in Partial Fulfillment of the Requirements

for the Professional Degree
\end{abstract}

\title{
MASTER OF ENGINEERING
}

Department of Mechanical Engineering

December 2006 



\section{THE EFFECT OF TAPERED FLUTED STEMS ON PROXIMAL STRESS SHIELDING IN THE HUMAN FEMUR}

Submitted by:

Justin Steve Conway

A Thesis Approved on

(Date)

by the Following Reading and Examination Committee:

Dr. William P. Hnat, Thesis Director

Dr. Michael J. Voor

Dr. Terence A. Weigel 


\section{ACKNOWLEDEMENTS}

I would like to thank Dr. Hnat for this excellent thesis opportunity and his expertise and guidance throughout. I would also like to thank John Jones and Dr. Arthur Malkani for their assistance with the many tasks involved with this study. Special thanks to Howmedica Osteonics Corporation for their financial support.

I would like to thank God for my many blessings. I would like to thank my parents

for their love and support throughout engineering school. Finally, I would like to give a special thanks to my wife, Ashley, for her unconditional love and encouragement. 


\begin{abstract}
Modular hip implants are currently being used in total hip arthroplasty revision procedures because it is common to have little or no bone left in the proximal region of the femur and it is difficult to accurately size implants based off of radiographs or other medical imaging techniques. The effect of modular systems using tapered fluted stems on proximal stress shielding in the human femur is the focus of this study. Seven modular implants were press-fit into seven femurs, where there was little or no contact between the modular body and the test femur. Finally, hydroxyapatite bone cement was added to create an interface between the modular body and femur.

Stress shielding is perhaps one of the most critical complications that occur after total hip arthroplasty (THA). Insertion of the prosthesis permanently alters the stress distribution in the human femur. Stress shielding occurs in those areas in which a bone experiences a reduction of stress. Essentially, the prosthesis "shields" the stress from the bone by transmitting the force through the implant rather than the bone, which can lead to a decrease in bone mineral density due to the reduction of stress or failure of the implant itself.

Seven test femurs were instrumented with strain gages to measure the strain at three different levels. Two loading conditions were applied to represent the forces exerted on the femur when a human is in a natural standing position. The loading conditions were applied to the intact femur: when the prosthesis was inserted into the femur with a pressfit; and when hydroxyapatite bone cement was injected around the implant in the proximal region.
\end{abstract}


All femurs exhibited stress shielding effects after surgically inserting the modular implants. The experimental data confirmed that the greatest amount of stress shielding occurred primarily in the proximal and mid-stem regions. The strains at the junction between the modular body and stem were relatively low. The experimental data also confirmed that with the addition of BoneSource ${ }^{\circledR}$ Hydroxyapatite cement the strain in the proximal and mid-stem regions significantly increased, but stress shielding still occurred. The strains at the junction between the body and stem also decreased. 


\section{TABLE OF CONTENTS}

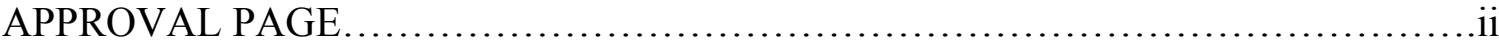

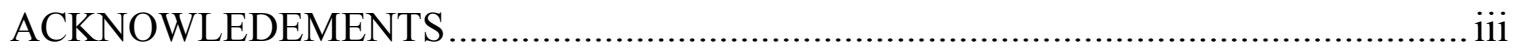

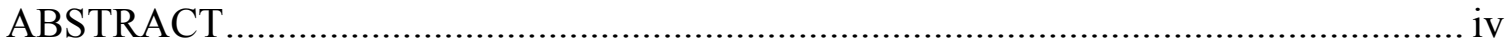

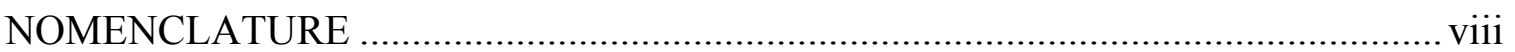

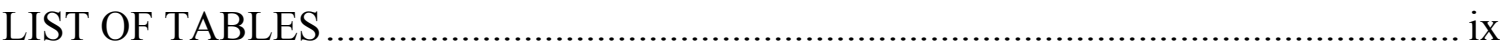

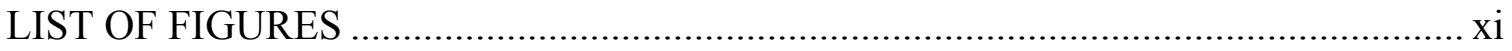

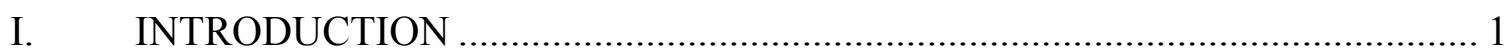

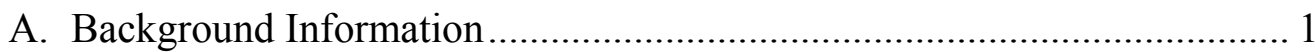

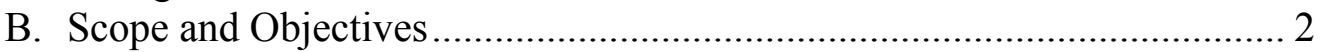

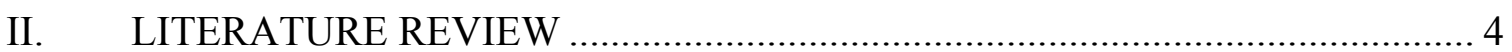

III. INSTRUMENTATION AND EQUIPMENT .................................................. 8

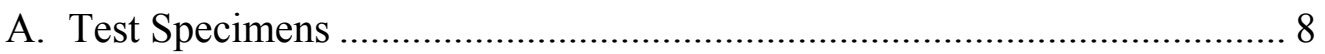

B. Data Acquisition Equipment................................................................ 13

C. Two Leg Stance Model Test Machine .................................................... 17

D. Two-Leg Stance Model and Fixtures....................................................... 20

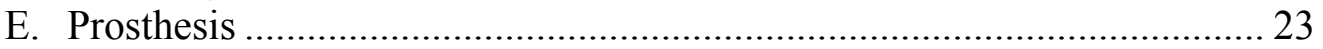

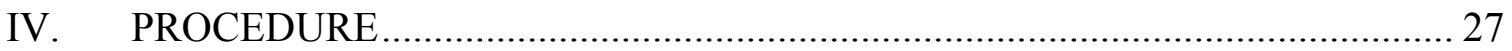

A. Experimental Phases of Study ………………….................................... 27

B. Implementation of Hip Implants ............................................................. 27

C. Alteration of Modular Body Coarse Surface .......................................... 32

D. Placement of Hydroxyapatite Bone Cement............................................... 35

E. Two Leg Stance Testing ........................................................................... 38

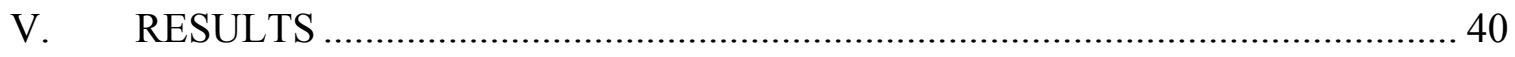

A. Press Fit Prosthesis Strain Data ………………...................................... 40

B. Cemented Prosthesis Data..................................................................... 42

C. Modular Body Strain Data ..................................................................... 46

D. Linearity and Repeatability of Load Cases ............................................... 47

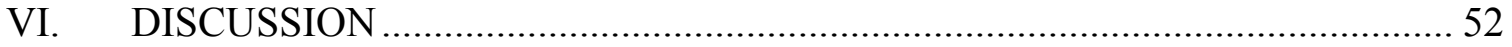




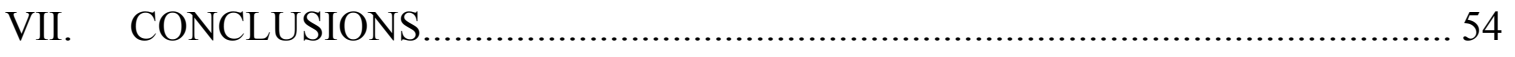

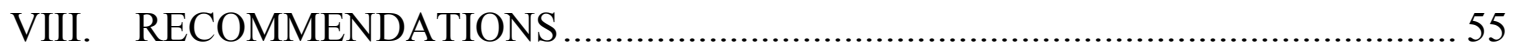

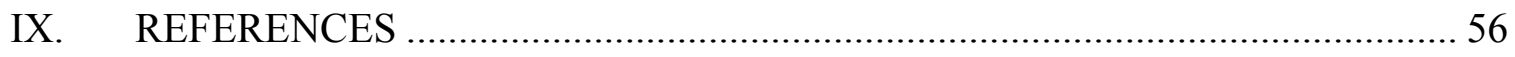

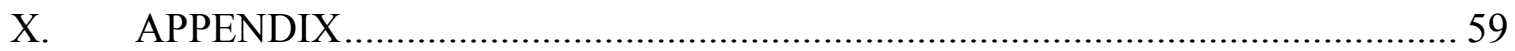

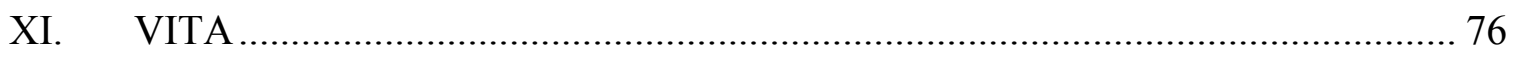




\section{NOMENCLATURE}

THA

$\mu \varepsilon$

$v i$

MTS

Diaphysis

Metaphysis

Postero

Antero

Greater Trochanter

Cancellous

Resorption

Stress Shielding
Total Hip Arthroplasty

microstrain, the ratio of elongation with respect to the original length

Virtual Instrument

Material Testing System

The shaft of main mid section of a long bone.

The growing part of a long bone between the diaphysis and the epiphysis.

A combining form meaning posterior; postero-lateral, situated back and at the side.

A combining form meaning anterior; antero-lateral, situated front and at the side.

A strong area at the proximal and lateral part of the shaft of the femur, overhanging the root of the neck; it gives attachment to the gluteus medius and minimus, piriformis, obturator internus and externus, and gemelli muscles.

Denoting bone that has a lattice-like or spongy structure.

Loss of bone mass

A decrease in bone mineral density as the result of removal of normal stress from the bone by an implant after THA. 


\section{LIST OF TABLES}

TABLE I. Strain gage surface and region locations on femur........................................ 12

TABLE II. Uniaxial strain gage surface locations on modular body............................. 35

TABLE III. Percent decrease between intact and press fit cases with a $180 \mathrm{~N}$ load. ...... 42

TABLE IV. Percent decrease between intact and press fit cases with a $360 \mathrm{~N}$ load....... 42

TABLE V. Percent decrease between intact state and with the addition of hydroxyapatite

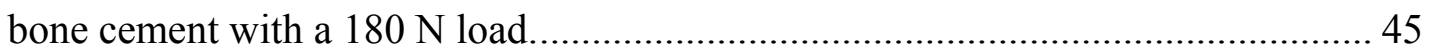

TABLE VI. Percent decrease between intact state and with the addition of

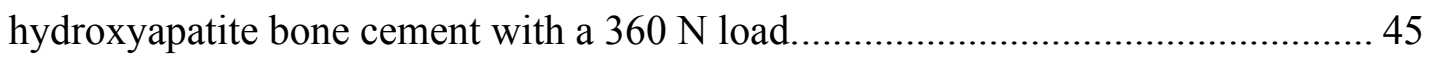

TABLE VII. Percent strain difference between $180 \mathrm{~N}$ and $360 \mathrm{~N}$ for intact case........... 48

TABLE VIII. Percent strain difference between $180 \mathrm{~N}$ and $360 \mathrm{~N}$ for cemented case... 48

TABLE IX. Mean and standard deviation between trials under $180 \mathrm{~N}$ for femur \#4139.49

TABLE X. Mean and standard deviation between trials under $360 \mathrm{~N}$ for femur \#4139. 50

TABLE XI. Average mean and standard deviation between trials under 180 N............. 50

TABLE XII. Average mean and standard deviation between trials under 360 N. .......... 51

TABLE XIII. Percent strain decrease between press fit and cemented loading cases on modular body

TABLE XIV. Mean and standard deviation between trials under $180 \mathrm{~N}$ for femur \#4140.

TABLE XV. Mean and standard deviation between trials under $360 \mathrm{~N}$ for femur \#4140.

TABLE XVI. Mean and standard deviation between trials under $180 \mathrm{~N}$ for femur \#4141. 
TABLE XVII. Mean and standard deviation between trials under $360 \mathrm{~N}$ for femur \#4141.

TABLE XVIII. Mean and standard deviation between trials under $180 \mathrm{~N}$ for femur \#4142...... 70

TABLE XIX. Mean and standard deviation between trials under $360 \mathrm{~N}$ for femur \#4142.

TABLE XX. Mean and standard deviation between trials under $180 \mathrm{~N}$ for femur $\# 4470$.

TABLE XXI. Mean and standard deviation between trials under $360 \mathrm{~N}$ for femur \#4470.

TABLE XXII. Mean and standard deviation between trials under $180 \mathrm{~N}$ for femur \#4471

TABLE XXIII. Mean and standard deviation between trials under $360 \mathrm{~N}$ for femur \#4471 73

TABLE XXIV. Mean and standard deviation between trials under $180 \mathrm{~N}$ for femur \#4472.

TABLE XXV. Mean and standard deviation between trials under $360 \mathrm{~N}$ for femur \#4472 75 


\section{LIST OF FIGURES}

FIGURE 1. Pacific Research Laboratories ${ }^{29} 3^{\text {rd }}$ generation left femur. .......................... 8

FIGURE 2. Gage locations on composite test femur............................................... 10

FIGURE 3. Distal end of femur featuring solder terminals...................................... 12

FIGURE 4. Strain gage numbering convention and locations on anterior surface (left)

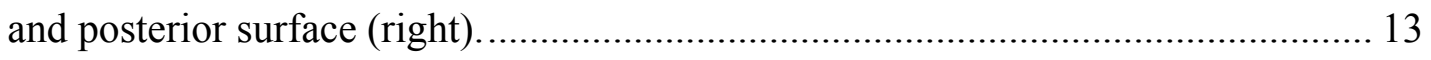

FIGURE 5. One-half Wheatstone bridge wiring circuit. ........................................ 14

FIGURE 6. Laptop, Junction Box and SCXI components. .................................... 15

FIGURE 7. National Instruments ${ }^{31}$ LabVIEW virtual instrument front panel. .............. 16

FIGURE 8. Free body diagram of loading conditions in the frontal plane view............ 18

FIGURE 9. MTS machine with test femur and fixtures inserted. ............................... 19

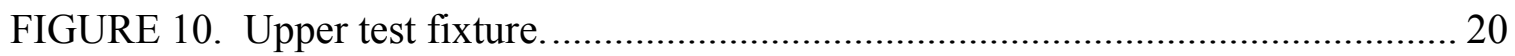

FIGURE 11. Lower test fixture. .................................................................. 21

FIGURE 12. MTS FlexTest SE, strain conditioner, and Station Manager..................... 22

FIGURE 13. Front panel of MTS Station Manager controller.................................... 23

FIGURE 14. Modular hip proximal bodies and stems. ........................................... 24

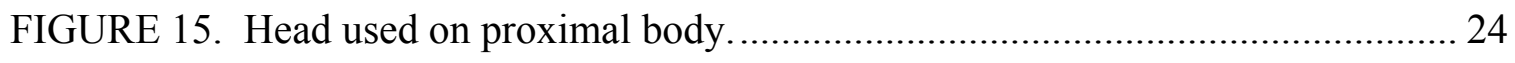

FIGURE 16. Stryker Howmedica Osteonics conical distal reamer set. ......................... 25

FIGURE 17. Stryker Howmedica Osteonics proximal cone reamer set......................... 25

FIGURE 18. Stryker Howmedica Osteonics power saw........................................... 26

FIGURE 19. Removal of femoral head using Stryker power saw............................... 28

FIGURE 20. Orthopedic surgeon performing reaming process. ................................ 29

FIGURE 21. Orthopedic surgeon performing reaming process. ................................ 30 
FIGURE 22. Femur after successful reaming procedure.

FIGURE 23. Orthopedic surgeon inserting modular stem.......................................... 32

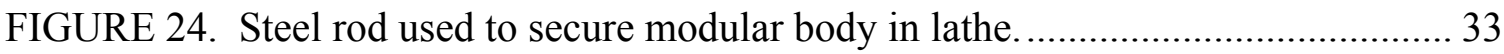

FIGURE 25. Process used to remove coarse surface on modular body. ........................ 33

FIGURE 26. Modular body before (left) and after (right) the polishing process............ 34

FIGURE 27. Gage number and location of strain gages on medial (left) and lateral (right)

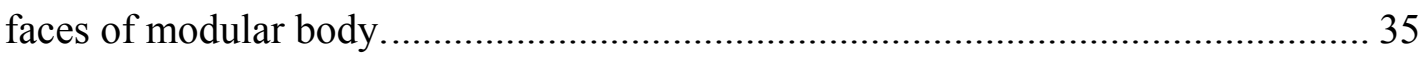

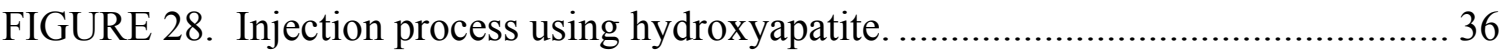

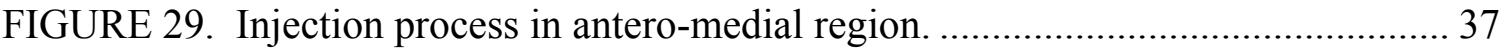

FIGURE 30. End result of addition of hydroxyapatite bone cement........................... 37

FIGURE 31. Resulting intact strains and press fit strains with a $360 \mathrm{~N}$ load for femur

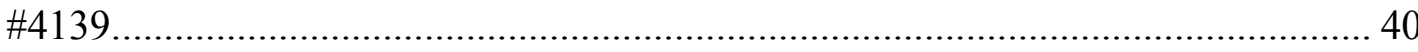

FIGURE 32. Resulting average intact strains and press fit strains with a $360 \mathrm{~N}$ load of all femurs. 41

FIGURE 33. Resulting intact strains and cemented strains with a $360 \mathrm{~N}$ load for femur \#4139.

FIGURE 34. Resulting average intact strains and cemented strains with a $360 \mathrm{~N}$ load of all femurs 44

FIGURE 35. Resulting surface strains on body for femur \#4139 ................................ 46

FIGURE 36. Resulting average surface strains on body for all femurs........................ 47

FIGURE 37. Measured intact, press fit, and cemented surface strains with a $180 \mathrm{~N}$ load for femur \#4139. 60 
FIGURE 38. Measured intact, press fit, and cemented surface strains with a $180 \mathrm{~N}$ load for femur \#4140. 60

FIGURE 39. Measured intact, press fit, and cemented surface strains with a $180 \mathrm{~N}$ load for femur \#4141. 61

FIGURE 40. Measured intact, press fit, and cemented surface strains with a $180 \mathrm{~N}$ load for femur \#4142. 61

FIGURE 41. Measured intact, press fit, and cemented surface strains with a $180 \mathrm{~N}$ load for femur $\# 4470$. 62

FIGURE 42. Measured intact, press fit, and cemented surface strains with a $180 \mathrm{~N}$ load for femur \#4471. 62

FIGURE 43. Measured intact, press fit, and cemented surface strains with a $180 \mathrm{~N}$ load for femur \#4472. 63

FIGURE 44. Measured intact, press fit, and cemented surface strains with a $360 \mathrm{~N}$ load for femur \#4139. 63

FIGURE 45. Measured intact, press fit, and cemented surface strains with a $360 \mathrm{~N}$ load for femur \#4140. 64

FIGURE 46. Measured intact, press fit, and cemented surface strains with a $360 \mathrm{~N}$ load for femur \#4141. 64

FIGURE 47. Measured intact, press fit, and cemented surface strains with a $360 \mathrm{~N}$ load for femur $\# 4142$. 65

FIGURE 48. Measured intact, press fit, and cemented surface strains with a $360 \mathrm{~N}$ load for femur $\# 4470$. 65 
FIGURE 49. Measured intact, press fit, and cemented surface strains with a $360 \mathrm{~N}$ load for femur \#4471. 66

FIGURE 50. Measured intact, press fit, and cemented surface strains with a $360 \mathrm{~N}$ load for femur $\# 4472$. . . 66 


\section{INTRODUCTION}

\section{A. Background Information}

Total hip arthroplasty (THA) is one of the most widely performed orthopedic procedures in the United States, and its cost is a major contributor to health care costs in the United States. ${ }^{1}$ Modular fluted stems are being used to improve rotational stability of hip implants in revision surgeries. ${ }^{2-3}$ In addition, there are questions regarding the effectiveness of the fluted stems on proximal stress shielding and the potential for failure at the junction of the stem and the proximal body.

A benefit of using modular implants is that surgeons have the freedom to independently size the head, body, and stem. This means that each individual part, ie. head, body and stem, can be carefully selected to create a customized implant that best fits a particular patient's joint. This gives a wide array of options to the surgeon in order to choose a size that best fits the needs of each individual patient. Current non-invasive practices utilize x-rays and CT scans to predict the stem and body size needed for a total hip arthroplasty (THA). During the operation the actual stem and body sizes needed may differ to ensure a tight fit between the implant and femur. The surgeon can have a range of sizes for the head, body and stem available, whereas with a custom molded implant the predicted size is the only option.

Stress shielding is defined as osteopenia occurring in bone as the result of removal of normal stress from the bone by an implant. ${ }^{4}$ There are many methods for quantifying the amount of stress shielding. One of the most popular methods of measuring stress shielding effects is bone mineral density (BMD) measurements. For example, Bulter et al. ${ }^{5}$ used femurs from cadavers and x-rays to quantify the amount of stress shielding 
caused by the prosthesis. There have been many studies showing proximal stress shielding caused by hip arthroplasty. ${ }^{6-7}$ After a THA the natural stress distribution on the femur is altered. The implant will carry a portion of the load and distribute some of the load to the mid-shaft region of the femur. This causes a reduction of stress in some areas of the remaining bone, primarily in the proximal region. This phenomenon is called stress shielding. Bone growth and remodeling are primarily dictated on a need basis, similar to muscle. If bone experiences little or no stress there will be a loss of bone mass in that region. This is known as bone resorption and can cause the prosthesis to loosen from the bone. If bone experiences stress, bone mass will be maintained in that area to support the stress. Studies have shown that a tighter fit in the proximal area reduces stress shielding and improves implant stability. ${ }^{8-9}$

\section{B. Scope and Objectives}

The scope of this study is to investigate axial surface strains on an intact femur before and after the addition of BoneSource ${ }^{\circledR}$ Hydroxyapatite Bone Void Filler in the proximal region. The degree of stress shielding in the proximal region before and after the addition of bone cement will be determined using a dual leg stance model. The objectives for this study included the following:

- Measure the proximal and mid-shaft femur surface strains using $3^{\text {rd }}$ generation composite femurs and the dual leg stance model.

- The surface strains for the intact femurs will be measured by loading the femur to $180 \mathrm{~N}$ and $360 \mathrm{~N}$. These strains will be used as a basis for determining the amount of stress shielding. 
- Following total hip arthroplasty, the surface strains for each femur will be measured under load and the decrease in strain from the intact condition will determine the amount of stress shielding.

- BoneSource ${ }^{\circledR}$ Hydroxyapatite bone cement will then be added around the proximal body to provide additional support in the proximal area.

- The surface strains will be measured under load to determine if a significant reduction in stress shielding has occurred.

- Two strain gages will be attached to the proximal body to measure the strains near the junction of the stem and body.

- The proximal body strains will be measured during loading before and after the addition of hydroxyapatite bone cement. 


\section{LITERATURE REVIEW}

It was reported that there were 234,000 total hip replacement surgeries conducted in 2004 in the United States alone. ${ }^{10}$ The rate of hip replacements increased from 27.1 per 10,000 population in 1995 to 37.3 in 2004 . It is the most common surgical hip procedure performed in adults and one of the most common major orthopedic procedures performed in individuals over 65 years of age. ${ }^{1}$ Kurtz et al. ${ }^{11}$ reported a relatively constant revision burden of $17.5 \%$ for total hip arthroplasty from 1991 to 2002, with revisions accounting for approximately $20 \%$ of all total hip arthroplasty cost expenditures. ${ }^{12}$

Kurtz et al. also constructed a model to predict the future rate of revision total hip arthroplasty. They projected 48,000 revisions in 2010 , more than 67,000 in 2020 , and nearly 97,000 in 2030 (a 137\% increase from 2005). Similarly, they projected a greater than twofold increase in primary total hip arthroplasties (from 240,000 to 570,000) from 2005 to 2030 . They also projected that the number of practicing orthopedic surgeons in the United States would increase from approximately 20,000 in 2010 to 26,000 in 2030. On the basis of their numbers, the mean case load for each surgeon would continue to increase from decade to decade. Moreover, the increasing volume of revisions will undoubtedly pose a challenge to resource utilization and cost containment. The authors concluded that revision total hip arthroplasty is excellent for improving quality of life despite a high rate of complications in the patient population. ${ }^{11}$

There have been studies conducted to understand the characteristics and reaction human femurs have under many loading conditions such as the single leg stance, the two leg stance, and torsional loading after total hip arthroplasty (THA). ${ }^{2,9,12,16,17,35}$ These 
studies are critical in understanding and determining the stress distribution following THA.

Once an implant has been inserted, the stress distribution in the femur is dramatically changed. Some of the load is now carried by the implant and is distributed to the part of the implant that has the tightest fit causing a reduction of stress in certain areas of the remaining bone. This phenomenon is known as stress shielding. When bone experiences a considerably reduced amount of stress there will be a loss of bone mass. This occurrence, known as resorption, will further lead to the loosening of the prosthesis. ${ }^{13}$ The majority of studies show that stress shielding is more prevalent in the proximal region of the femur.

New studies are investigating the importance of proximal loading on the femur. Santori et al. ${ }^{14}$ reported that proximal loading preserves in time metaphyseal bone stock. Studies have been conducted to determine the effects of cement-stem debonding due to repetitive dynamic loading, eventually resulting in gross loosening. Verdonschot and Ries found that the survival of a cemented THA is enhanced by a firm and lasting bond between the stem and cement mantle. Verdonschot et al. also found that the stemcement debonding not only elevated the initial stress levels, but also had an impact on the failure process of the cement. ${ }^{8,15}$ FEA models have also been developed to predict long term failure in cemented implants. By using the FEA models, experimental setups have been validated. ${ }^{16}$

Porous coatings help by providing a rough surface at the diaphyseal portion of the implant which scratches into the inner walls of the femur and interlock with it. ${ }^{17}$ Porous coatings also help promote better implant-bone adhesion. The flutes on the stem engage 
the diaphyseal cortical bone and help provide torsional stability but consequently increase stiffness slightly.

It is also important to understand the risks and complications associated with revision THA in order to ensure longer implant life and effects to the patient. Some of the risks include osteolysis and wear, infection, dislocation, periprosthetic femoral fracture, and nerve palsy, acetabular cup loosening, and implant loosening. All of these risks and complications increase with revision surgeries and are important in understanding which direction research efforts can be directed to make the surgeries more effective and efficient. $^{12}$

Stress shielding is also a large concern in revision THA. Commonly, stress shielding has already occurred due to the primary THA, but it is important to slow the rate of stress shielding to help increase implant longevity. This can be achieved to a certain extent by loading the proximal region of the femur. By loading the proximal region of the femur the strains in the mid-shaft region of the femur are reduced and more bone stock is retained in the proximal region than if completely unloaded.

Although the number of postmortem retrievals is limited, hydroxyapatite bone cement coated femoral stems consistently have shown satisfactory fixation, with little evidence of adverse reactions, such as osteolysis and third body wear, from hydroxyapatite particles. Several new technologies that are purported to improve implant fixation, minimize wear, and increase the survivorship and functionality of hip replacements recently have been introduced or are on the horizon. Only through the systematic analysis of large patient populations with these devices and through the analysis of failed and successful implants with adjacent periprosthetic tissues will we be able to establish the role that these 
innovations will have in the treatment of the patient requiring a primary or revision hip replacement. ${ }^{18}$ Several animal studies have shown short-term histologic and biomechanical benefits associated with hydroxyapatite coating of cementless implants. ${ }^{19-}$

${ }^{22}$ Studies of retrievals from humans also have been reported. ${ }^{23-27}$

Optimization of the variables, conditions, and considerations previously mentioned while still maintaining long life implant stability and minimizing stress shielding remains an unresolved issue in the design and use of implants. One attempt to solve these problems has been the design of a modular component in which the stem and the proximal body are separate parts. These modular components allow the metaphysis to be sized independently of the diaphysis. ${ }^{28}$ It was components of this type which were used in this study. 


\section{INSTRUMENTATION AND EQUIPMENT}

\section{A. Test Specimens}

This study used seven $3^{\text {rd }}$ generation composite bone models manufactured by Sawbones ${ }^{\circledR}$ (a division of Pacific Research Laboratories).$^{29}$ Composite bones are designed to simulate the physical behaviors of human bone while also providing an alternative to cadavers for testing purposes, where special handling and precautions must be taken to carry out studies. Composite bones are also anatomically accurate and consistent in comparison with real human femurs. A mixture of glass fibers and epoxy resin pressure injected around a foam core allow the composite bone to model cortical bone more accurately. The $3^{\text {rd }}$ generation composite femur used in this study is shown in Figure 1.

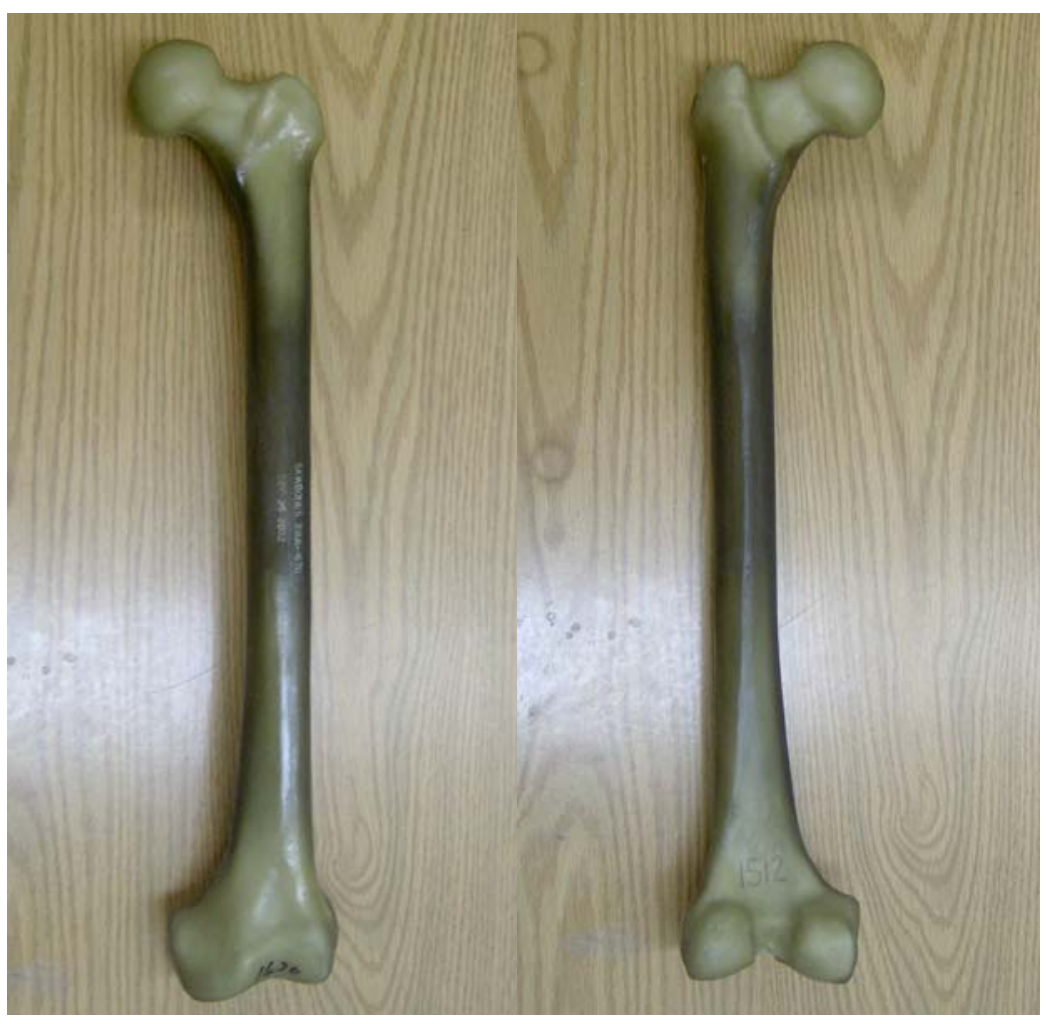

FIGURE 1. Pacific Research Laboratories ${ }^{29} 3^{\text {rd }}$ generation left femur. 
Each composite femur and corresponding hip implant was instrumented using the following Vishay Measurements Group, Inc. ${ }^{30}$ strain gages and equipment:

- CEA-13-125UN-350 Uniaxial Strain Gages

- CPF-75D Bondable Terminals

- M-Line Mark V Soldering Station

- M-Line M-Bond 200 Adhesive

- M-Line 200 Catalyst-C

- M-Line M-Coat A Air Drying Polyurethane Glue

- Denatured Alcohol

- M-Line 134-AWP Single Conductor Wire

- 3 M-Line 326-DFV 3 Conductor Cable (100 ft. spools)

- “44” Rosin Core Solder

Four uniaxial strain gages were positioned at the proximal region of the femur, $8.5 \mathrm{~cm}$ below highest point of greater trochanter. Four uniaxial gages were positioned $13 \mathrm{~cm}$ below highest point of greater trochanter and four uniaxial gages were positioned at the mid-shaft region of the femur, $25 \mathrm{~cm}$ below highest point of greater trochanter. Each uniaxial strain gage was aligned with the femoral axis. Bondable solder terminals, CFD$75 \mathrm{D}$, were mounted at the distal region, $32 \mathrm{~cm}$ below the highest point of the greater trochanter. Figure 2 shows the highest point of the greater trochanter, solder terminals, proximal and mid-shaft gage locations and orientations. 


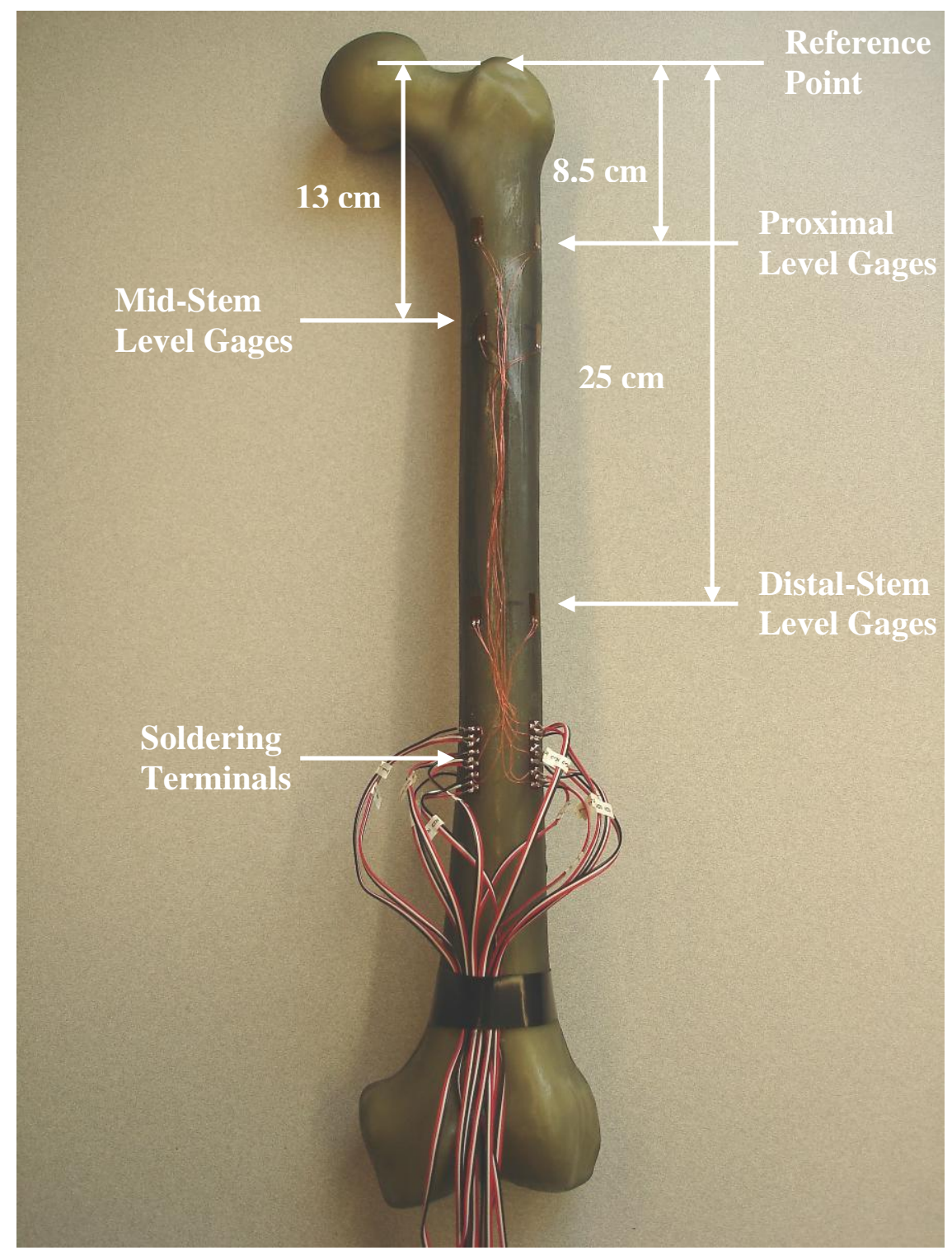

FIGURE 2. Gage locations on composite test femur.

A series of steps were taken to ensure proper gage installation. First, a swab drenched in GC-6 isopropyl alcohol was used to degrease the gaging area. Next, 220-grit silicon-carbide paper was used to remove any surface scale or oxide that may have been present on the outer surface of the composite femur. After abrading the surface, the bone surface was wiped again with a swab drenched in isopropyl alcohol. Next, a swab wetted with M-Prep Conditioner A was used to condition the surface and remove any impurities. 
The M-Prep Conditioner A was wiped with a clean, dry swab before it had time to dry to ensure that a contaminating film was not left that could reduce the chances of a good bond. Marks were made on the surface of the femur with a number two pencil to help properly align the strain gage. A swab wetted with a liberal amount of M-Prep Neutralizer $5 \mathrm{~A}$ was applied to the area where the gage was to be applied. Tweezers were used to remove the gage from the transparent envelope and placed on a piece of scotch tape. Using the marks previously made on the surface as a guide, the gage was properly aligned. The gage was peeled back and a small amount of M-Line 200 Catalyst-C was brushed on the gage and allowed to dry for fifteen seconds. A small amount of M-Bond 200 was applied followed by three minutes of thumb pressure and three minutes of exposure to a heated lamp. Finally, the scotch tape was peeled back at a sharp angle and removed. Each gage was then wired to the bondable terminals using M-Line 134-AWP single conducting wires. Approximately $91 \mathrm{~cm}$ of 326-DFC 3 conductor wire was soldered to the bondable terminals for each gage. Labels were attached to the three lead conducting wires to clearly indicate its corresponding gage. Next, the conducting wires were securely fastened to the femur using electrical tape. Slack was created to ensure that the soldering terminals and gages were not accidentally torn off. The last step involved brushing M-Coat Air Drying Polyurethane Coating over the uniaxial strain gages and single conducting wires to protect them from accidentally being ripped off and to keep moisture from damaging the gages. The final result of the instrumentation process is shown in Figure 3. 


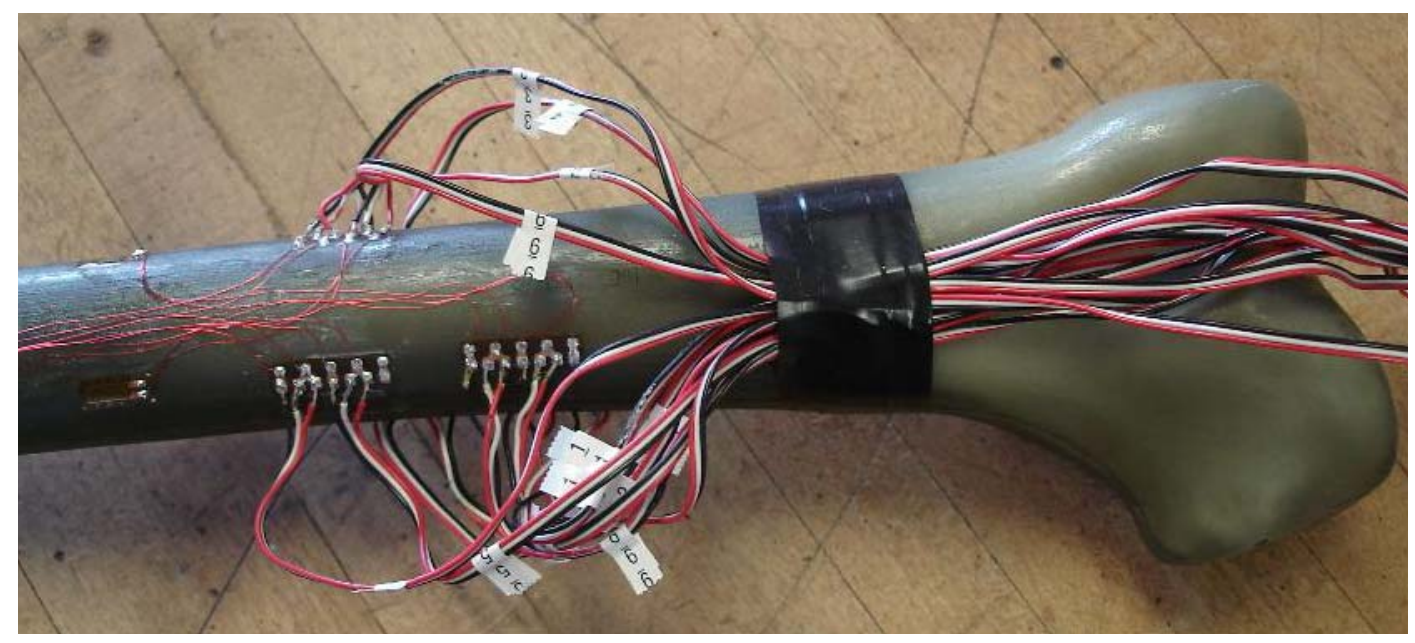

FIGURE 3. Distal end of femur featuring solder terminals.

A digital multimeter was used to check for continuity and proper adhesion. It was confirmed that each gage read $350 \pm 1 \Omega$. The gage location for each corresponding gage placed on each femur is listed in Table I. Figure 4 shows the numbering convention and the lateral and medial regions on the anterior and posterior surfaces, respectively.

TABLE I. Strain gage surface and region locations on femur.

\begin{tabular}{|c|c|c|}
\hline Gage \# & Surface & Level \\
\hline \hline 1 & Antero-medial & Proximal \\
\hline 2 & Antero-lateral & Proximal \\
\hline 3 & Postero-lateral & Proximal \\
\hline 4 & Postero-medial & Proximal \\
\hline 5 & Antero-medial & Mid-Stem \\
\hline 6 & Antero-lateral & Mid-Stem \\
\hline 7 & Postero-lateral & Mid-Stem \\
\hline 8 & Postero-medial & Mid-Stem \\
\hline 9 & Antero-medial & Distal-Stem \\
\hline 10 & Antero-lateral & Distal-Stem \\
\hline 11 & Postero-lateral & Distal-Stem \\
\hline 12 & Postero-medial & Distal-Stem \\
\hline
\end{tabular}




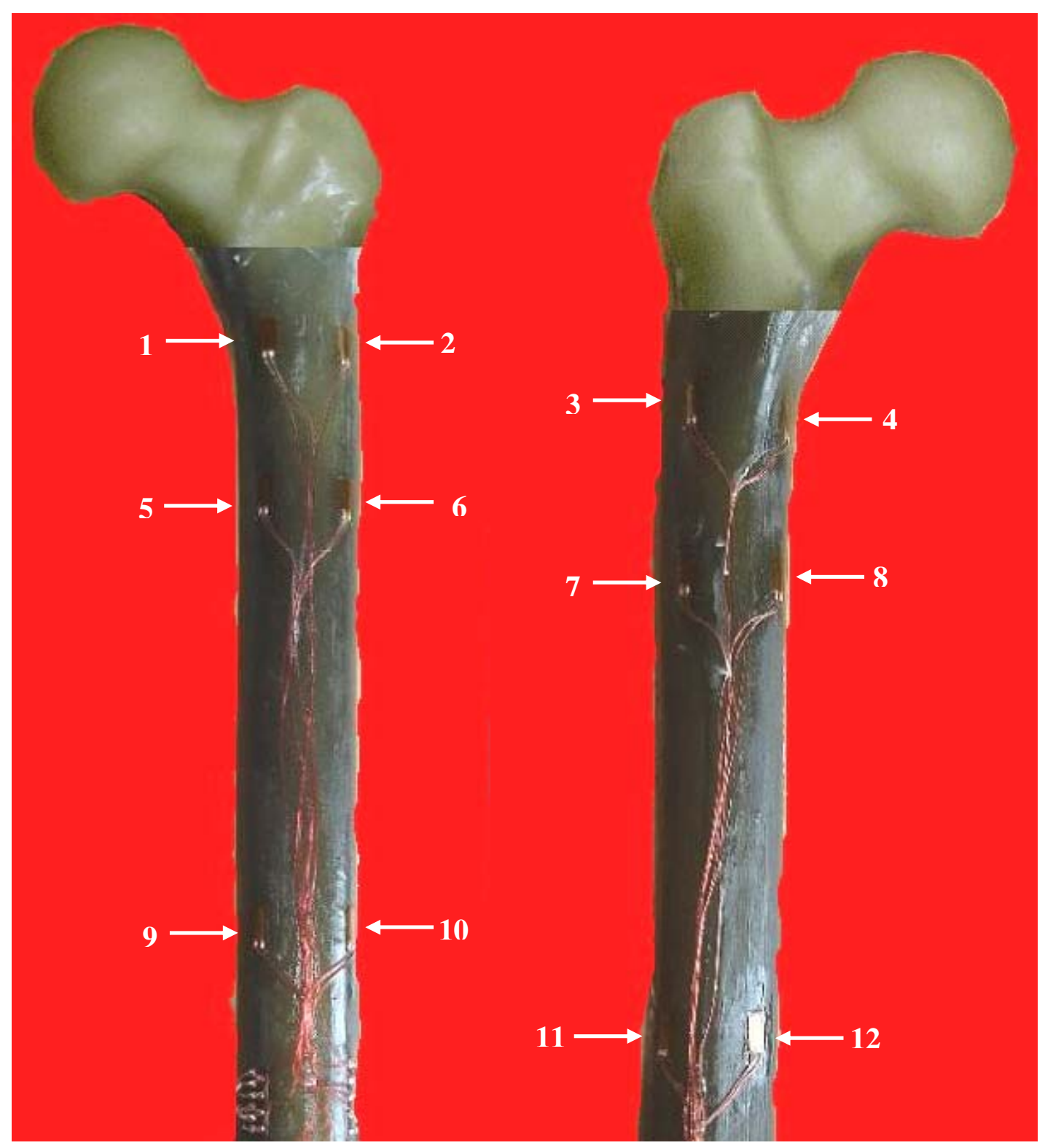

FIGURE 4. Strain gage numbering convention and locations on anterior surface (left) and posterior surface (right).

\section{B. Data Acquisition Equipment}

The uniaxial strain gages from two femurs that were to be tested were wired in a onehalf Wheatstone bridge configuration and connected to a National Instruments ${ }^{31}$ SCXI 1122 Strain-Conditioning Unit. By using a half bridge configuration, all of the strain effects due to temperature change cancel out and only strains due to the applied load were 
measured and recorded. The circuit diagram used to configure the National Instruments ${ }^{31}$ SCXI strain conditioning unit is shown in Figure 5 where $\mathrm{V}$ is the excitation voltage and $\Delta \mathrm{E}$ is the output voltage.

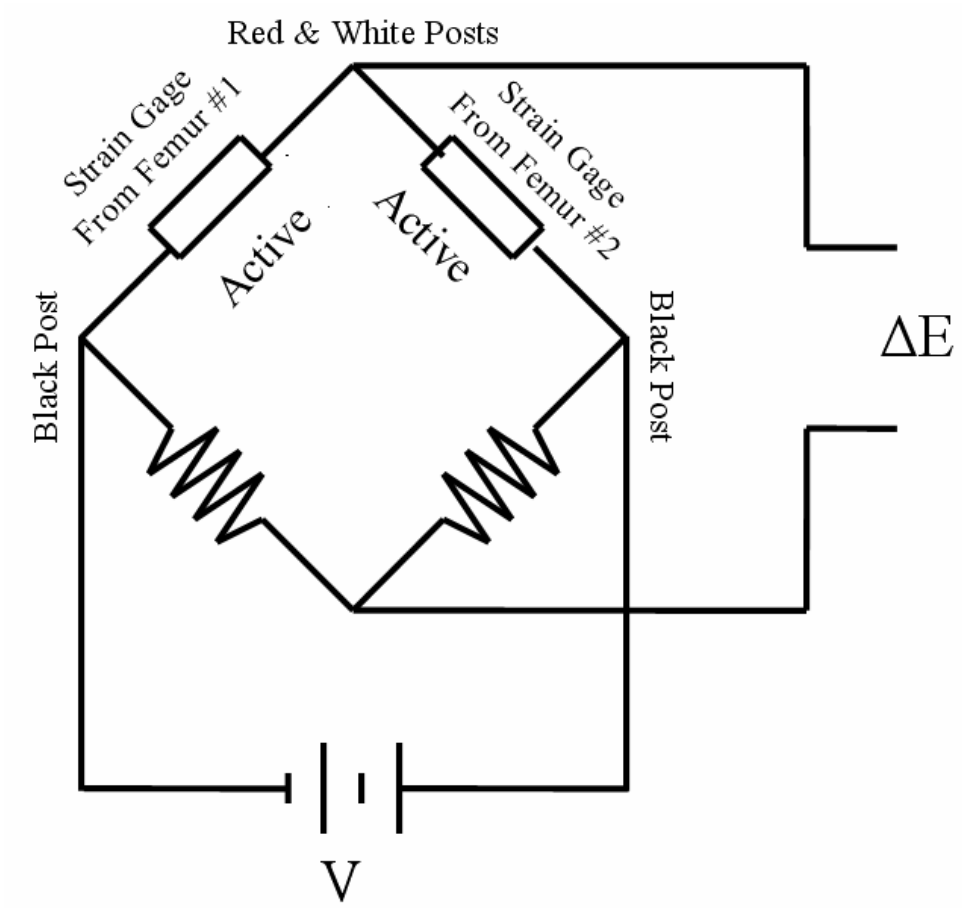

FIGURE 5. One-half Wheatstone bridge wiring circuit.

Figure 6 shows the laptop, junction box and the SCXI 1000, 1322, and 1122 components used to collect and process all of the data for this study. 


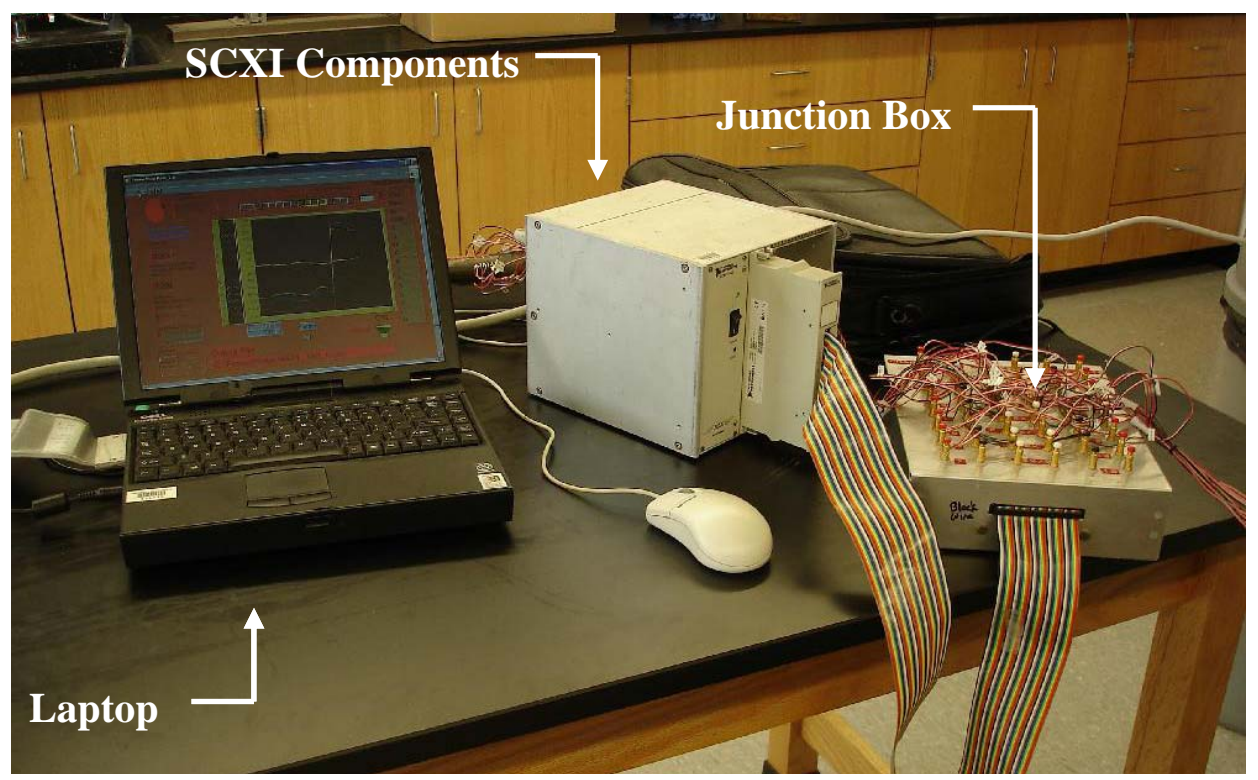

FIGURE 6. Laptop, Junction Box and SCXI components.

In order to supply the excitation voltage to the bridge all of the black leads from one of the test femurs were wired to the same black post, while all of the black leads from the other femur in the circuit were wired to the adjacent black lead on the junction box. The red and white leads were wired together and clamped into the appropriate post, denoted as channels 0 through 15 . The junction box was used to connect the strain gages to the National Instruments ${ }^{31}$ SCXI 1122 module, as shown in Figure 6. The corresponding voltage signals were read into National Instruments LabVIEW 6.1. ${ }^{31}$ LabVIEW 6.1 was used to collect, display, read, and write the measured strains values to a file. A previously created LabVIEW virtual instrument (vi) was used specifically for this project. $^{32}$ The front panel of the vi is shown in Figure 7. 


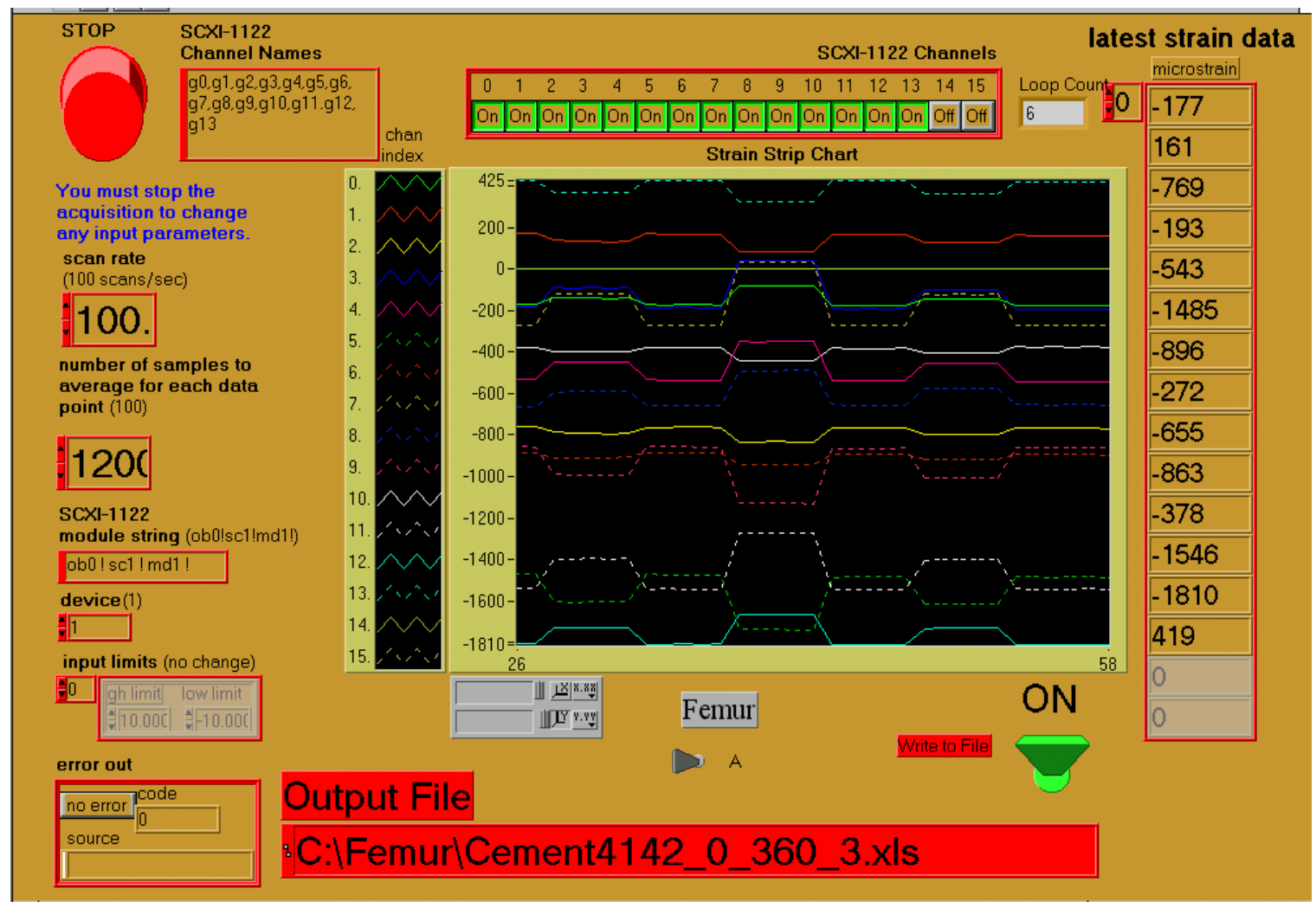

FIGURE 7. National Instruments ${ }^{31}$ LabVIEW virtual instrument front panel.

The vi has many features and controls specifically designed to use in this study. The stop button, channel names, scan rate, data averaging, and module input string are all located on the left side of the vi front panel. Channel identification names were typed in the "Channel Names" box. When data was written to a file these names appeared at the top of the data to clearly identify each corresponding gage. The channels to be used for each experiment were selected at the top of the vi under the "SCXI-1122 Channels" heading. Channels zero through eleven were used for the twelve strain gages mounted on each test femur and channels twelve and thirteen were used for the strain gages on the anterior and posterior faces, respectively, of the modular implant body. A scan rate of 100 scans per second for each data point was used for all tests. The switch located at the center of the vi near the bottom under the heading "Femur" was used to associate the 
strain values with the correct sign. A positive sign denoted tension and a negative sign denoted compression. This switch allowed for each femur to be tested without rewiring the black leads since all of the gages from one of the femurs were wired to the positive leg of the Wheatstone bridge circuit and the strain gages from the other test femur were wired to the negative leg of the bridge circuit. The waveform chart in the middle of the vi displays the strains graphically and is updated after each cycle of the test. The column under the heading "latest strain data" is the strain gage readings displayed digitally. Finally, the box in the lower left hand corner of the vi under the heading "error out" is where any errors that may occur will be reported which is helpful in diagnosing problems during data collection.

The LavVIEW vi used in this study did not contain a calibration process to balance each Wheatstone bridge circuit. Instead, an unloaded trial was conducted to obtain the offset surface strains for each strain gage. Immediately afterwards, the test femur was loaded and the resulting strains were recorded. The actual measured surface strain readings while being loaded were actually determined after taking the difference between the unloaded and loaded trials.

\section{Two Leg Stance Model Test Machine}

An 810 Material Testing System (MTS) located at the Belknap Research Building at the University of Louisville was used to produce a compressive load, consisting of axial and bending components, on each test femur. A free body diagram of the loading conditions each test femur was exposed to is shown in Figure 8. 


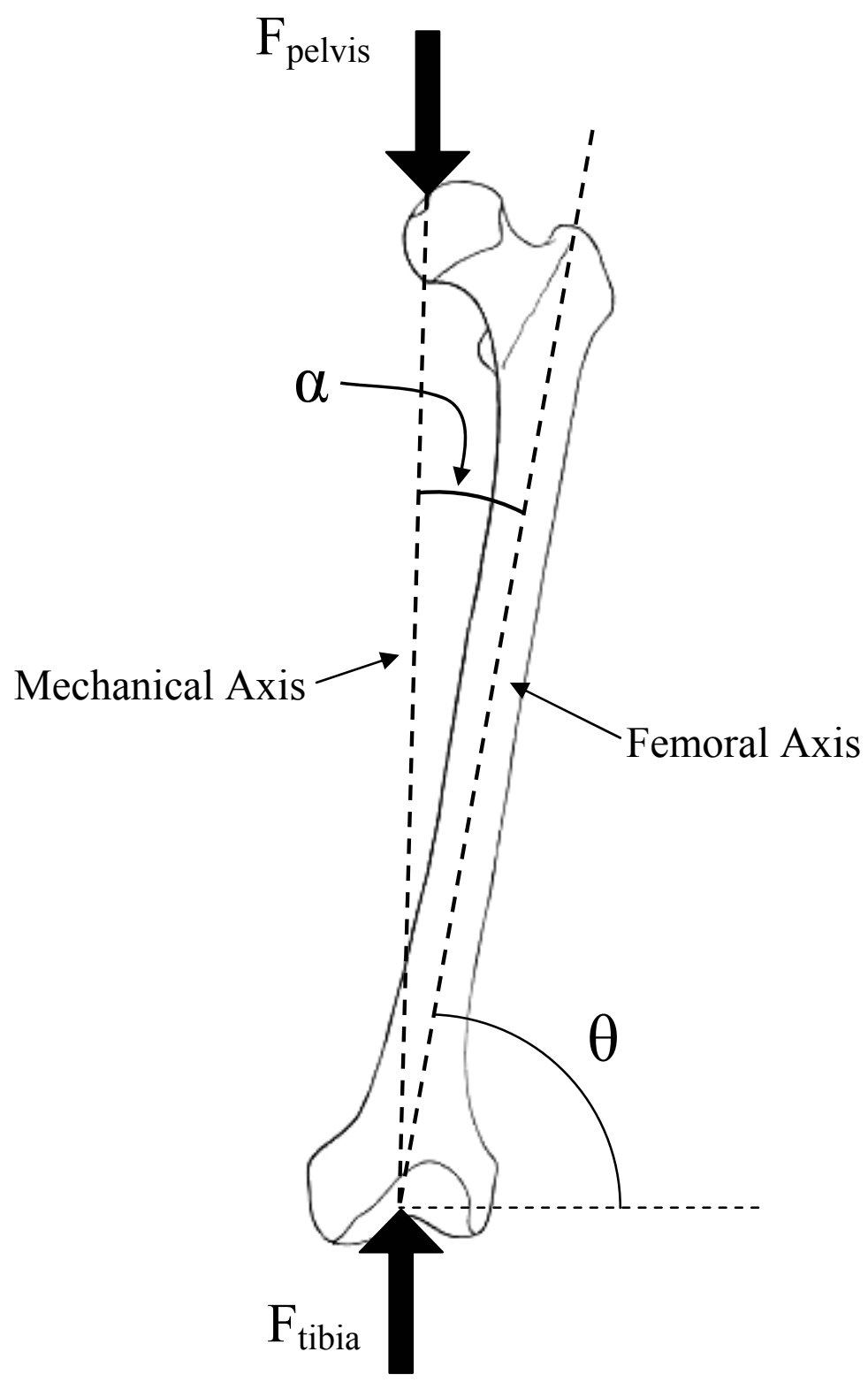

FIGURE 8. Free body diagram of loading conditions in the frontal plane view.

The force of the upper body weight transmitted by the pelvis over the area of the femoral head is $\mathrm{F}_{\text {pelvis. }}$ The force exerted on the medial and lateral condyles at the distal end of the femur is $\mathrm{F}_{\text {tibia. }}$ The mechanical axis is defined as the line between the two forces acting on the femur in its anatomical position in a two-leg stance. The femoral axis is defined as the line that is parallel to the shaft of the femur. The angle between the 
femoral axis and the transverse plane is $\theta$. The angle between the mechanical axis and the femoral axis is $\alpha$. For this study $\alpha$ was approximately $10^{\circ}$.

The MTS machine included an adjustable crosshead, which was utilized to obtain the proper spacing for the femur and testing fixtures. The MTS testing machine incorporated model 647 Hydraulic Wedge Grips on the crosshead actuator, which held the upper and lower test fixtures in place. Figure 9 shows the 810 MTS machine used for this study.

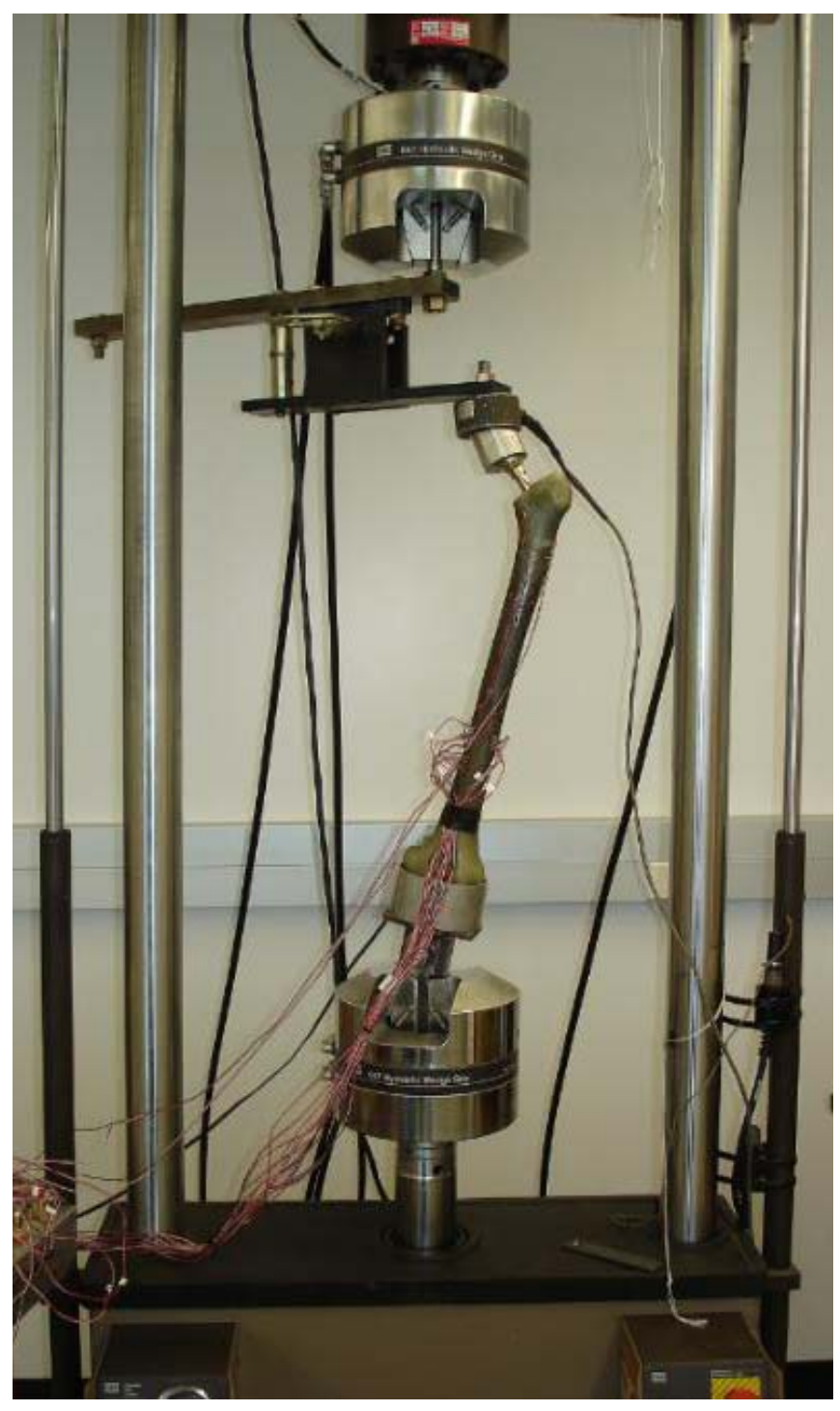

FIGURE 9. MTS machine with test femur and fixtures inserted. 
Connected to the MTS was a MTS FlexTest SE Console which was used to control and monitor the machine. Once the upper and lower fixtures were put into place the axial load transducer was zeroed under a no load condition. The MTS machine operated under displacement control to place a small amount of pre-load on each test femur before operating in force control to apply the appropriate load. Under force control a specified amount of force was applied and maintained.

\section{Two-Leg Stance Model and Fixtures}

The testing fixtures used in this study were created in-house. ${ }^{33}$ The fixtures were designed to model the two leg stance and simulate the boundary conditions on the femur when loaded as shown in Figure 8. A close up view of the upper and lower test fixtures are shown in Figures 10 and 11, respectively.

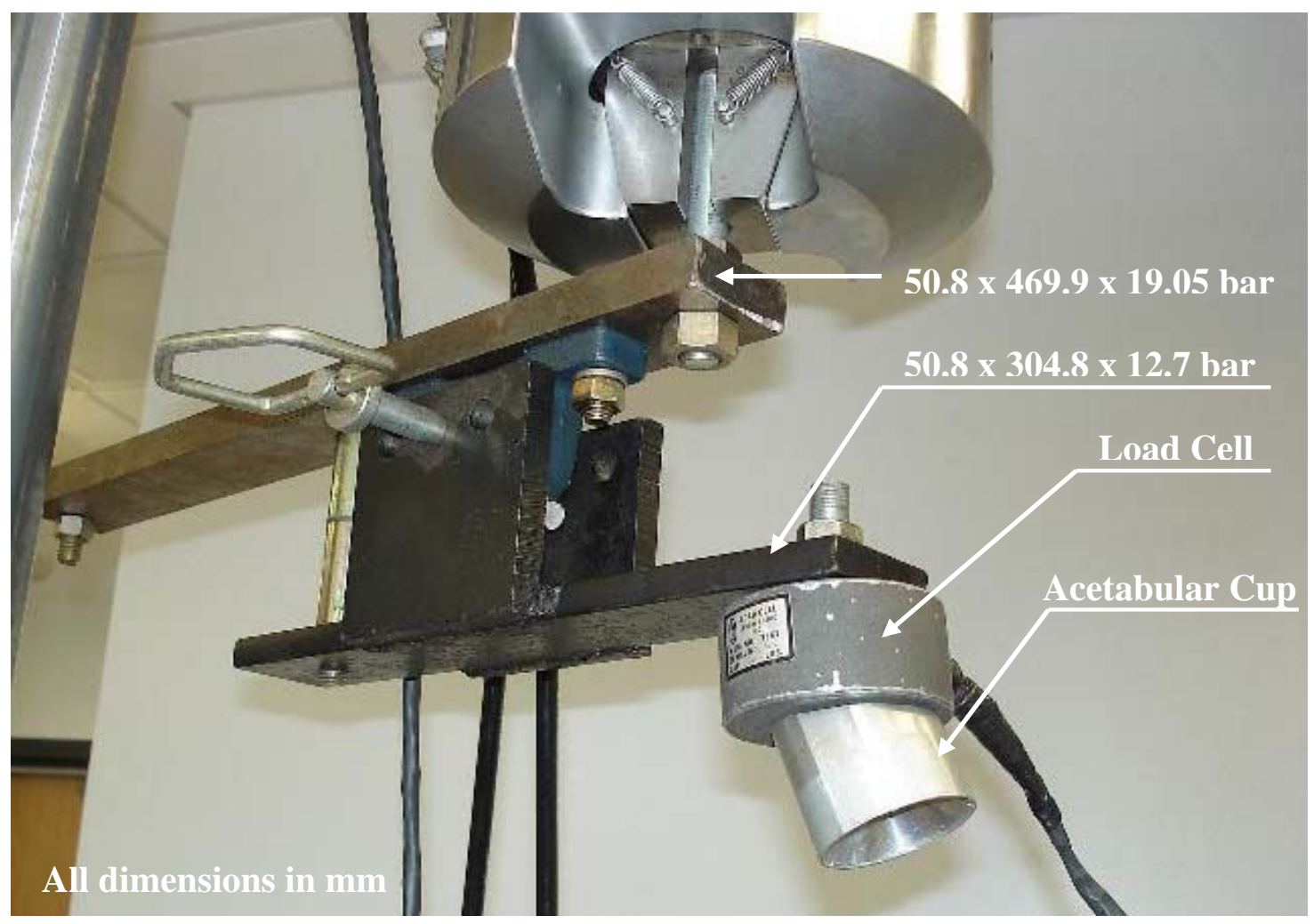

FIGURE 10. Upper test fixture. 


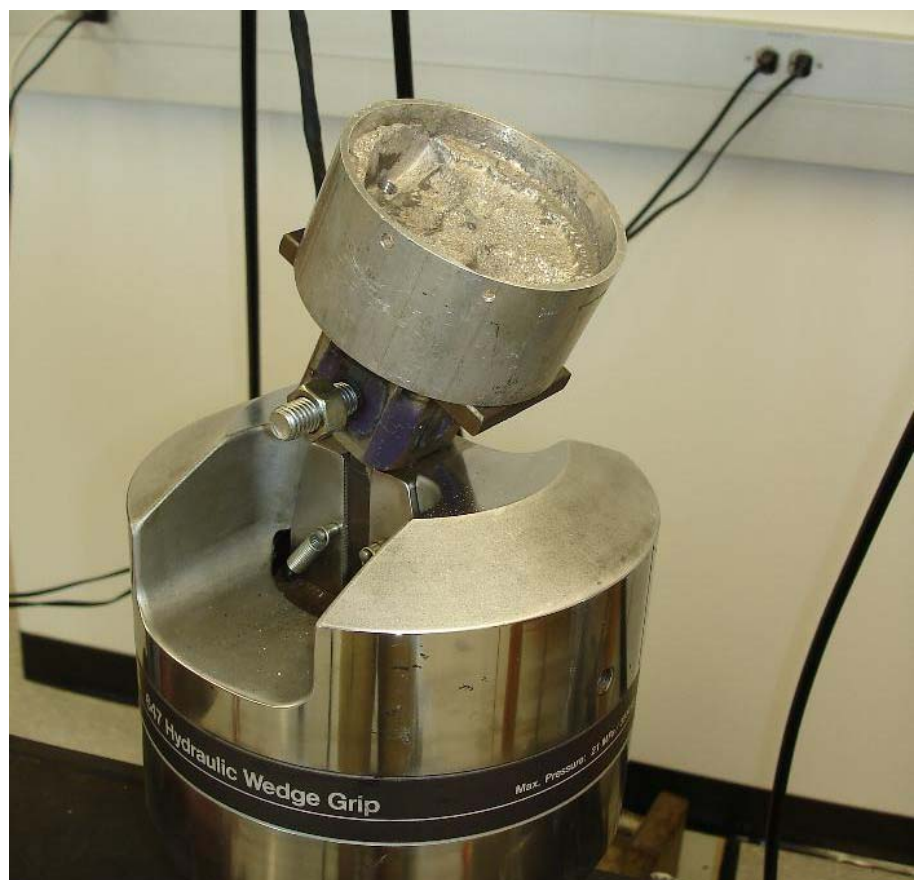

FIGURE 11. Lower test fixture.

The bottom fixture consisted of a cup with a mold filling that was specifically made to fit the lateral and medial condyles. The upper and lower test fixtures held the test femur securely in place and created the proper boundary conditions on the femur.

A load cell manufactured by Lebow Association Inc. (Model \#3167, Serial number 520, Capacity $200 \mathrm{lbs}$.) was mounted between the acetabular cup and fixture on the upper test fixture which would monitor the force exerted on the femur while the MTS was operating under force control. The load cell was attached to a Measurements Group 2120 strain gage conditioner which was connected to a MTS FlexTest SE Console as shown in Figure 12. 


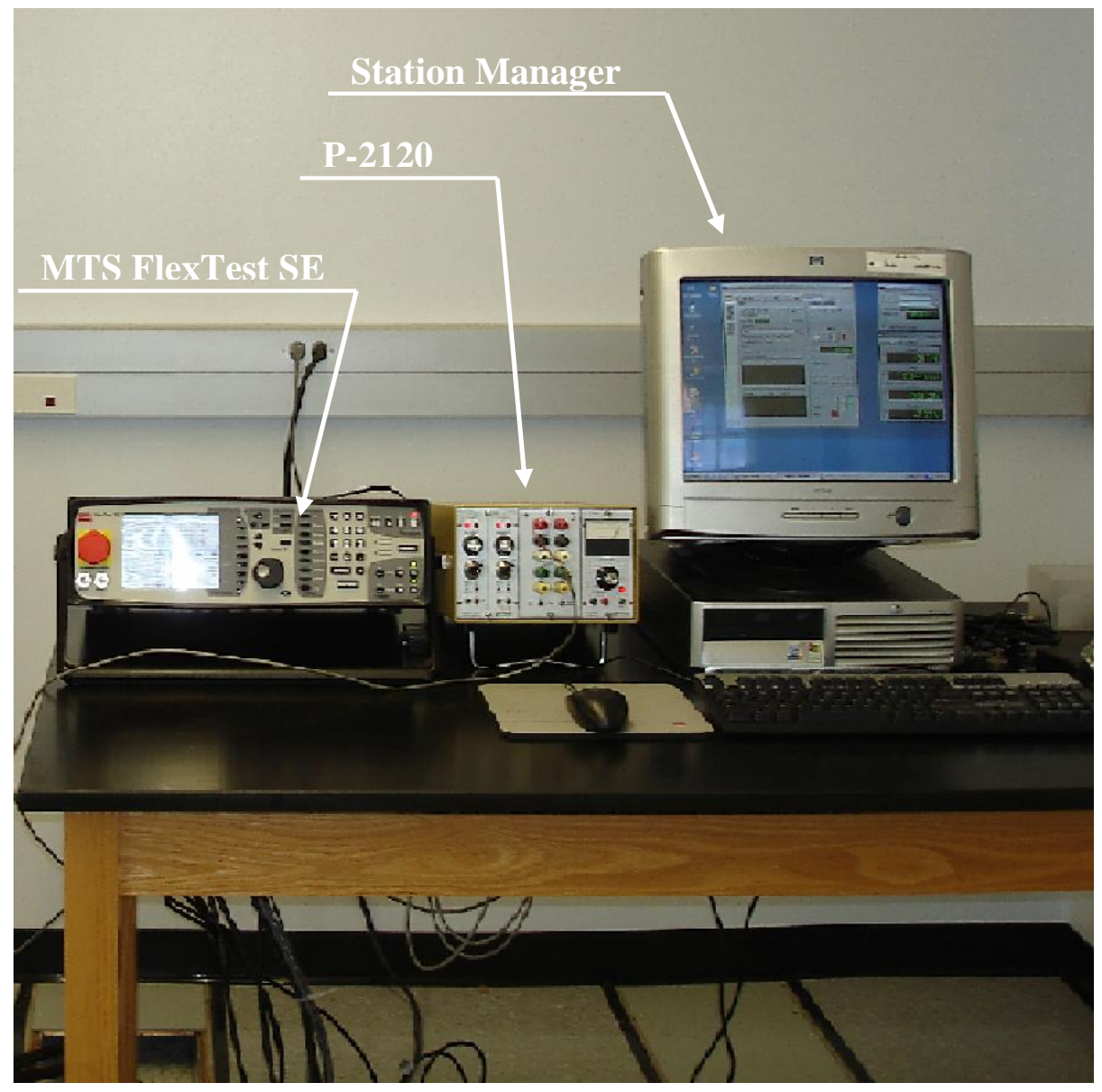

FIGURE 12. MTS FlexTest SE, strain conditioner, and Station Manager.

The MTS machine was controlled by the Station Manager. The front panel of the Station Manager is shown in Figure 13. The Station Controls in the middle of the front panel activated the hydraulic wedge grips. The Manual Controls in the upper right of the front panel switched between displacement control and force control. The slide meter was used to manually position the test fixtures. The digital displays in the bottom right of the front panel showed the force on the load cell within the hydraulic test fixtures (denoted as "Ch Force") and the force on the $200 \mathrm{lb}$ load cell between the upper test fixture and the Acetabular cup (denoted as "Ch Lebow"). 


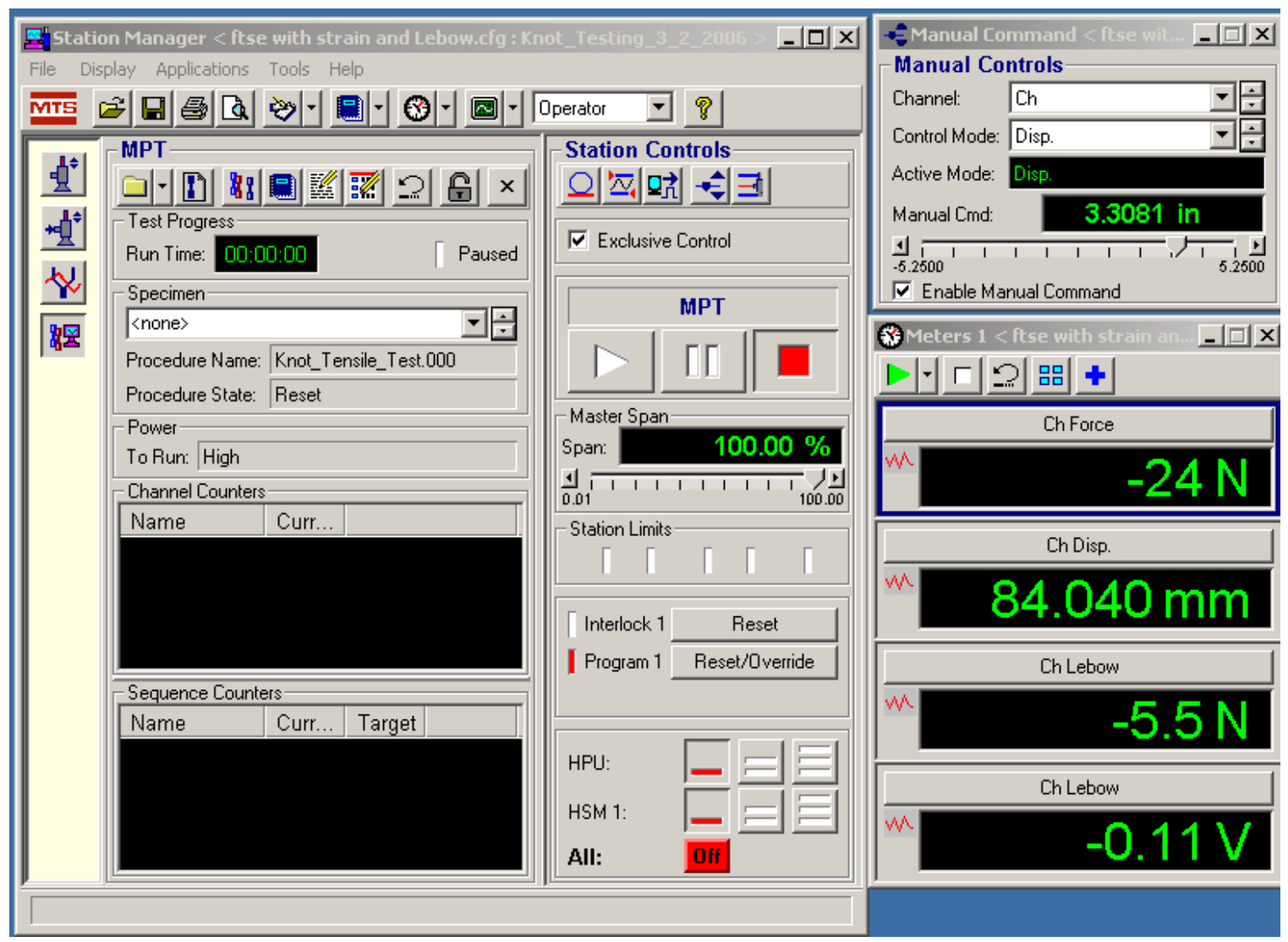

FIGURE 13. Front panel of MTS Station Manager controller.

\section{E. Prosthesis}

All seven identical prostheses used in this study were modular. The stems, proximal bodies, and heads were all independent components. The modular implants are primarily used in revision total hip replacements and are designed so that the surgeon can select the appropriate size that fits each particular patient.

All of the stems used in the study were tapered Modular Hip System Distal Fluted Stems manufactured by Stryker Howmedica Osteonics. ${ }^{34}$ The length of each stem was $225 \mathrm{~mm}$ and the diameter of each stem was $15 \mathrm{~mm}$. All proximal bodies used in this study were manufactured by Stryker Howmedica Osteonics. ${ }^{34}$ The Modular Hip System +10 mm Proximal Body w/Bolt was used with the tapered stem. The "w/Bolt" indicates 
that a bolt was used to secure the body to the stem. The seven tapered fluted stems with proximal bodies that were used in this study are shown in Figure 14.

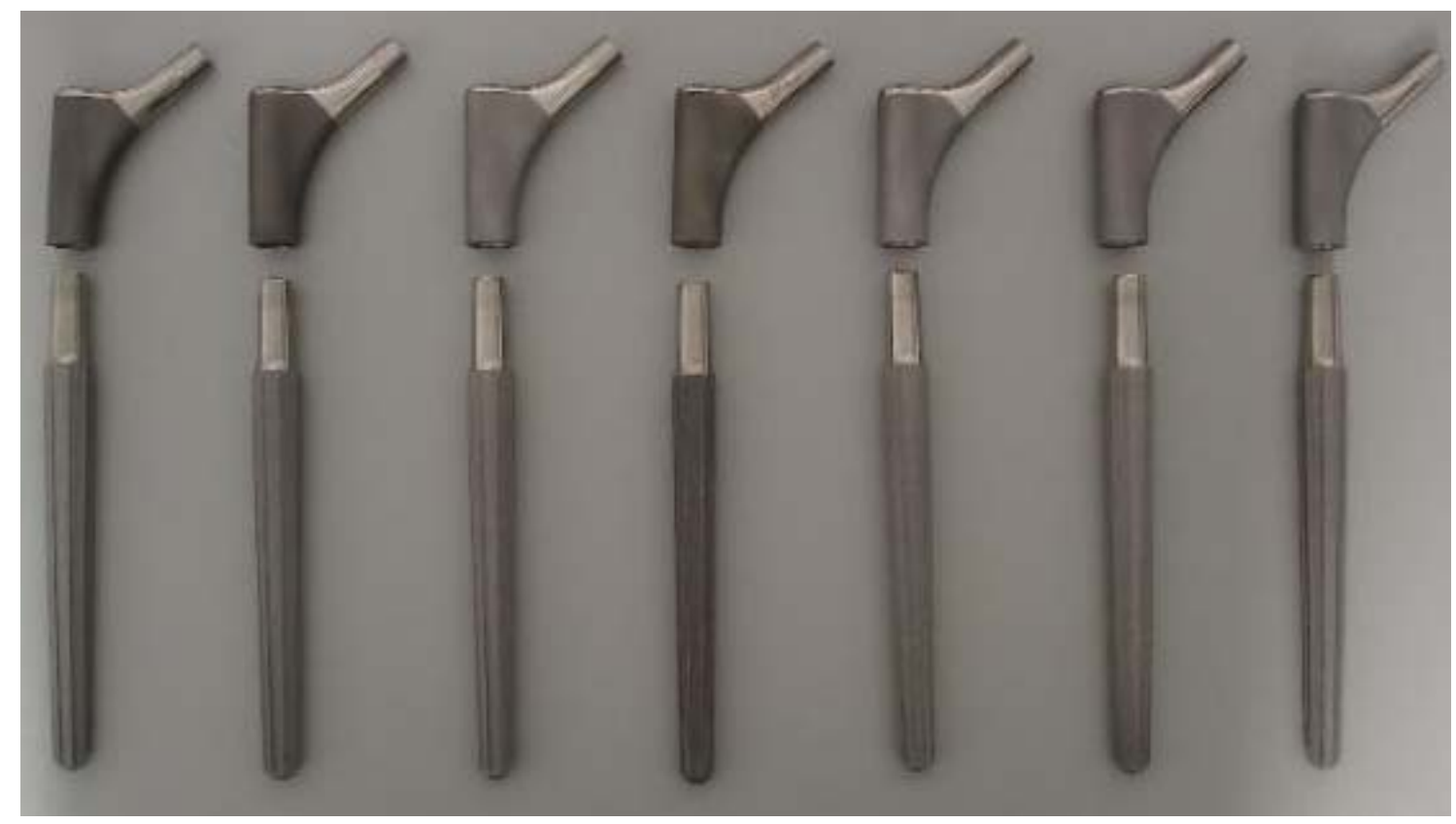

FIGURE 14. Modular hip proximal bodies and stems.

Figure 15 shows the head that was used on the proximal bodies. The head was manufactured by Stryker Howmedica Osteonics. ${ }^{34}$ The head that was used on the proximal bodies was the $5^{\circ} 38^{\prime} 37^{\prime \prime}$ SPD1 $12.446 \mathrm{BC} 28 \mathrm{MMNK}+10$.

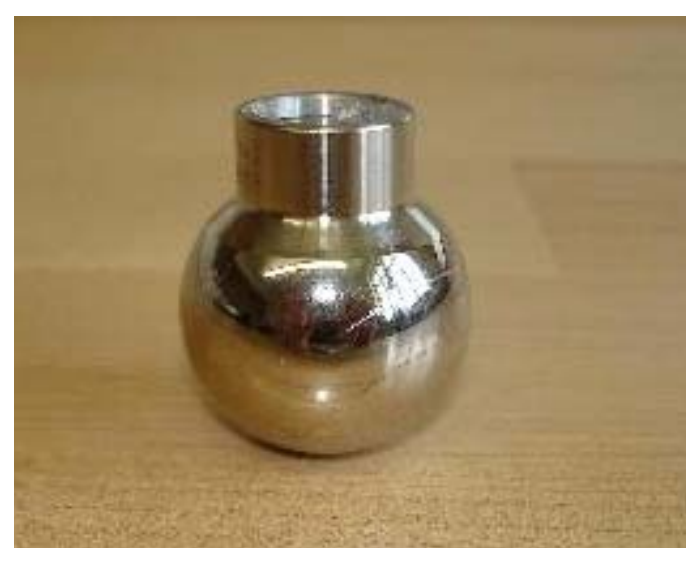

FIGURE 15. Head used on proximal body. 
All reamers and broaches used on the femurs were manufactured by Stryker

Howmedica Osteonics. ${ }^{34}$ The restoration modular conical distal reamers used by the orthopedic surgeon that inserted the modular tapered stems are shown in Figure 16.

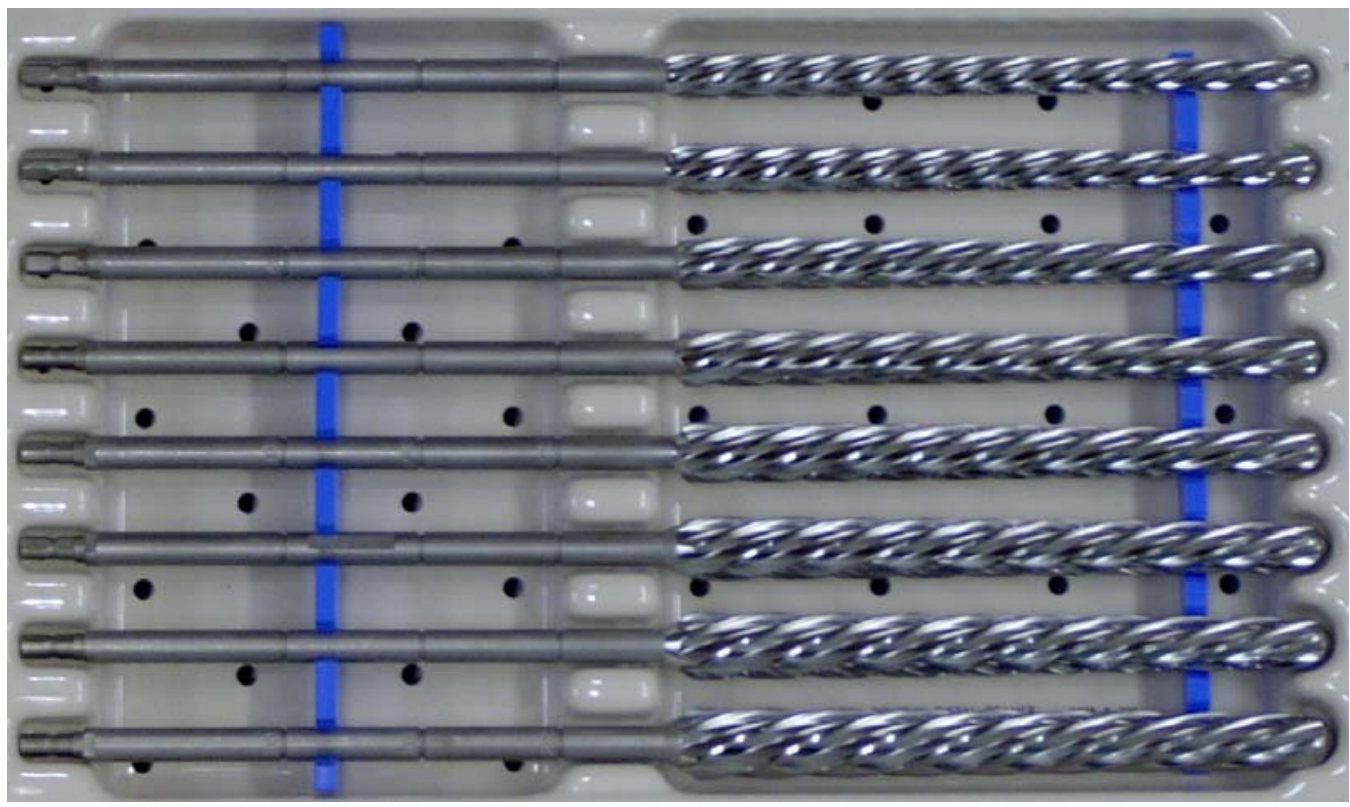

FIGURE 16. Stryker Howmedica Osteonics conical distal reamer set.

Proximal cone reamers, shown in Figure 17, were used to remove the material in the proximal region.

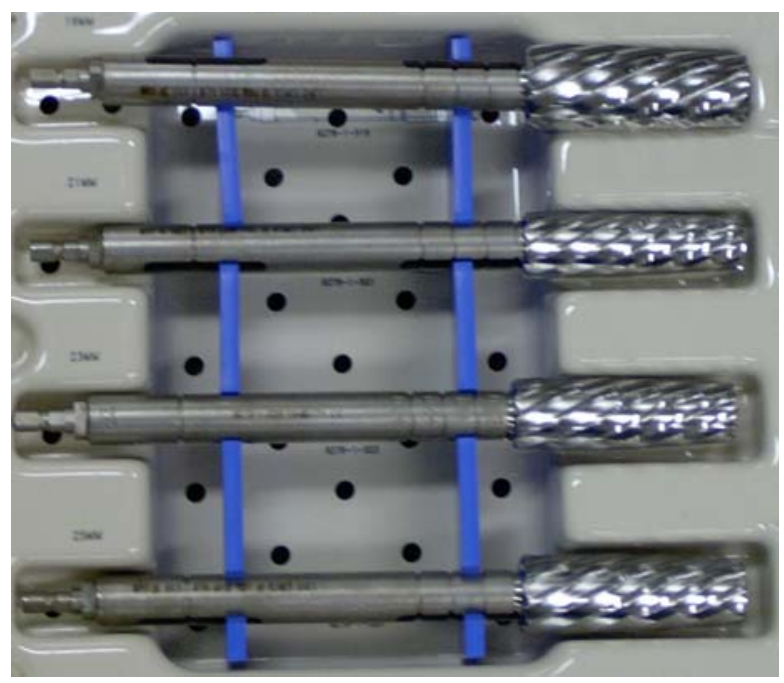

FIGURE 17. Stryker Howmedica Osteonics proximal cone reamer set. 
Additional tools used in the implantation process included a mallet, slide hammer, vice, and power drill. Figure 18 shows the Stryker Power Saw that was used to remove femur head.

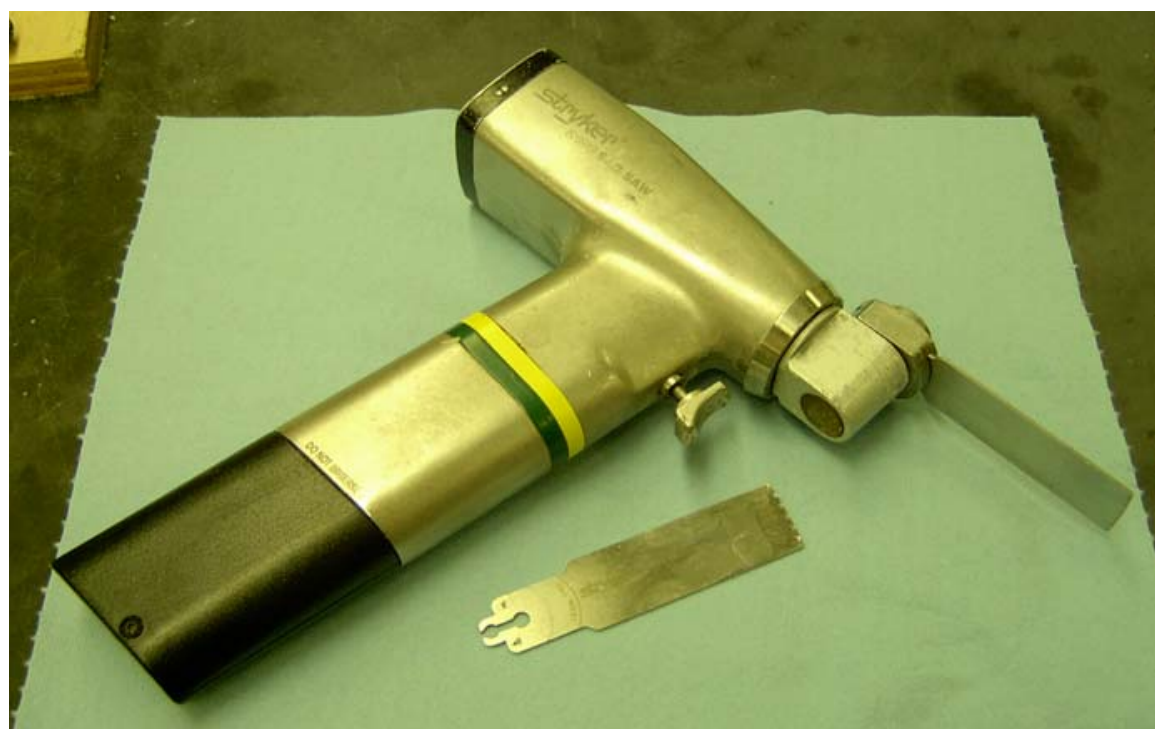

FIGURE 18. Stryker Howmedica Osteonics power saw. 


\section{PROCEDURE}

\section{A. Experimental Phases of Study}

There were three sequential phases involved with this particular study that consisted of the following:

- Phase I - Testing of intact femurs to examine initial strain distribution

- Phase II - Insert modular implant using press fit and examine change in strain distribution

- Phase III - Insert BoneSource ${ }^{\circledR}$ Hydroxyapatite bone cement around modular implant and examine change in strain distribution

Phase I involved examining the strain throughout the femurs without any kind of modifications to the structure of the femur (i.e. no implant inserted). Phase II was performed after Phase I was completed. Modular implants were inserted and the exact same procedure was carried out as the intact testing and the resulting strains were examined and recorded. Phase III followed Phase II. Hydroxyapatite bone cement was placed around the implant and allowed to set. The exact same procedure was carried out as the intact testing and the resulting strains were examined and recorded.

\section{B. Implementation of Hip Implants}

All seven of the modular implants were inserted by an orthopedic surgeon in the Orthopedic Bioengineering Laboratory at the University of Louisville medical campus. The process began by removing the femoral head from the femur using the Stryker Power Saw as shown in Figure 19. 


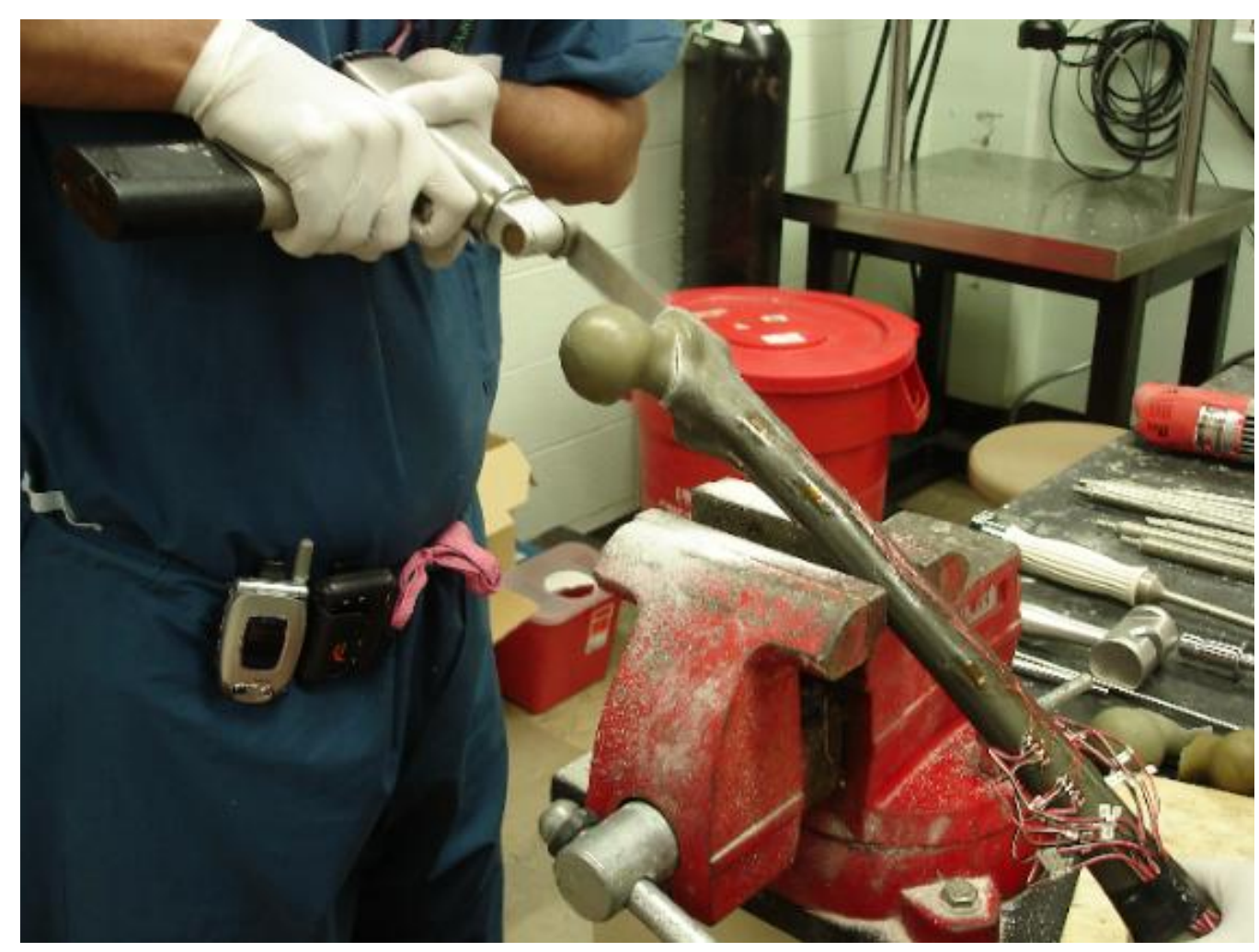

FIGURE 19. Removal of femoral head using Stryker power saw.

A starter awl bit was used to drill down into the femur directed along the femoral axis to remove enough porous material to allow the reamers to remove the rest of the unwanted material. The awl bit had marks in five millimeter increments starting in the middle and extending to the end portion of the shaft to monitor the drilling depth. A drilling depth of $225 \mathrm{~mm}$ was used measuring from the top of the lateral side down the femoral axis. This particular depth was chosen because this was the length of each of the stems.

When the appropriate depth was achieved, Stryker Howmedica Osteonics reamers were used. A small diameter reamer, $12.5 \mathrm{~mm}$, was first employed. As the reaming process continued, other reamers with increasing diameters in increments of $0.5 \mathrm{~mm}$ were used until a cavity of $15 \mathrm{~mm}$ was achieved. During the reaming process the femurs were removed from a vice grip that held them secured so that the loose material and debris that 
would accumulate inside the cavity could be removed. The reaming process is shown in Figure 20.

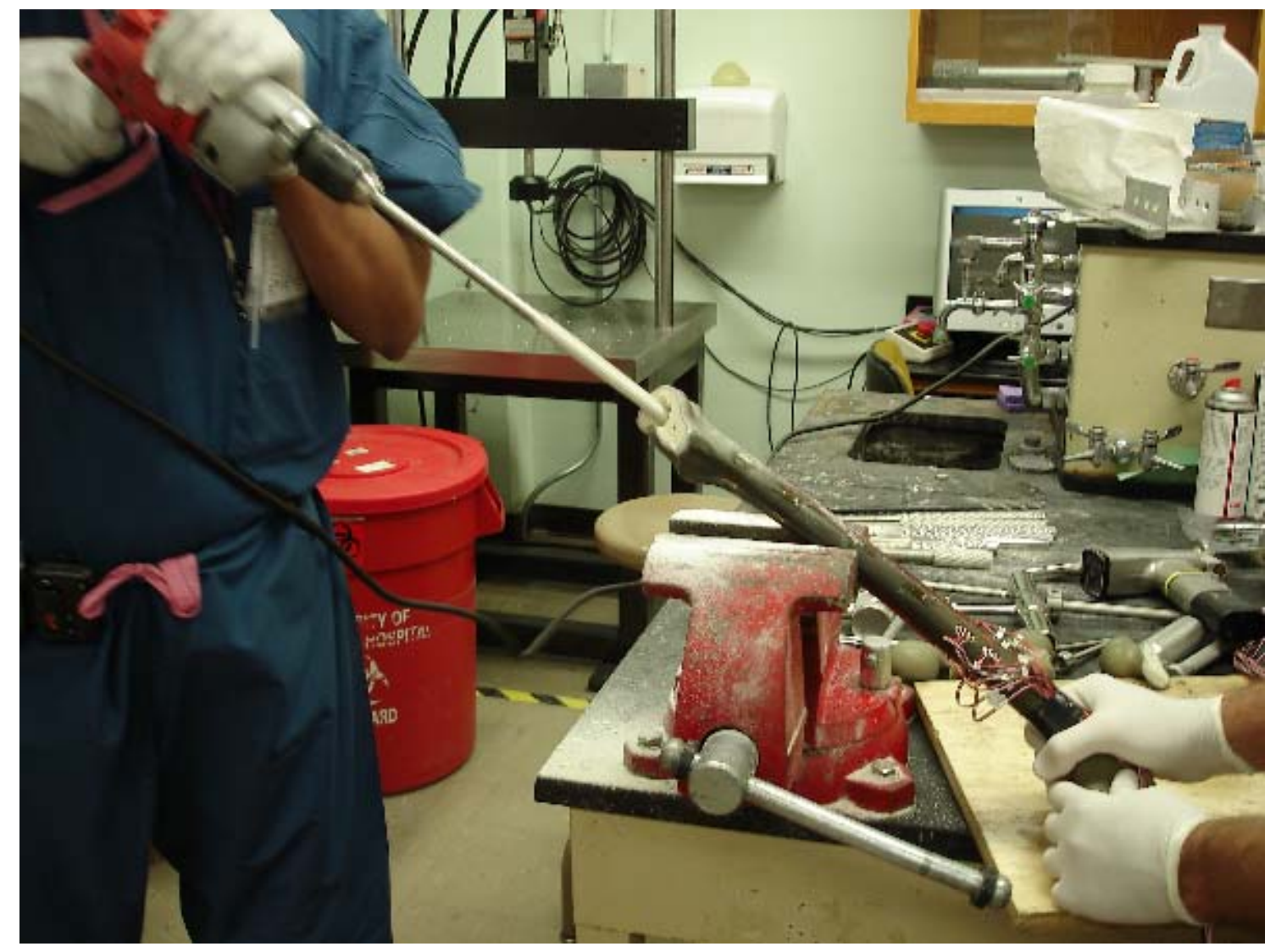

FIGURE 20. Orthopedic surgeon performing reaming process.

After all of the material and debris from the canal of the femur was removed, a large diameter reamer was used to remove material from the proximal region of the femur to insure that the modular body would not make contact with the femur. The reaming process of removing all of the material in the proximal region is shown in Figure 21. 


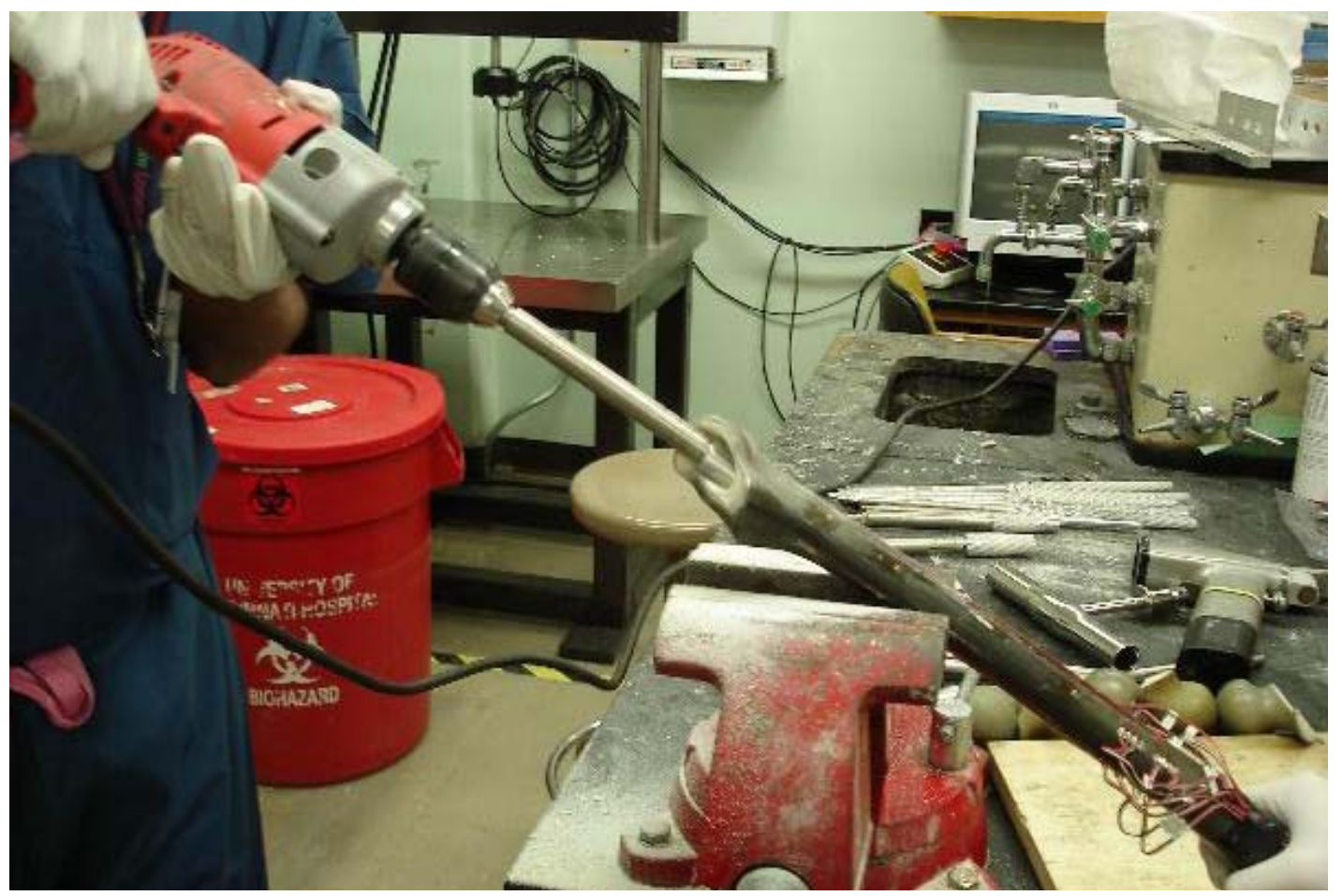

FIGURE 21. Orthopedic surgeon performing reaming process.

The material in the proximal region was also removed so that the Hydroxyapatite bone cement could be injected around the modular body in the third phase of this study. This step concluded the reaming process. A close up view of the completed reaming process is shown in Figure 22. 


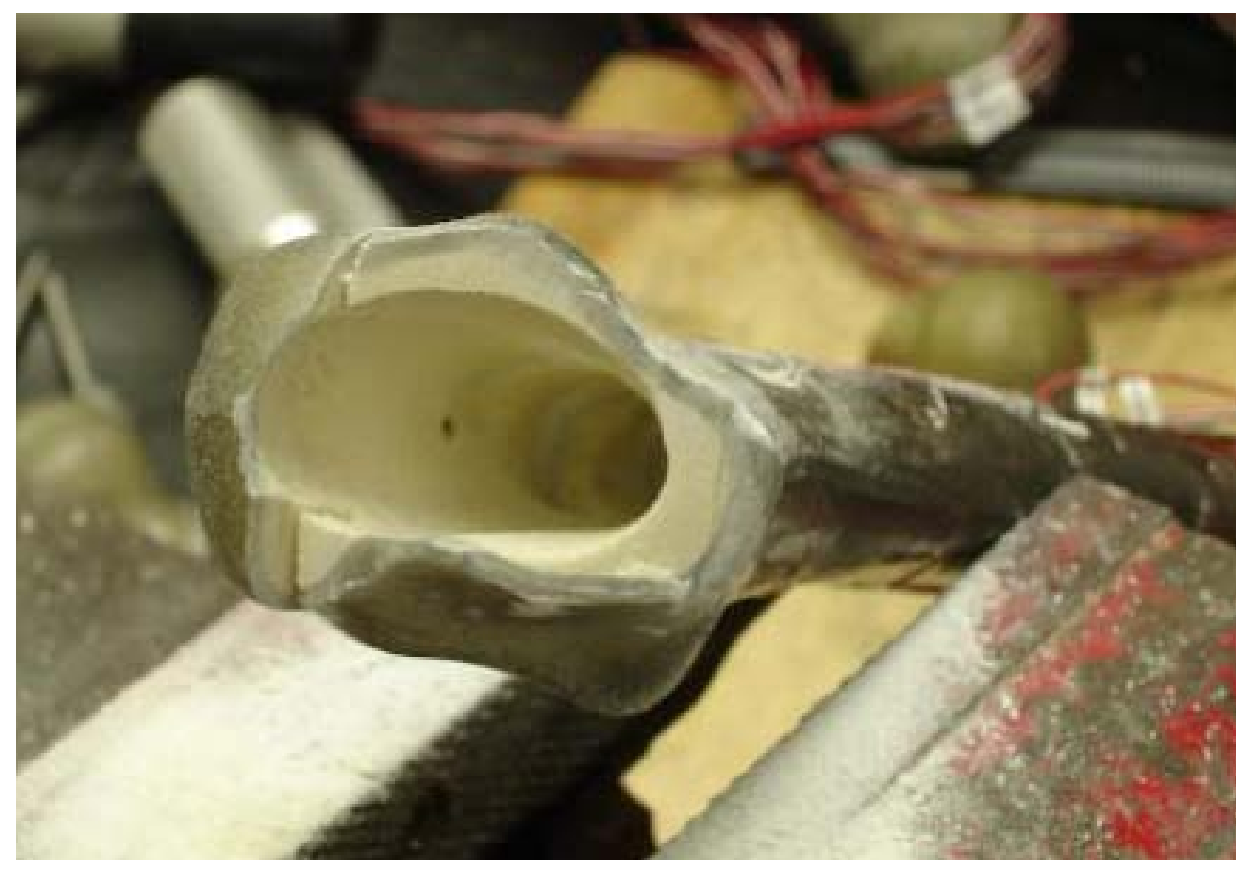

FIGURE 22. Femur after successful reaming procedure.

The reamers and femurs became hot after an extended period of time of drilling. The temperature of the femurs was monitored closely to insure that cracks would not develop on the femurs. The temperature was monitored simply by touching the femurs and reamers. The reaming process was halted for a short period of time if the reamers or femurs felt too hot to the touch. This indicated that the reamers were contacting and removing the cortical bone. This also had the potential of dulling the reamers. The surgeon tried to avoid this by realigning the reamer to remove the softer material.

The stem inserter and hammer was used to drive in the modular stem after the diameter of the cavity was $15 \mathrm{~mm}$. The stem was hammered into position until the 225 mm depth was reached. A close up of the insertion of the modular stem using the stem inserter and hammer is shown in Figure 23. 


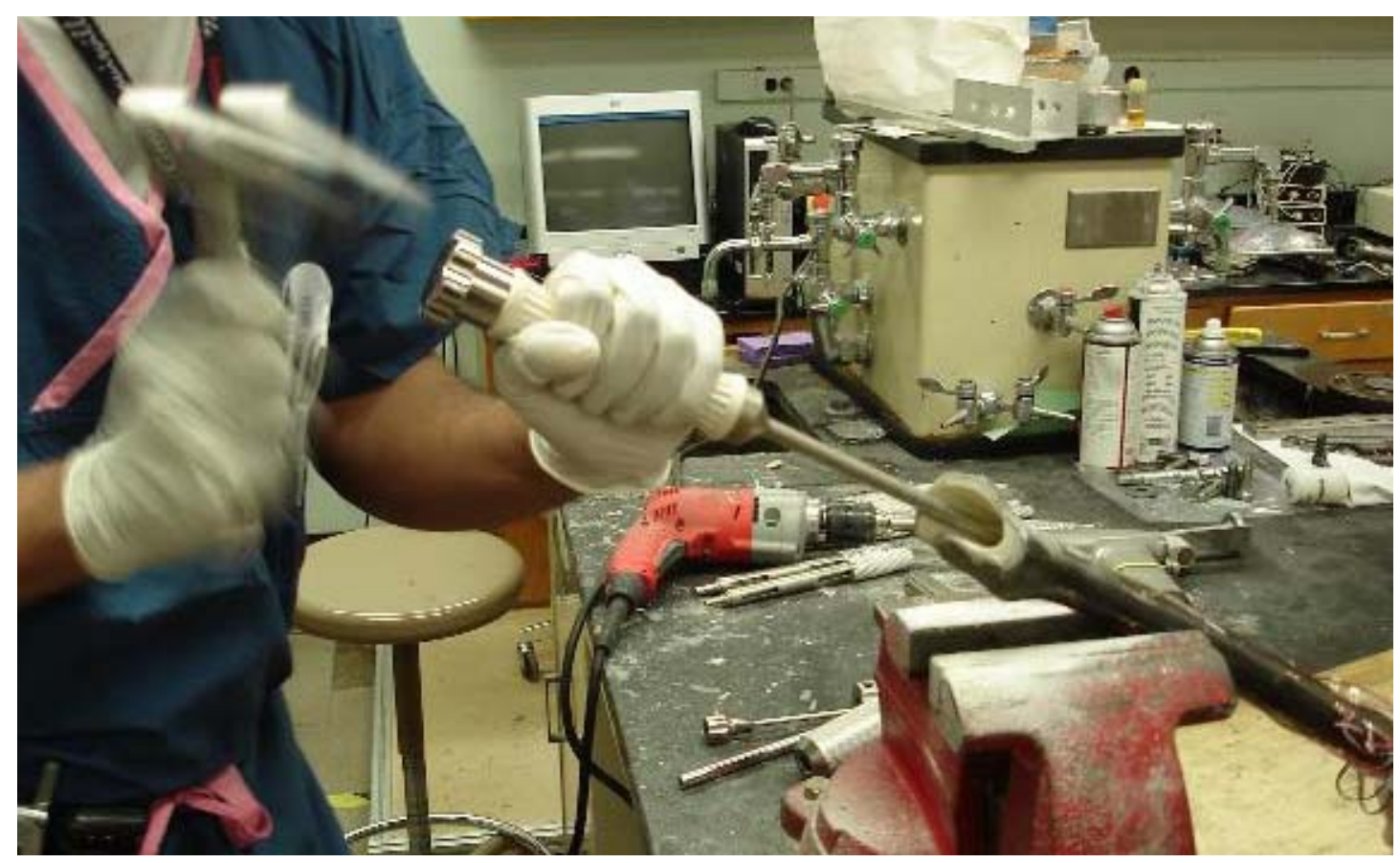

FIGURE 23. Orthopedic surgeon inserting modular stem.

\section{Alteration of Modular Body Coarse Surface}

Two uniaxial strain gages supplied from Vishay Measurements Group, Inc. were mounted on each modular implant body. To ensure adequate bonding of the strain gage, the coarse surface on the modular body was removed. The coarse surface on the modular implant is present in order to promote better implant-bone adhesion after THA.

The coarse surface on the modular body was polished in a lathe at the University of Louisville Machine Shop. In order for each modular body to be polished, a steel rod was crafted to fit inside the cavity of the body that would be secured to the lathe as shown in Figure 24. 


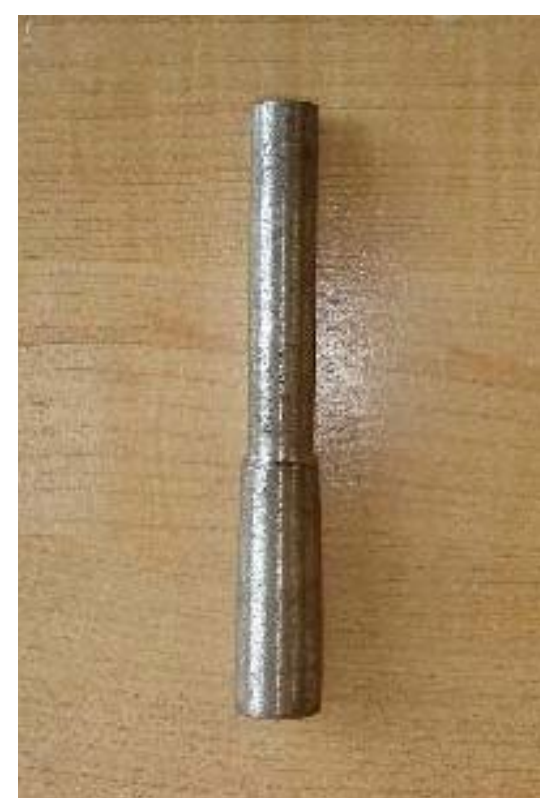

FIGURE 24. Steel rod used to secure modular body in lathe.

The rod was inserted into the modular body and secured into place on the lathe.

Aluminum oxide 220 grit sand paper was used to remove the coarse surface and polish the surface. The process of removing the coarse surface of each implant body is shown in Figure 25.

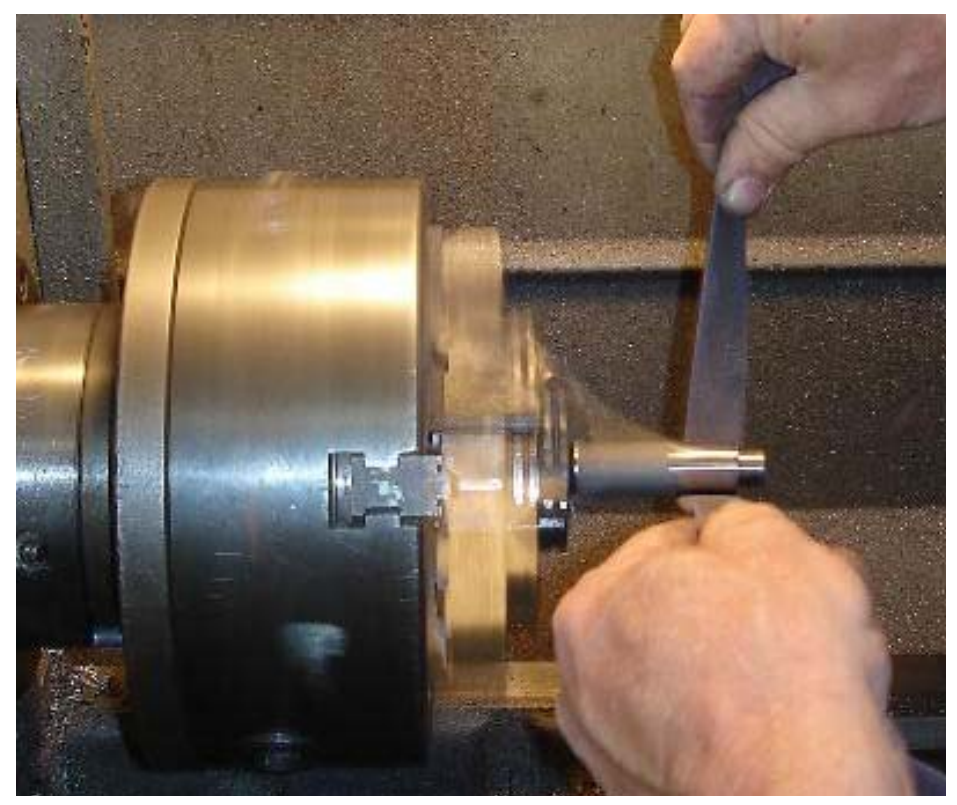

FIGURE 25. Process used to remove coarse surface on modular body. 
The time to polish each surface with the sand paper varied from three to five minutes. Each implant was inspected to see if the surface looked free of the coarse material. If more of the coarse surface needed to be removed the lathe would be turned back on and more aluminum oxide 220 grit sand paper would be applied. After the polishing procedure the modular bodies were removed and allowed to cool for ten minutes. Figure 26 shows the modular body before and after the polishing process.

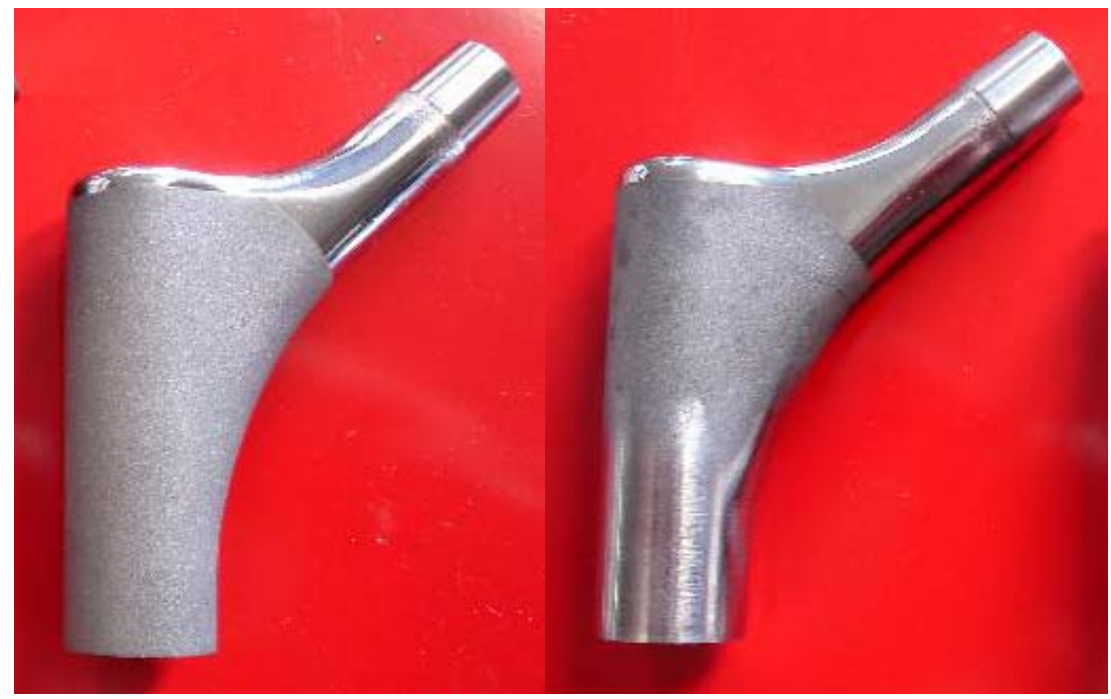

FIGURE 26. Modular body before (left) and after (right) the polishing process.

After the polishing procedure, uniaxial strain gages were mounted on the medial and lateral faces of the body. Each strain gage was mounted at the bottom of the modular body at the interface where the body comes into contact with the tapered stem to monitor the strain at that point. The location for the gages placed on each modular body, with respect to the test femur, is listed in Table II. The location of the strain gages mounted on modular body implant on the medial and lateral faces are shown in Figure 27. 
TABLE II. Uniaxial strain gage surface locations on modular body.

\begin{tabular}{|c|c|c|}
\hline Gage \# & Surface & Level \\
\hline \hline 13 & Anterior & Proximal \\
\hline 14 & Posterior & Proximal \\
\hline
\end{tabular}

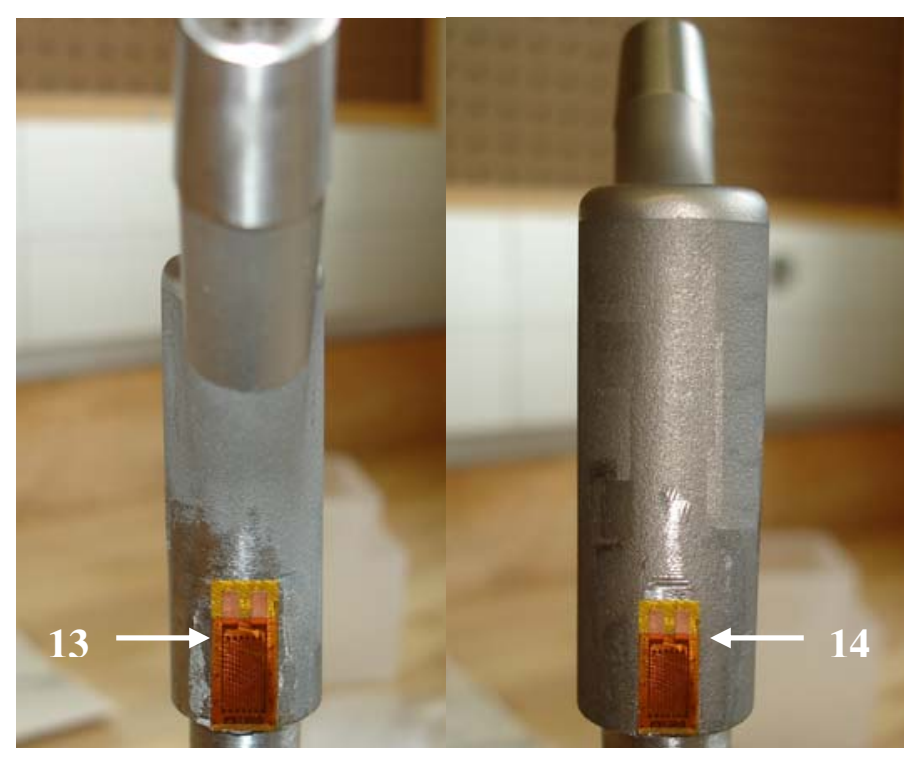

FIGURE 27. Gage number and location of strain gages on medial (left) and lateral (right) faces of modular body.

Each gage was wired to bondable terminals using M-Line 134-AWP single conducting wires. Approximately $61 \mathrm{~cm}$ of $326-\mathrm{DFC} 3$ conductor wire was soldered to the bondable terminals for each gage to provide strain relief. A digital multimeter was used to check for continuity and proper adhesion. It was confirmed that each gage read $350 \pm 1 \Omega$.

\section{Placement of Hydroxyapatite Bone Cement}

BoneSource ${ }^{\circledR}$ Hydroxyapatite, bone cement for orthopedic defect filling, was injected around all seven test femurs by an orthopedic surgeon in the Orthopedic Bioengineering 
Laboratory at the University of Louisville medical campus. The process began by mixing approximately $14 \mathrm{cc}$ of tap water with 10.0 grams of hydroxyapatite. A syringe with a flexible needle was used to inject the mixture of fluid around the body of each modular implant. The injection process is shown in Figure 28.

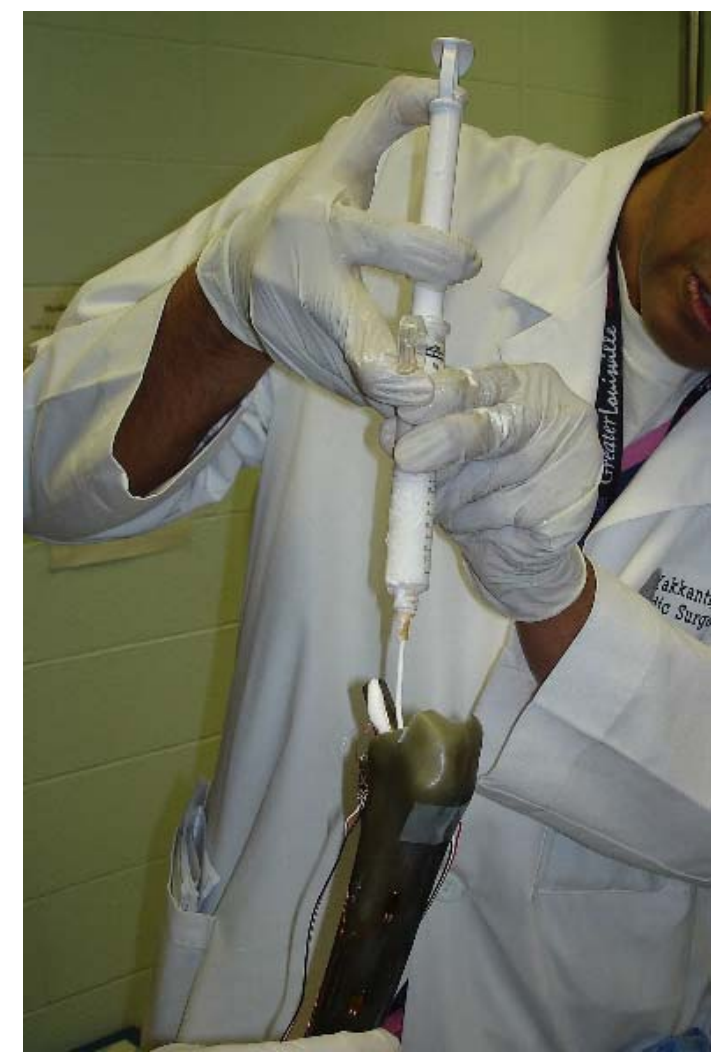

FIGURE 28. Injection process using hydroxyapatite.

With the excess water content, the mixture could easily flow into and fill the void between the implant and femur in the proximal region. Approximately $10 \mathrm{cc}$ was sufficient to completely fill the void in the proximal region of each test femur. Careful attention was paid to make sure that the void was completely filled, especially in the antero-medial region. A close-up view of the injection process is shown in Figure 29. 


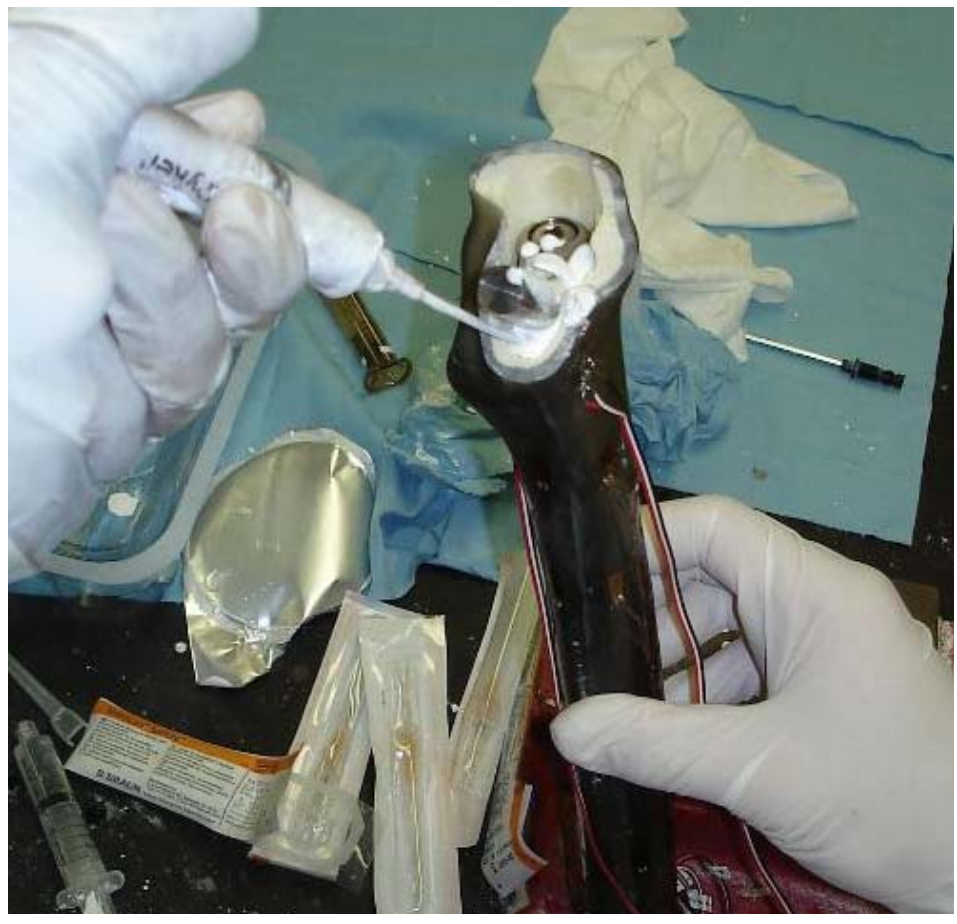

FIGURE 29. Injection process in antero-medial region.

The resulting construct after the hydroxyapatite bone cement was injected around the implant to fill the cavity between the implant and femur is shown in Figure 30.

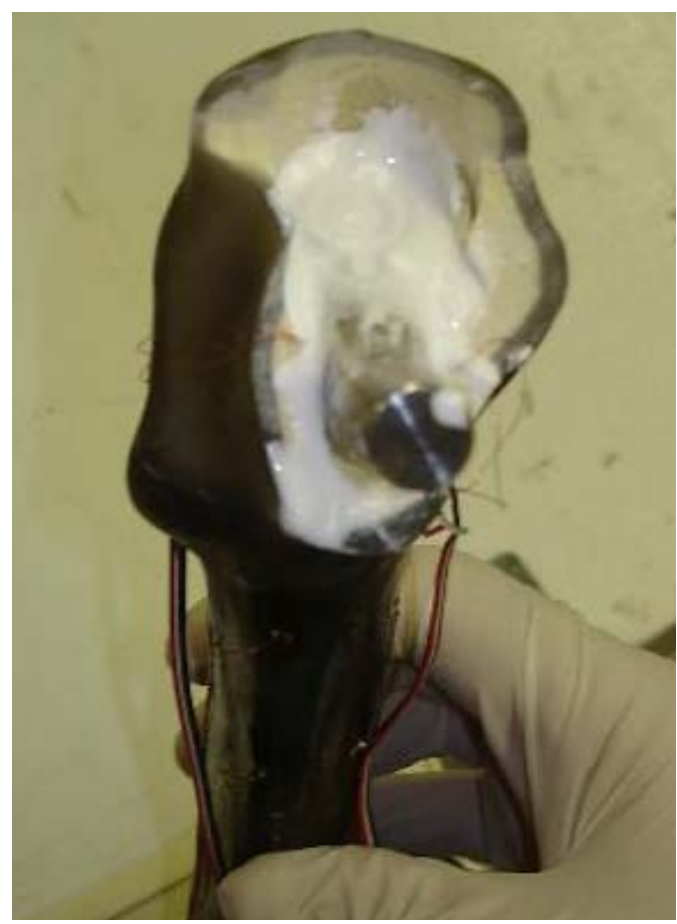

FIGURE 30. End result of addition of hydroxyapatite bone cement. 
Each test femur was placed upright in a storage container in an enclosed, dry area and allowed to cure over the course of five days to ensure that the extra moisture content had sufficient time to evaporate. At the end of five days the moisture contained in the hydroxyapatite mixture evaporated. Also, as a result, the hydroxyapatite bone cement was observed to have small surface cracks.

\section{E. Two Leg Stance Testing}

There were several steps incorporated into performing the two leg stance test. First, the upper and lower test fixtures were inserted into the hydraulic wedge grips on the MTS. Next, the Station Manager was used to adjust the crosshead to an appropriate height to allow the test femur to be loaded between the two fixtures. The MTS system was operated in displacement control while monitoring the load. Displacement control enabled the displacement of the actuator to be controlled. Loads were placed on the femur by raising the actuator.

Next, a no load test was implemented and the resulting strains were recorded. Each test femur was then mounted between the fixtures of the MTS machine and secured using displacement control to apply a small amount of pre-load on the femur. Then, the Station Manager was switched into force control. A load cell mounted between the upper test fixture and acetabular cup was connected to a Measurements Group 2120 which monitored the force exerted on the test femur. A compressive load of $180 \mathrm{~N}$ was administered. After the strain readings were recorded the test femur was removed from the MTS machine and allowed to rest for ten minutes to allow the test femur to relax and the strains to return to the no load level as reported in a study conducted by Fries. ${ }^{35}$ This process was repeated except a $360 \mathrm{~N}$ compressive load was applied to each test femur, 
which is half the weight of an average male. The entire process was repeated three times on each test femur to determine data repeatability.

The LabVIEW vi used in this study did not incorporate a calibration process to zero out the strains, thus what is referred to in this study as "zero strain condition" test was the zero load strain. Then a trial was carried out in which the load was placed on the femur. Only after the difference was taken between the loaded and unloaded trials was the actual strain experienced by the femur resolved. 


\section{RESULTS}

\section{A. Press Fit Prosthesis Strain Data}

For the intact condition (Phase I) the strains were largest in the proximal region and lowest in the distal region. Figures 31 and 32 show the intact surface strains and the surface strains after the insertion of the modular implant for femur \#4139 and the average surface strains of all of the test femurs under a $360 \mathrm{~N}$ compressive load, respectively.

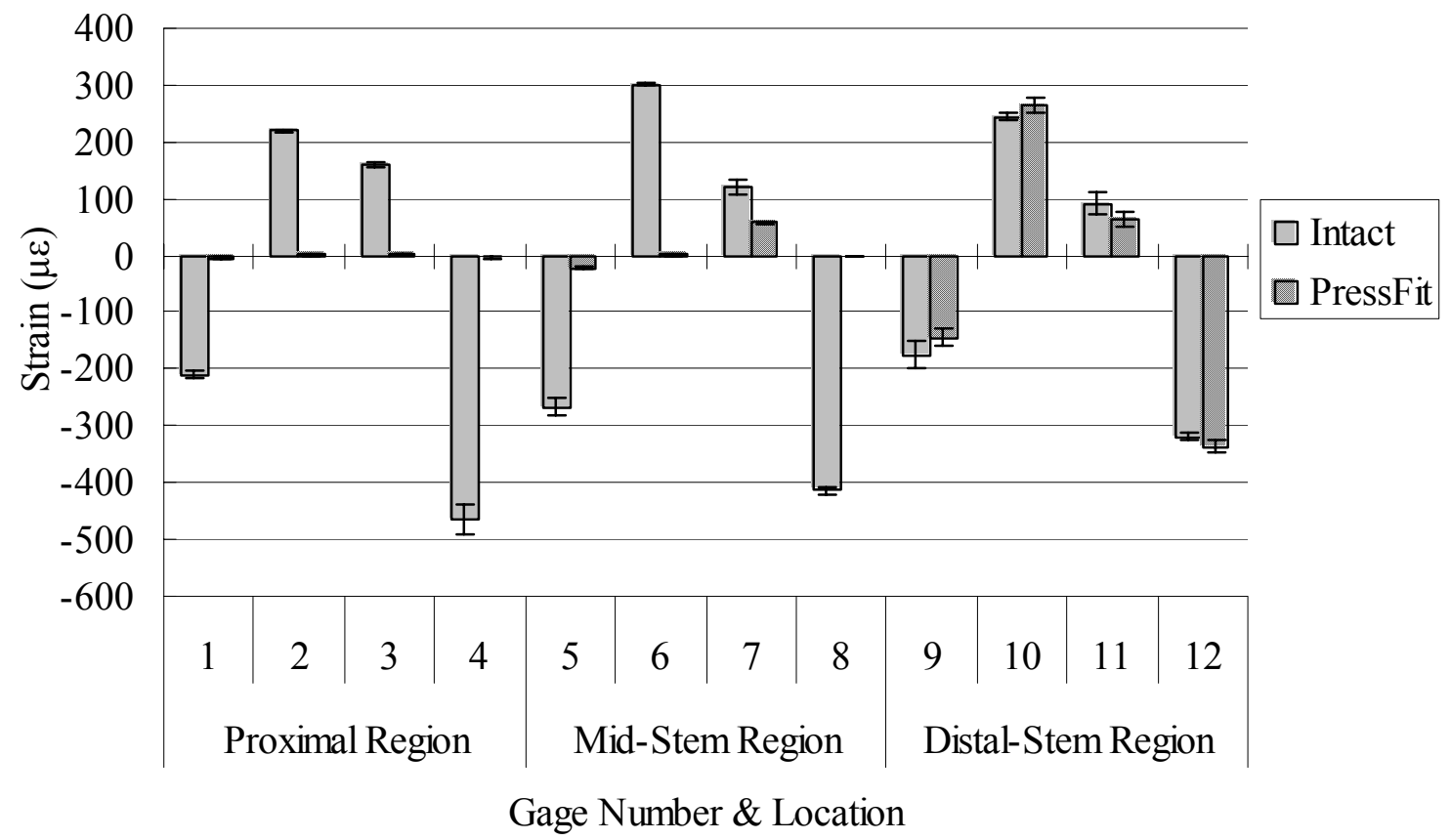

FIGURE 31. Resulting intact strains and press fit strains with a $360 \mathrm{~N}$ load for femur \#4139. 


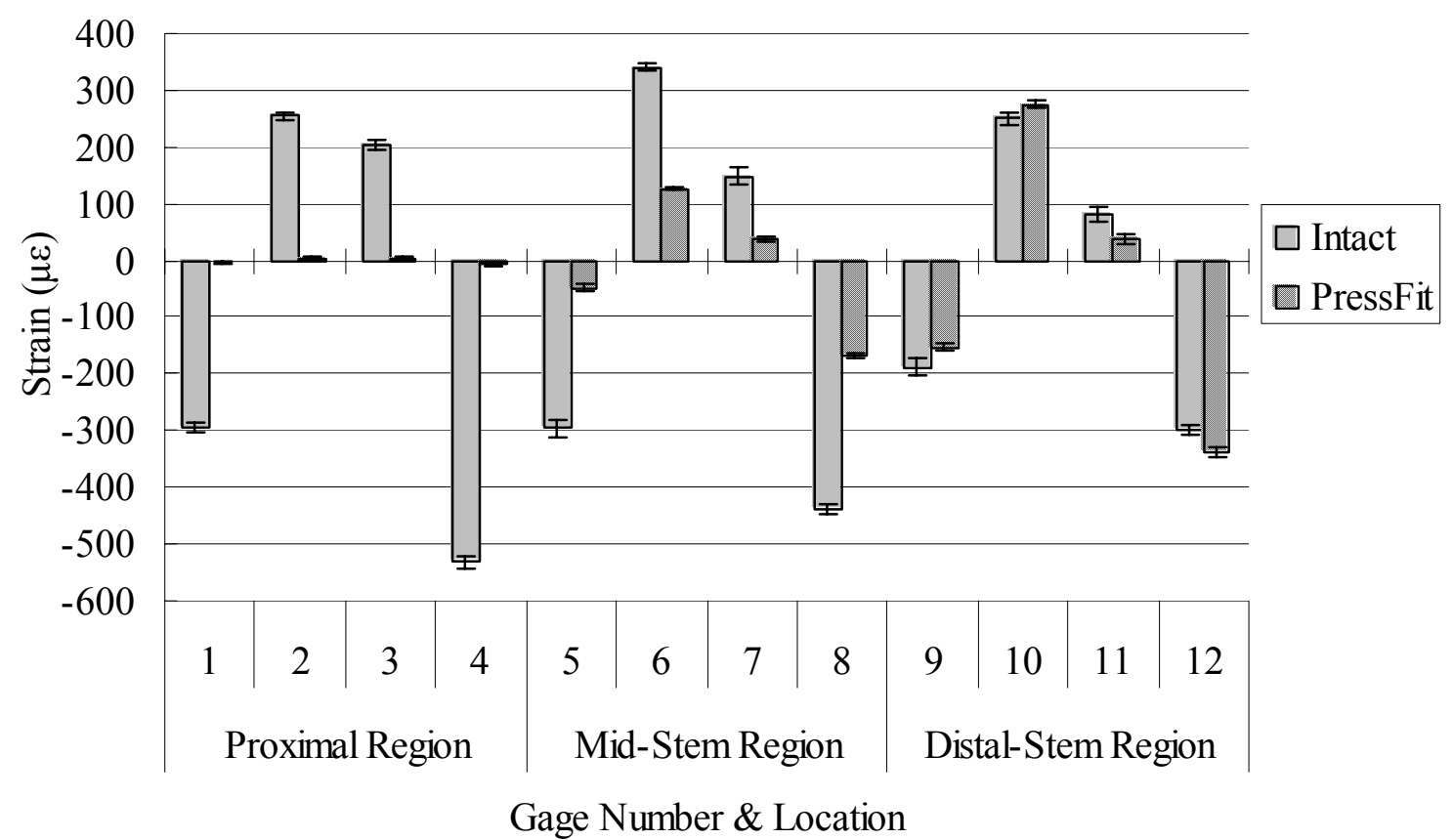

FIGURE 32. Resulting average intact strains and press fit strains with a $360 \mathrm{~N}$ load of all femurs.

The strains were compressive on the medial side of the femur and tensile on the lateral side. Note for all results presented that a negative strain value denotes that the strain gage is in compression and a positive strain value denotes that the strain gage is in tension. Overall, stress shielding occurred in every region except the distal-stem level antero-lateral and postero-medial areas. Similar results were obtained from the other six test femurs as shown in the appendix. The percent decrease in surface strain from the intact state to the press fit state for each test femur under $180 \mathrm{~N}$ and $360 \mathrm{~N}$ compressive loads is shown in Tables III and IV, respectively. 
TABLE III. Percent decrease between intact and press fit cases with a $180 \mathrm{~N}$ load.

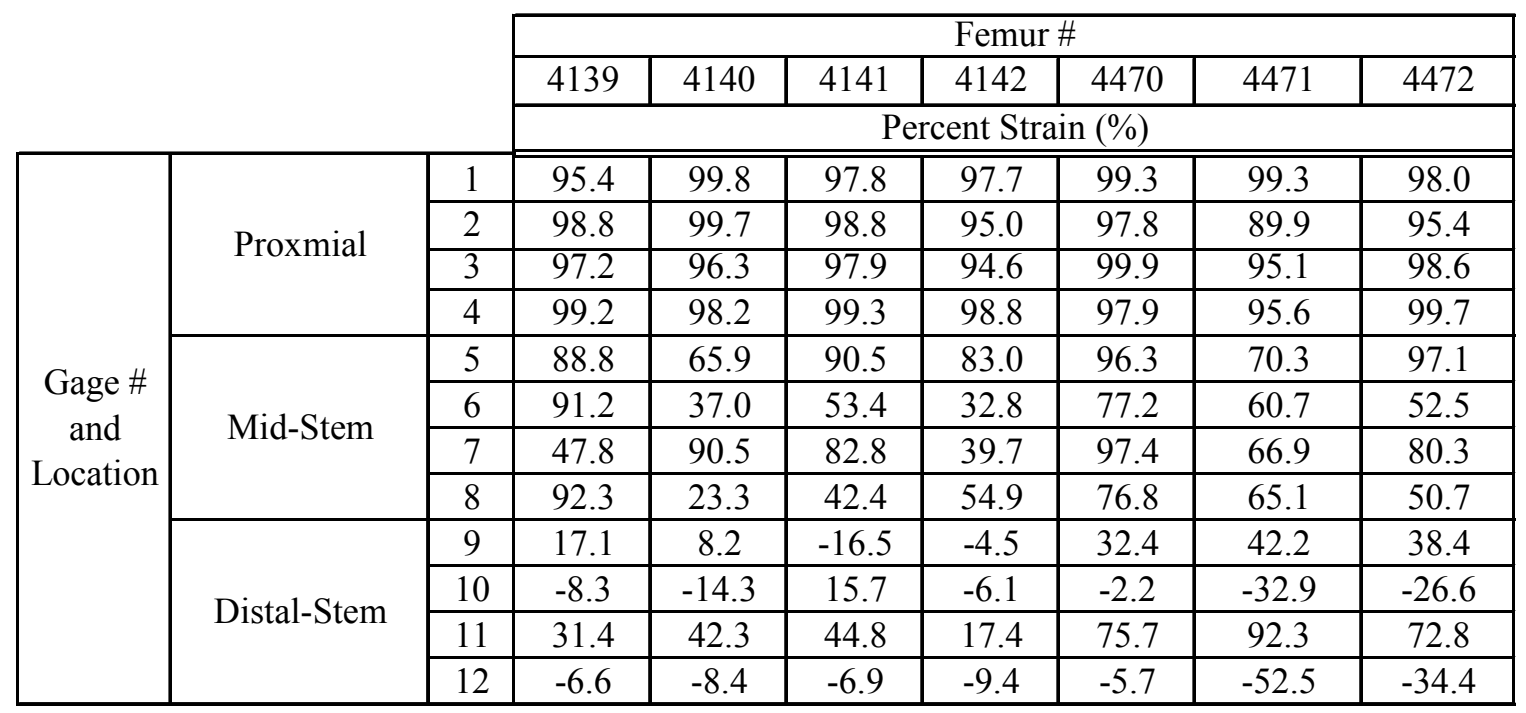

TABLE IV. Percent decrease between intact and press fit cases with a $360 \mathrm{~N}$ load.

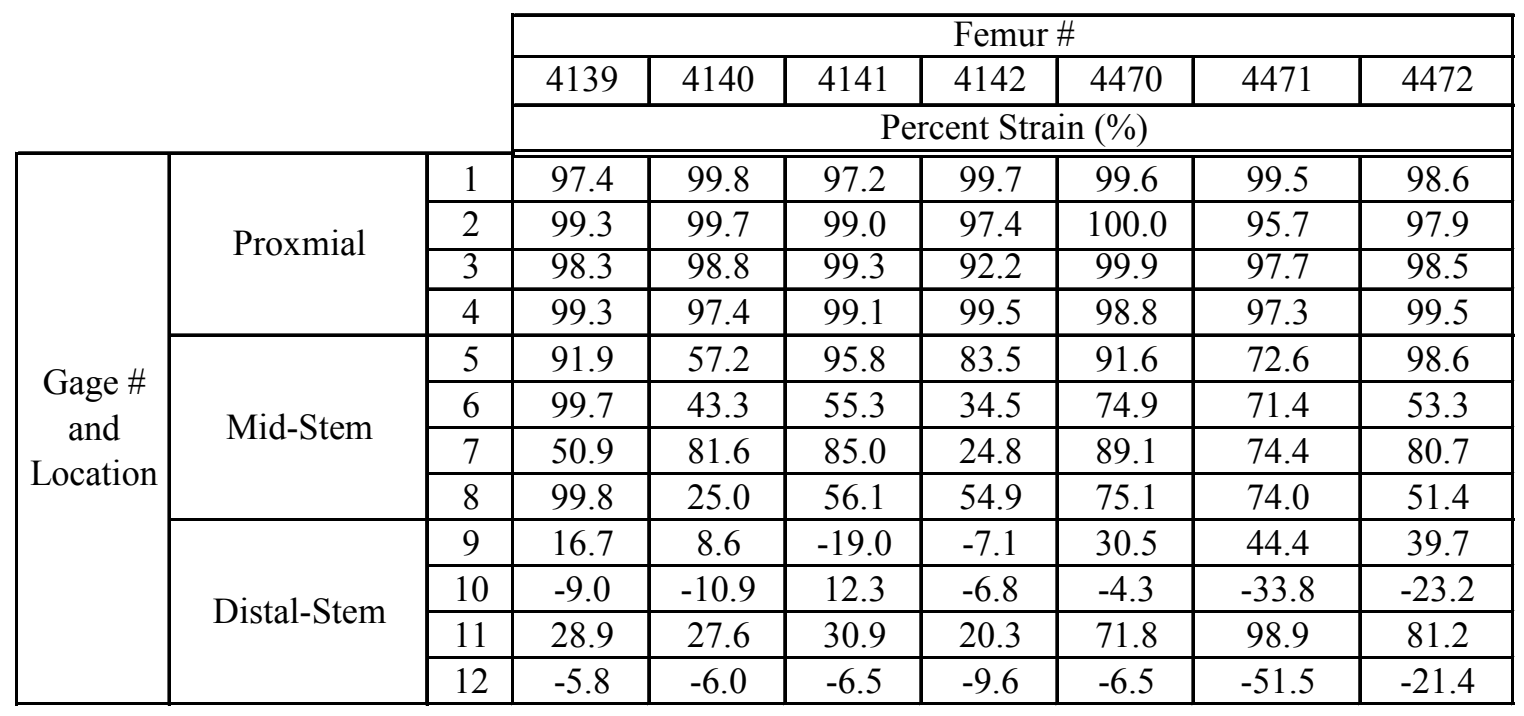

Overall, there was a significant drop in surface strain on the femurs since ten of the twelve strain gages experienced a reduction of strain under each load condition.

\section{B. Cemented Prosthesis Data}

After administering the hydroxyapatite bone cement around the modular implant, the strain distribution throughout the femur changed. Figures 33 and 34 show the intact 
surface strains and the surface strains after administering the hydroxyapatite bone cement under a $360 \mathrm{~N}$ load for femur $\# 4139$ and the average surface strains of all of the test femurs under a $360 \mathrm{~N}$ load, respectively.

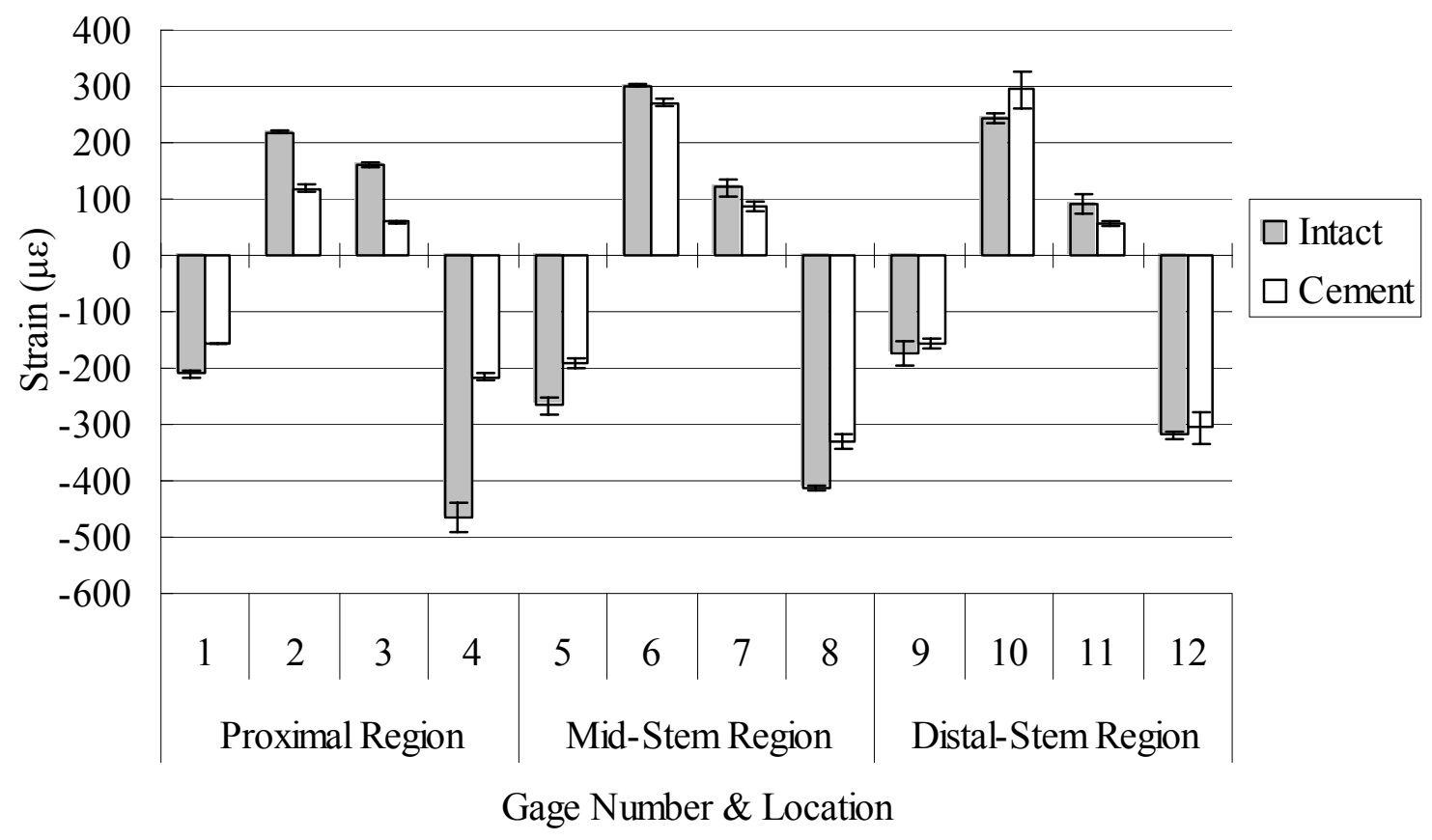

FIGURE 33. Resulting intact strains and cemented strains with a $360 \mathrm{~N}$ load for femur \#4139. 


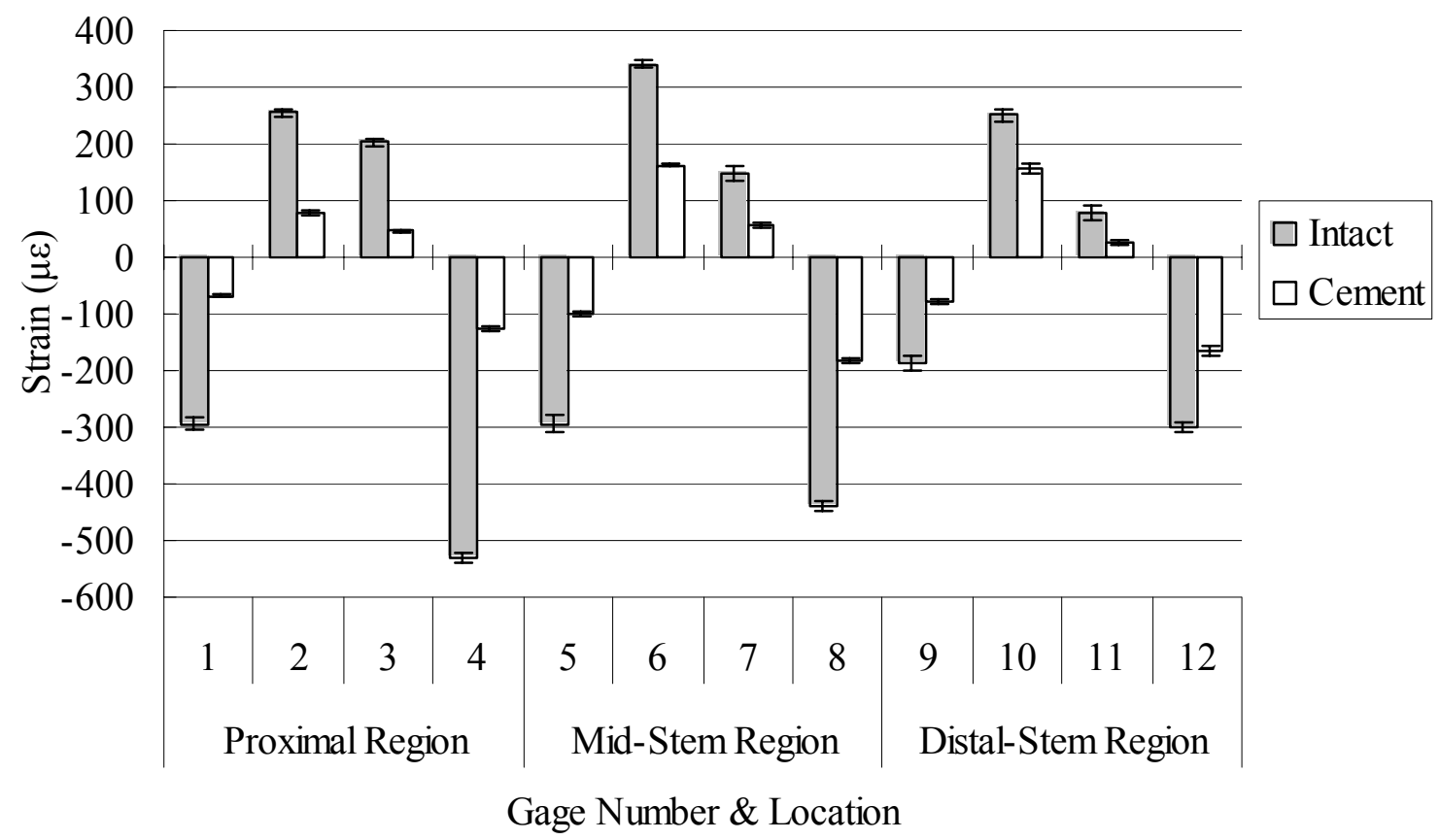

FIGURE 34. Resulting average intact strains and cemented strains with a $360 \mathrm{~N}$ load of all femurs.

Similar results were obtained from the other six test femurs as shown in the appendix. The percent decrease in surface strain from the intact state and with the addition of hydroxyapatite state for each test femur with $180 \mathrm{~N}$ and $360 \mathrm{~N}$ load conditions is shown in Tables V and VI, respectively. 
TABLE V. Percent decrease between intact state and with the addition of hydroxyapatite bone cement with a $180 \mathrm{~N}$ load.

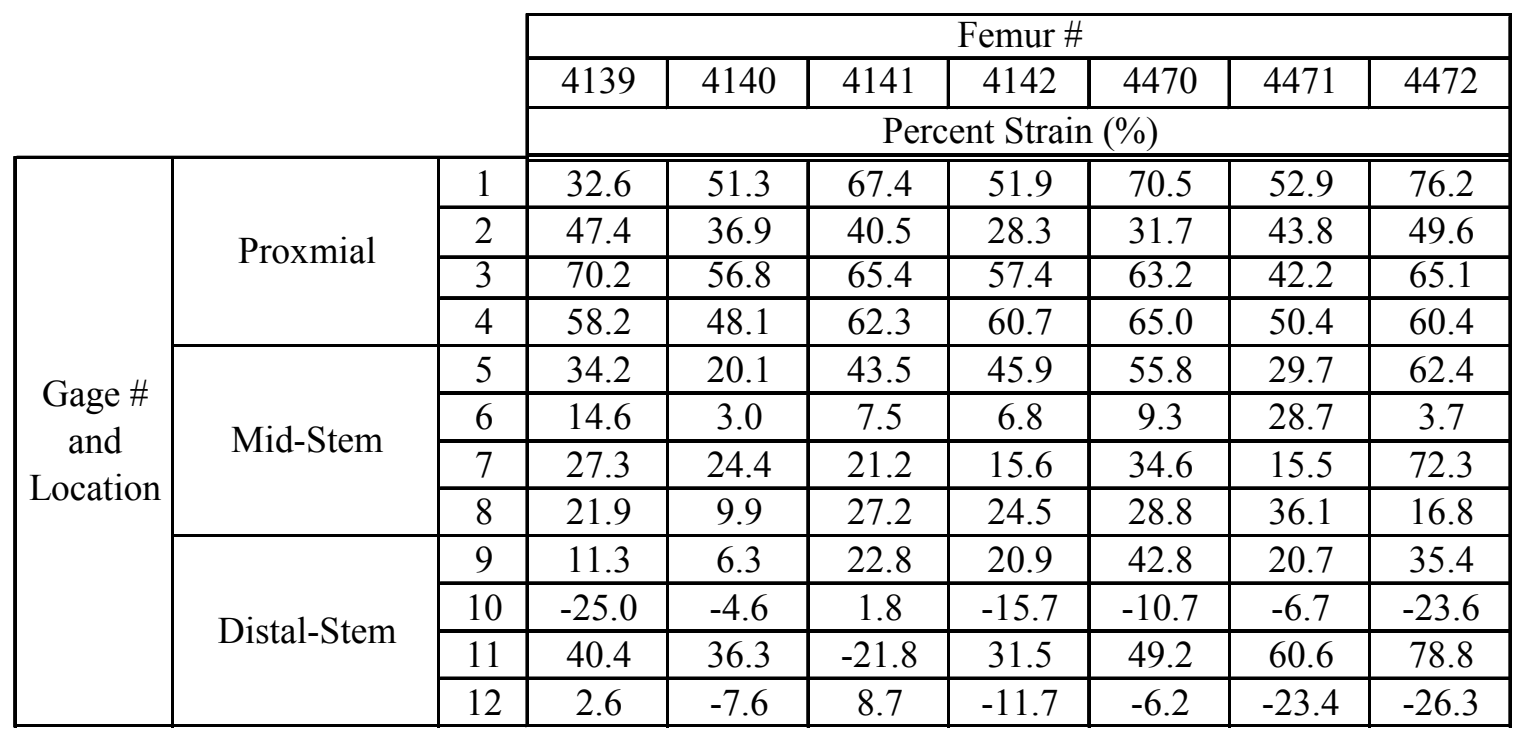

TABLE VI. Percent decrease between intact state and with the addition of hydroxyapatite bone cement with a $360 \mathrm{~N}$ load.

\begin{tabular}{|c|c|c|c|c|c|c|c|c|c|}
\hline & \multicolumn{7}{|c|}{ Femur \# } \\
\hline & & & 4139 & 4140 & 4141 & 4142 & 4470 & 4471 & 4472 \\
\hline & & & \multicolumn{7}{|c|}{ Percent Strain $(\%)$} \\
\hline \multirow{12}{*}{$\begin{array}{c}\text { Gage \# } \\
\text { and } \\
\text { Location }\end{array}$} & \multirow{4}{*}{ Proxmial } & 1 & 25.6 & 46.7 & 66.5 & $\bar{~} 52.4$ & 67.3 & 50.0 & 72.6 \\
\hline & & 2 & 45.9 & 39.2 & 43.8 & 33.5 & 41.0 & 49.1 & 52.0 \\
\hline & & 3 & 63.0 & 55.0 & 65.2 & 52.8 & 67.1 & 40.0 & 70.4 \\
\hline & & 4 & 53.5 & 44.9 & 60.6 & 51.5 & 64.0 & 48.7 & 56.9 \\
\hline & \multirow{4}{*}{ Mid-Stem } & 5 & 28.9 & 13.7 & 36.9 & 37.7 & 49.9 & 23.6 & 58.6 \\
\hline & & 6 & 10.4 & 3.6 & 8.5 & 8.1 & 12.0 & 29.6 & 7.7 \\
\hline & & 7 & 27.2 & 22.4 & 20.8 & 19.1 & 39.6 & 9.6 & 79.4 \\
\hline & & 8 & 20.3 & 10.4 & 21.9 & 20.1 & 26.8 & 36.2 & 16.9 \\
\hline & \multirow{4}{*}{ Distal-Stem } & 9 & 10.3 & 6.0 & 14.1 & 17.7 & 26.4 & 16.5 & 34.8 \\
\hline & & 10 & -20.9 & -7.0 & 2.3 & -11.7 & -10.5 & -10.9 & -21.4 \\
\hline & & 11 & 39.4 & 33.5 & -20.8 & 22.2 & 67.0 & 53.0 & 86.7 \\
\hline & & 12 & 4.0 & -7.1 & 7.9 & -12.9 & -5.2 & -24.7 & -21.0 \\
\hline
\end{tabular}




\section{Modular Body Strain Data}

The resulting strains on the modular bodies were measured before and after the addition of the hydroxyapatite bone cement. Overall, the surface strains recorded were relatively low. Figures 35 and 36 show the measured surface strains on the medial and lateral faces of the modular bodies under a load of $180 \mathrm{~N}$ and $360 \mathrm{~N}$ for femur $\# 4139$ and the overall average of all of the bodies, respectively.

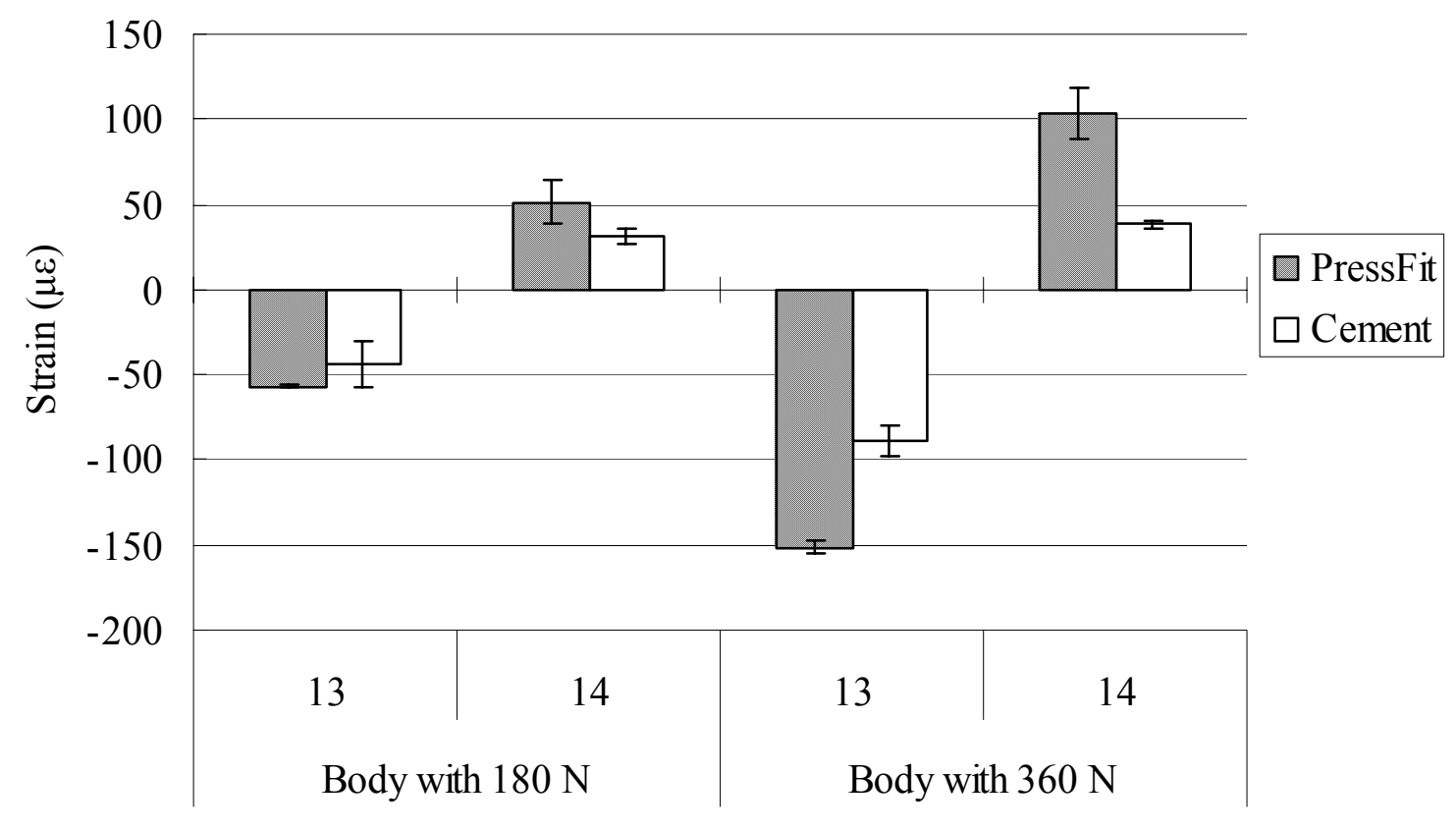

Gage Number \& Location

FIGURE 35. Resulting surface strains on body for femur \#4139. 


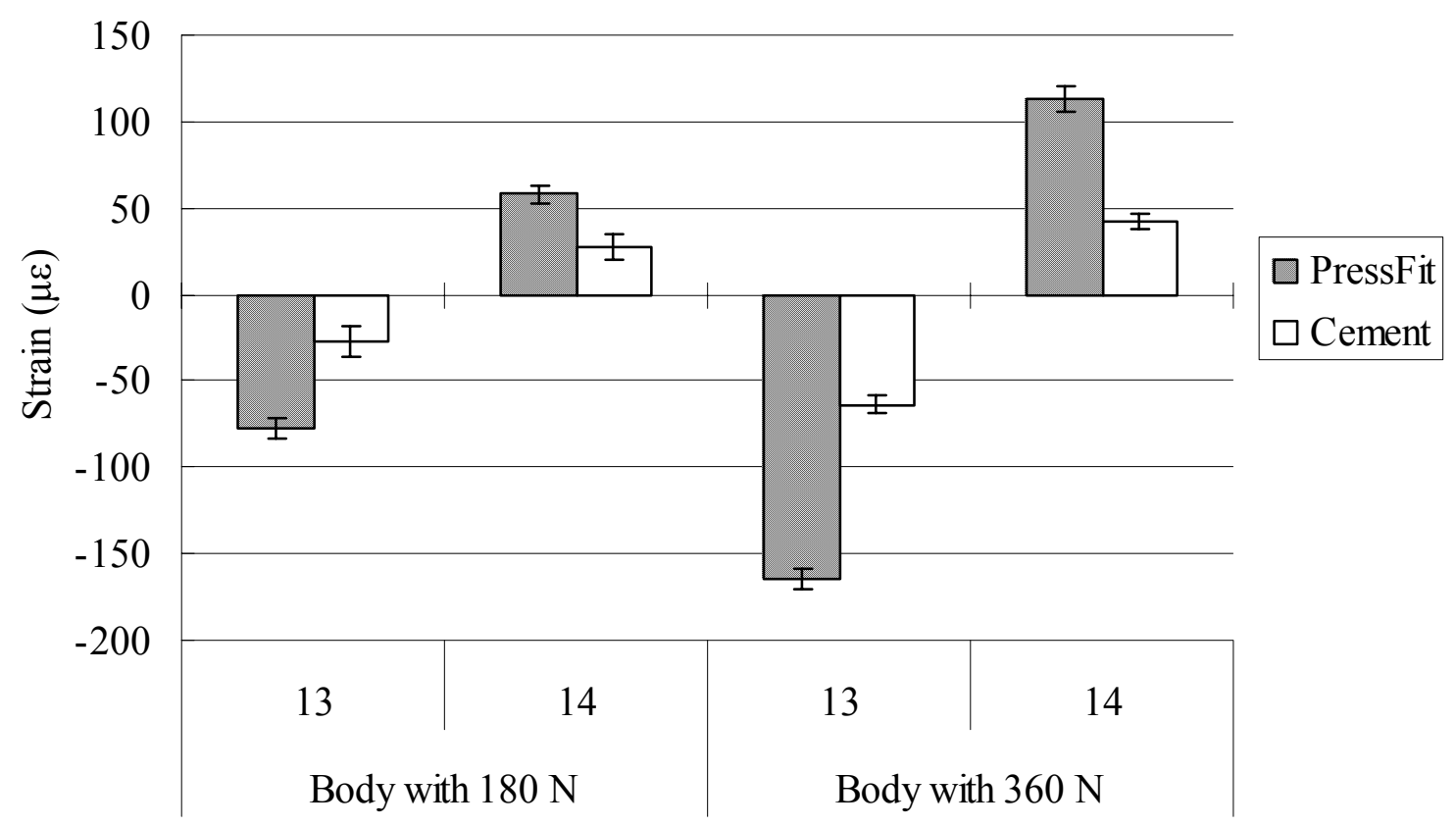

Gage Number \& Location

FIGURE 36. Resulting average surface strains on body for all femurs.

The maximum surface strain was $98 \mu \varepsilon$ in compression in response to a $180 \mathrm{~N}$ compressive load on femur \#4142. The maximum surface strain was $207 \mu \varepsilon$ in compression in response to a $360 \mathrm{~N}$ compressive load on femur \#4472. Similar results were obtained from the other test femurs as shown in the appendix. On average the surface strains were reduced by $20 \%$ after adding Hydroxyapatite bone cement.

\section{Linearity and Repeatability of Load Cases}

Shown in Tables VII and VIII is the percent strain difference between the $180 \mathrm{~N}$ loading cases and $360 \mathrm{~N}$ loading cases in the intact state and with the addition of the modular implant and cement, respectively. 
TABLE VII. Percent strain difference between $180 \mathrm{~N}$ and $360 \mathrm{~N}$ for intact case.

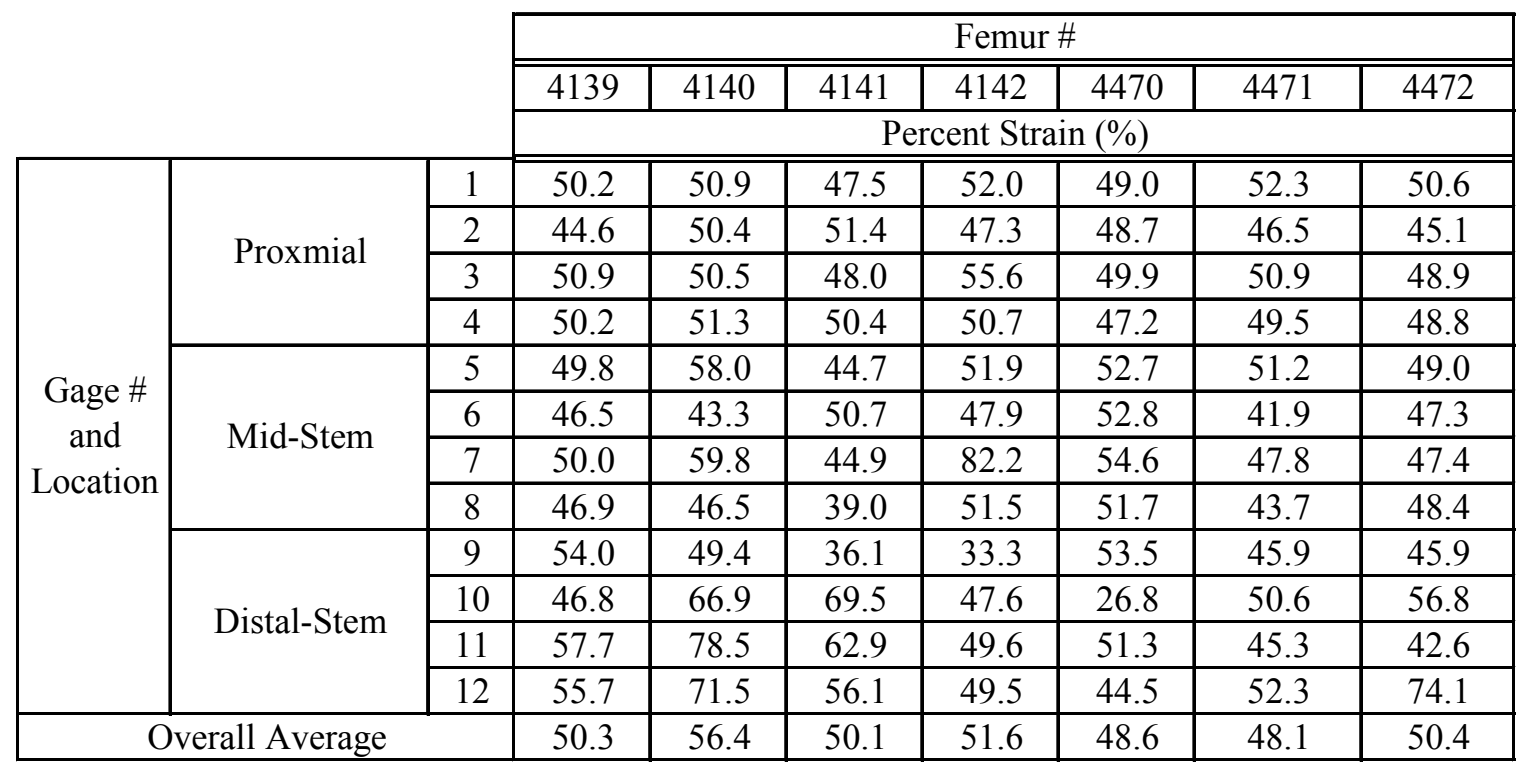

TABLE VIII. Percent strain difference between $180 \mathrm{~N}$ and $360 \mathrm{~N}$ for cemented case.

\begin{tabular}{|c|c|c|c|c|c|c|c|c|c|}
\hline & \multicolumn{7}{|c|}{ Femur \# } \\
\hline & & & 4139 & 4140 & 4141 & 4142 & 4470 & 4471 & 4472 \\
\hline & & & \multicolumn{7}{|c|}{ Percent Strain $(\%)$} \\
\hline \multirow{12}{*}{$\begin{array}{c}\text { Gage \# } \\
\text { and } \\
\text { Location }\end{array}$} & \multirow{4}{*}{ Proxmial } & 1 & 65.4 & 56.0 & 477.9 & 52.6 & 51.5 & 55.4 & 53.3 \\
\hline & & 2 & 46.3 & 47.4 & 47.7 & 41.0 & 38.6 & 44.2 & 44.2 \\
\hline & & 3 & 57.3 & 53.6 & 48.9 & 58.9 & 47.0 & 55.3 & 45.2 \\
\hline & & 4 & 54.7 & 54.5 & 51.7 & 60.2 & 48.4 & 52.1 & 51.7 \\
\hline & \multirow{4}{*}{ Mid-Stem } & 5 & 61.0 & 73.7 & 55.6 & 63.5 & 56.0 & 66.5 & 53.0 \\
\hline & & 6 & 71.3 & 41.5 & 46.5 & 42.4 & 39.6 & 47.9 & 23.3 \\
\hline & & 7 & 53.3 & 58.6 & 47.1 & 41.8 & 43.7 & 85.6 & 43.3 \\
\hline & & 8 & 54.7 & 47.7 & 64.3 & 62.9 & 54.2 & 49.5 & 48.7 \\
\hline & \multirow{4}{*}{ Distal-Stem } & 9 & 57.9 & 54.7 & 67.1 & 62.2 & 81.8 & 60.4 & 48.3 \\
\hline & & 10 & 60.6 & 33.7 & 43.4 & 71.6 & 53.6 & 32.1 & 54.7 \\
\hline & & 11 & 54.4 & 55.2 & 45.6 & 82.0 & 35.7 & 55.5 & 43.2 \\
\hline & & 12 & 32.3 & 55.3 & 58.4 & 45.6 & 61.2 & 48.7 & 57.7 \\
\hline \multicolumn{3}{|c|}{ erall Average } & 55.8 & 52.7 & 52.0 & 57.1 & 50.9 & 54.4 & 47.2 \\
\hline
\end{tabular}

The experimental data from Tables VII and VIII show that the magnitude of the strains for the $180 \mathrm{~N}$ load cases were approximately half of the magnitude of the strains for the $360 \mathrm{~N}$ load cases the intact and press cemented states. 
By using a load cell with a relatively small range, the resulting measured strains were more accurate. The strain mean and standard deviation between the three trials for both the $180 \mathrm{~N}$ and $360 \mathrm{~N}$ load cases for femur \#4139 are shown in Tables IX and X. The seven-femur average strain mean and standard deviation between the three trials for both $180 \mathrm{~N}$ and $360 \mathrm{~N}$ load cases are shown in Tables XI and XII.

TABLE IX. Mean and standard deviation between trials under $180 \mathrm{~N}$ for femur \#4139.

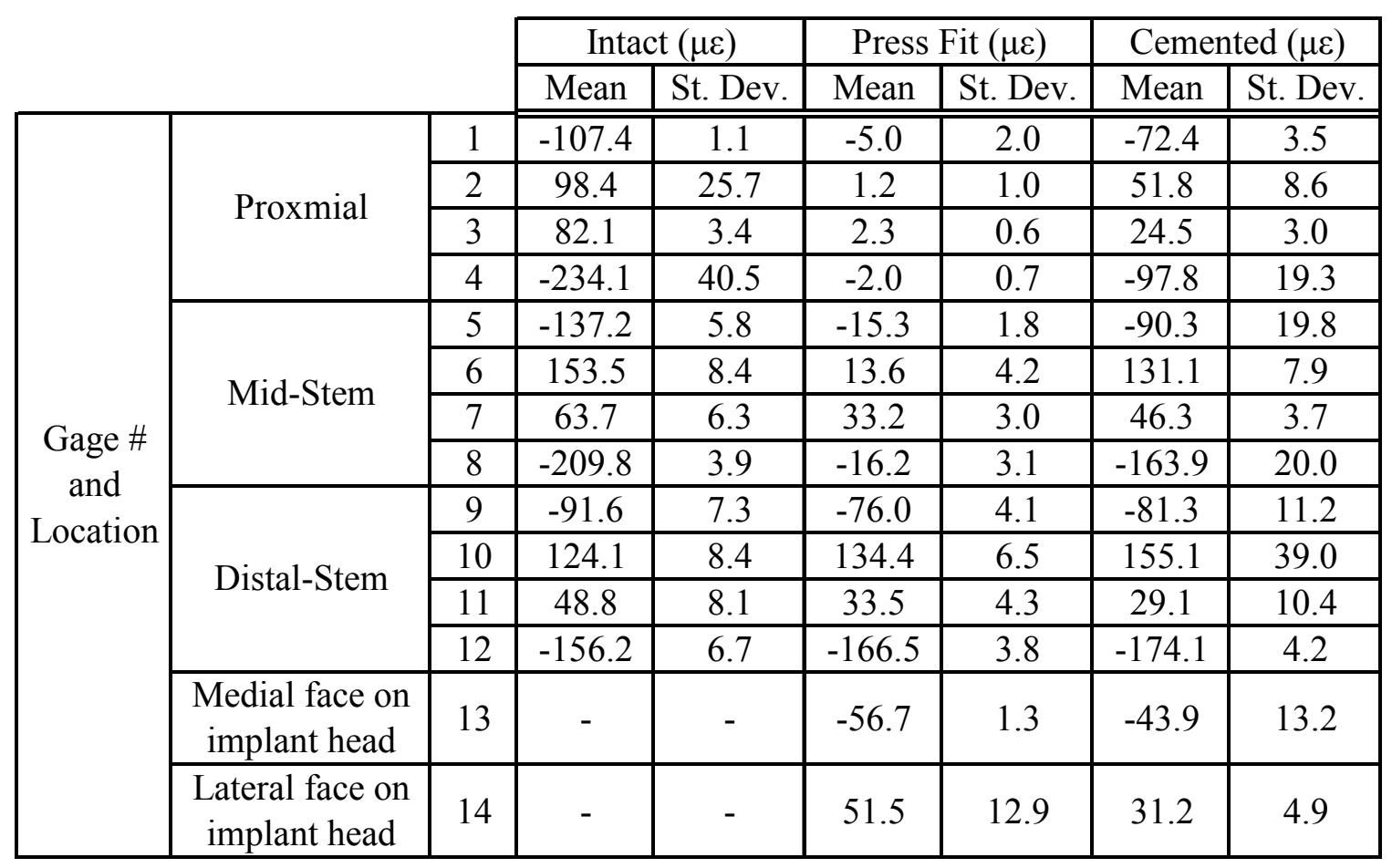


TABLE X. Mean and standard deviation between trials under $360 \mathrm{~N}$ for femur $\# 4139$.

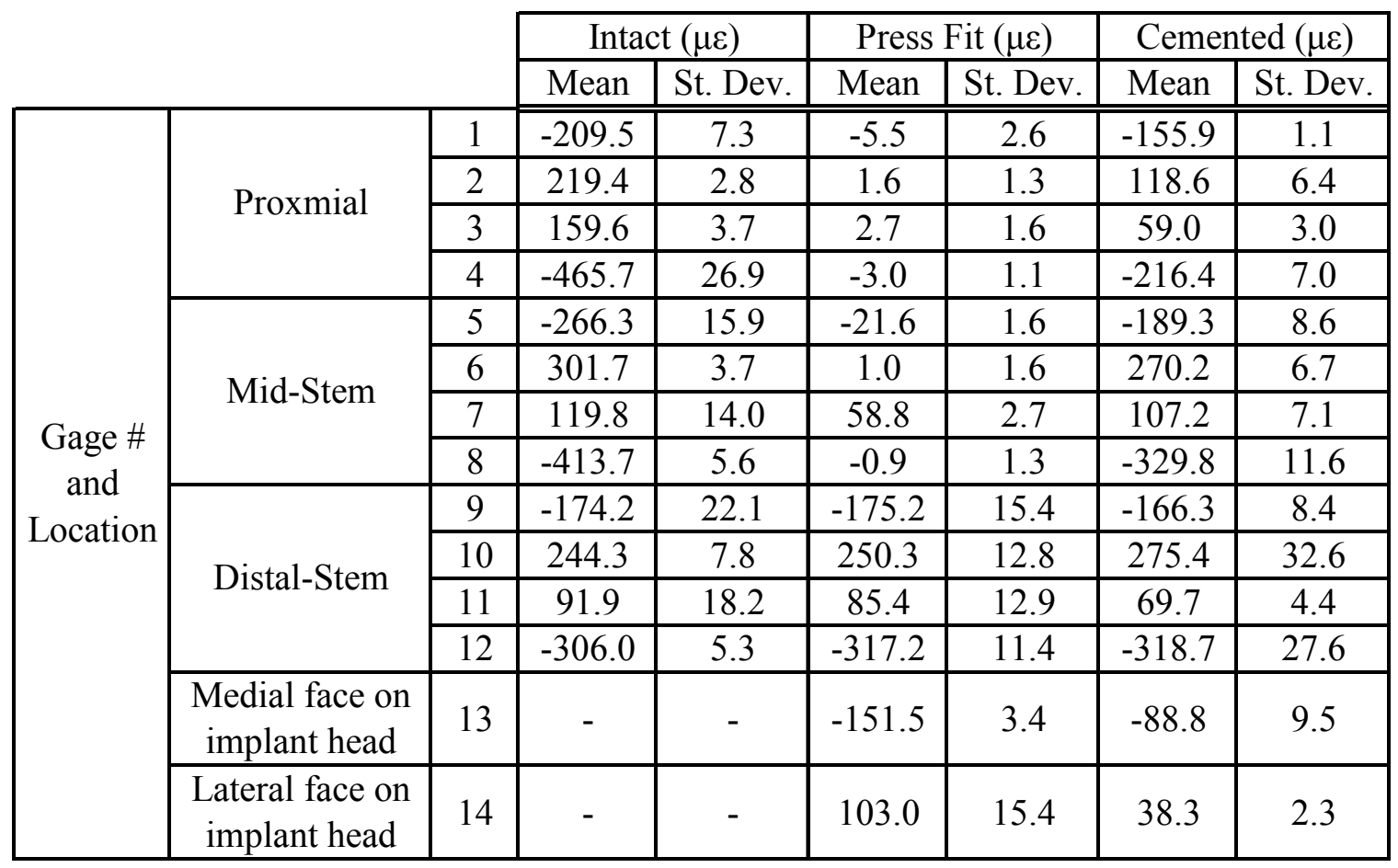

TABLE XI. Average mean and standard deviation between trials under $180 \mathrm{~N}$.

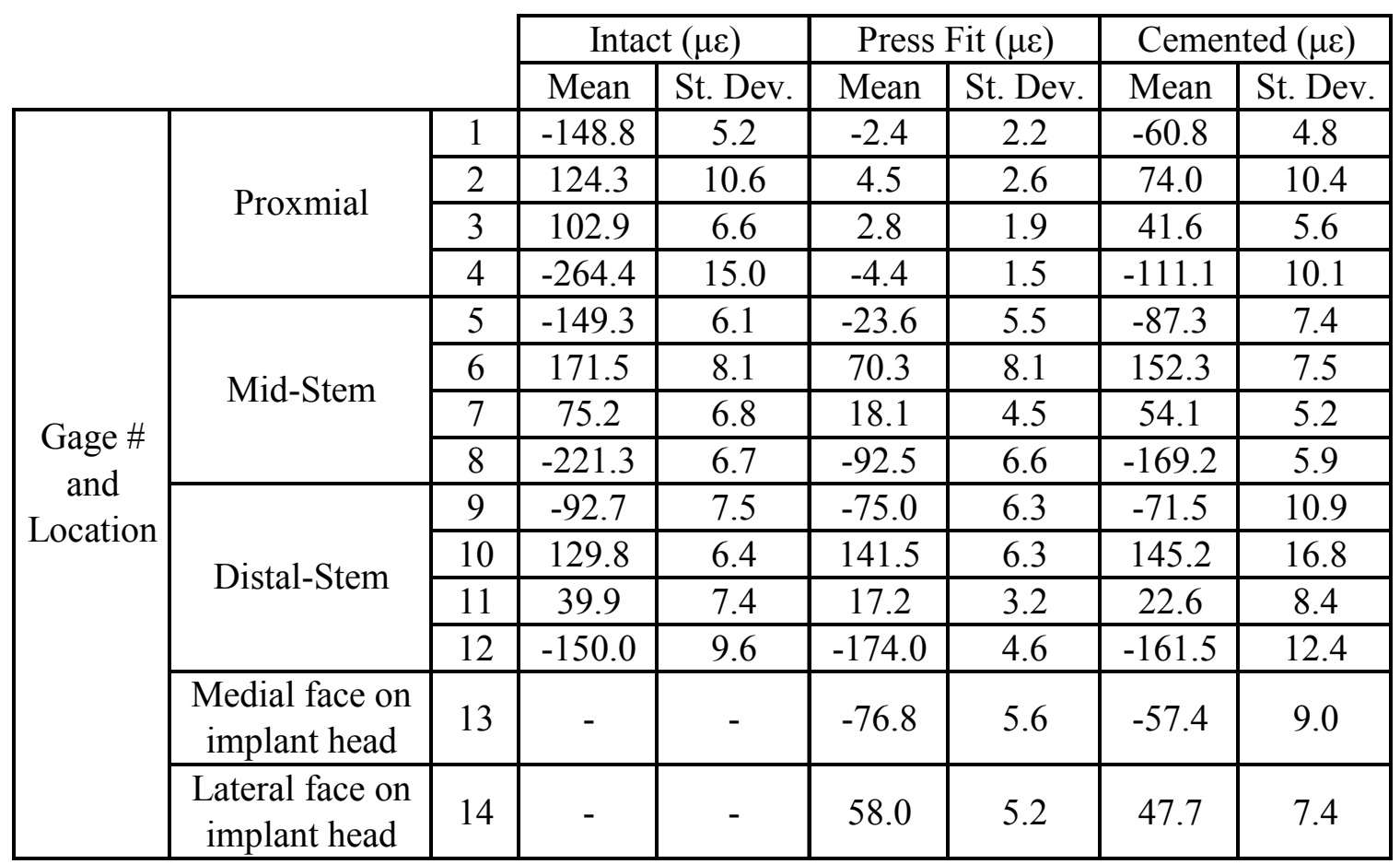


TABLE XII. Average mean and standard deviation between trials under $360 \mathrm{~N}$.

\begin{tabular}{|c|c|c|c|c|c|c|c|c|}
\hline & \multicolumn{2}{|c|}{ Intact $(\mu \varepsilon)$} & \multicolumn{2}{|c|}{ Press Fit $(\mu \varepsilon)$} & \multicolumn{2}{|c|}{ Cemented $(\mu \varepsilon)$} \\
\hline & & & Mean & St. Dev. & Mean & St. Dev. & Mean & St. Dev. \\
\hline \multirow{14}{*}{$\begin{array}{l}\text { Gage \# } \\
\text { and } \\
\text { Location }\end{array}$} & \multirow{4}{*}{ Proxmial } & 1 & -293.9 & 9.3 & -3.0 & 2.7 & -128.5 & 1.8 \\
\hline & & 2 & 254.8 & 6.4 & 3.8 & 1.8 & 141.3 & 3.7 \\
\hline & & 3 & 202.4 & 8.4 & 3.7 & 1.2 & 82.3 & 2.8 \\
\hline & & 4 & -531.3 & 9.8 & -7.0 & 2.1 & -241.0 & 3.8 \\
\hline & \multirow{4}{*}{ Mid-Stem } & 5 & -294.9 & 15.5 & -47.8 & 4.7 & -189.9 & 3.3 \\
\hline & & 6 & 340.0 & 7.5 & 126.6 & 3.8 & 300.0 & 2.9 \\
\hline & & 7 & 147.6 & 14.5 & 37.0 & 4.9 & 106.7 & 4.2 \\
\hline & & 8 & -439.5 & 8.8 & -165.9 & 4.4 & -346.2 & 3.7 \\
\hline & \multirow{4}{*}{ Distal-Stem } & 9 & -187.4 & 14.5 & -154.2 & 7.9 & -161.2 & 6.2 \\
\hline & & 10 & 250.1 & 9.7 & 274.6 & 5.0 & 272.3 & 8.2 \\
\hline & & 11 & 81.0 & 13.2 & 40.4 & 8.8 & 44.6 & 5.3 \\
\hline & & 12 & -296.6 & 8.9 & -335.1 & 8.0 & -325.0 & 8.7 \\
\hline & $\begin{array}{c}\text { Medial face on } \\
\text { implant head }\end{array}$ & 13 & - & - & -164.6 & 5.8 & -121.5 & 4.7 \\
\hline & $\begin{array}{l}\text { Lateral face on } \\
\text { implant head }\end{array}$ & 14 & - & - & 113.3 & 7.4 & 75.3 & 4.1 \\
\hline
\end{tabular}

Similar results for the individual femurs are shown in the tables located in the appendix. The maximum standard deviation is $40.5 \mu \varepsilon$ for the $180 \mathrm{~N}$ loading cases, as reported by Table IX, and $32.6 \mu \varepsilon$ for the $360 \mathrm{~N}$ loading cases, as reported by Table X, when comparing each individual test femur. From Tables XI and XII it is evident that data is precise and that there is very little variation since the maximum standard deviation is only $15.0 \mu \varepsilon$ for the $180 \mathrm{~N}$ loading cases and $15.5 \mu \varepsilon$ for the $360 \mathrm{~N}$ loading cases. Also, from the above tables it is evident that each femur was statistically similar to the overall average. This helps confirm data repeatability and reliability. 


\section{DISCUSSION}

Modular implants are primarily used for patients who have little or no bone in the proximal region. For this reason, modular implants are not designed to have a tight fit in the proximal region, specifically between the modular body and femur. Since the proximal body made virtually no contact with the bone in the proximal area of the bone, essentially none of the load was distributed in the proximal region. Therefore, the strains measured by the strain gages mounted in the proximal area were minimal and total stress shielding occurred.

On average the test femurs exhibited stress shielding in the proximal and mid-stem regions since the surface strains in the proximal and mid-stem regions did not return to the intact levels after completing Phase II and Phase III. Similar results were observed for each individual test femur as shown in the appendix.

The strain levels were not expected to return to intact levels (Phase I) after completing Phase II and Phase III due to the high stiffness incorporated into the modular implant. The implant itself is designed to transfer strains throughout the stem. It is important to understand that there was a significant increase in strain in the proximal and mid-stem regions, thus the overall strain in the distal-stem region was reduced. Over the course of time this will protect the stem from potential fracture or failure while promoting bone growth in the proximal and mid-stem regions. This will undoubtedly extend the lifetime of the implant and lower the possibility of complications.

The addition of hydroxyapatite bone cement had two successful outcomes. First, the strain in the proximal region increased significantly, which should reduce the stress in the implant and slow bone resorption. Second, there was a significant reduction of strain at 
the interface where the body contacts the stem, which should reduce the chance of fracture at the interface.

Two different loads of $180 \mathrm{~N}$ and $360 \mathrm{~N}$ were applied to each test femur while in the intact state, again in the press-fit state, and finally when hydroxyapatite bone cement was administered around the modular body in the proximal region. On average, the $180 \mathrm{~N}$ loading case was approximately half of the $360 \mathrm{~N}$ loading case. This is important in understanding that the surface strain levels are linear with respect to the loading range with a slope of approximately one half. For extremely low load cases or extremely high load cases this relationship, though, may no longer remain linear.

The load cell used in this study incorporated a range of 0 to $360 \mathrm{~N}$. Relatively small strain standard deviations were achieved in this study since the load cell allowed a constant load to be maintained, thereby resulting in a small strain variation. In a study, conducted by Fries, ${ }^{35}$ that used the same test fixtures, but did not incorporate the same load cell, much larger standard deviations between the range of $53 \mu \varepsilon-123 \mu \varepsilon$ were achieved as compared to standard deviations between the range of $6.4 \mu \varepsilon-15.5 \mu \varepsilon$ that were achieved in this study. The low and small range of standard deviations in this study are highly significant for data repeatability and reliability. 


\section{CONCLUSIONS}

Overall, all of the strain gages in the proximal region and mid-stem region experienced a dramatic drop in surface strain after the insertion of the modular implant. Additionally, the distal-stem level antero-medial and postero-lateral areas experienced a reduction in surface strains and stress shielding effects.

The greatest amount of stress shielding occurred in the proximal region since there was very little or no contact between the modular body and surrounding bone. The surface strain on the modular body was relatively low compared to the surface strains experienced by the test femur. The highest modular body surface strains were seen on the medial face of each modular body, which was in compression when loaded.

Overall, all femurs exhibited an increase in surface strains in all three examined regions after the addition of hydroxyapatite bone cement. On average, the surface strains returned to $46 \%$ of the intact levels in the proximal region, $74 \%$ in the mid-stem region, and $84 \%$ in the distal-stem region. Stress shielding was still evident since the surface strains in the proximal regions did not return to the intact level. The surface strains on the modular implants were reduced after the addition of hydroxyapatite. On average the surface strains were reduced by $20 \%$. The surface strains were low compared to strains that would be expected to represent stresses sufficient to cause implant failure.

Overall, there is little variation in the results from the two leg stance model since the maximum standard deviation for the $180 \mathrm{~N}$ loading cases was $15.0 \mu \varepsilon$ while the maximum standard deviation for the $360 \mathrm{~N}$ loading cases was $15.5 \mu \varepsilon$. 


\section{RECOMMENDATIONS}

The hydroxyapatite bone cement did increase the surface strains in the proximal and mid-stem regions, but they did not return to intact level. Therefore, in revision total hip arthroplasty it is recommended to supplement the proximal femur with hydroxyapatite bone cement or graft in cases of significant bone loss. This will allow the prosthesis to load the proximal femur and reduce the strain on the implant stem and avoid significant stress shielding associated with this reconstructive hip design.

It is also recommended that further testing be performed on each test femur that involves more rigorous action. The femurs in this study were primarily tested under static loading due to the ease of data collection and test setup. Fatigue or cyclic loading cases are suggested and single leg stance loading is recommended to understand if other factors will affect the performance of the hydroxyapatite on restoring surface strain on the femur.

It is recommended that further testing be performed on the modular implants especially at the junction where the body meets the stem. The surface strains were relatively low for the type of loading performed in this study. Suggested loading conditions include impulse loading or cyclic loading to see if the chance of failure is increased.

Finally, it is recommended that finite element analysis be performed on the femur and modular implant using the dual leg stance model. Boundary conditions should be defined and the proper loading conditions should be applied to the solid model. The FEA results can then be compared to the experimental data collected in this study. 


\section{REFERENCES}

1. Freburger, J., "An Analysis of the Relationship Between the Utilization of Physical Therapy Services and Outcomes of Care for Patients After Total Hip Arthroplasty," Physical Therapy, Volume 80, Number 5, pp. 448-458, May 2000.

2. Effenberger, H., Heiland, A., Ramsauer, T., Plitz, W., and Dorn, U., "A model for assessing the rotational stability of uncemented femoral implants," Arch Orthopedic Trauma Surgery, (121), pp. 60-64, 2001.

3. Naidu, S.H., Cuckler, J.M., Burkholder, T., and Ducheyne, P., "Initial stability of a modular uncemented, porous-coated femoral stem: a mechanical study, Am. J. Orthop., Dec; 25(12), pp. 829-834, 1996.

4. The American Heritage ${ }^{\circledR}$ Stedman's Medical Dictionary, 2nd Edition Copyright (C) 2004 by Houghton Mifflin Company.

5. Bulter, A., Bruce, W., Gillies, M., Morberg, P., Neil, M., Pocock, N., Turnbull, A., Walsh, W., "Strain Distribution and Bone Mineral Density Relationships," J. Bone Joint Surgery, Volume 83-B Supplement III, pp. 311, 2001.

6. Weinans, H., Huiskes, R., an Rietbergen, B., Sumner, D.R., Turner, T.M., Galante, J.O., "Adaptive bone-remodeling around bonded noncemented THA: a comparison between animal experiments and computer simulation," J. Orthopaedic Research, 11, pp. 500-513, 1993.

7. Sychterz, C.J., Engh, C.A., "The influence of clinical factors on periprosthetic bone remodeling," Clinical Orthopaedics and Related Research, 322, pp. 285-292, 1996.

8. Verdonschot, N., Huiskes, R., "The Effects of Cement-Stem Debonding in THA on the Long-term Failure Probability of Cement," J. Biomechanics, Vol. 30, No. 8, pp. 795-802, 1997.

9. Ries, M.D., Suzuki, Y., Renowitzky, G., Lotz, J.C., Barrack, R.L., Bourne, R. B., Rorabeck, C.H., "Effect of Cementless Bowed Stem Distal Surface Contour and Coronal Slot on Femoral Bone Strains and Torsional Stability," J. Arthroplasty, Vol. 18, No. 4, pp. 494-498, June 2003.

10. DeFrances, C., Podgomik, M., "2004 National Hospital Discharge Survey," Advance Data From Vital and Health Statistics, U.S. Department of Health and Human Services, Advance Data No. 371, May 4, 2006. 
11. Kurtz S, Mowat F, Ong K, Chan N, Lau E, Halpern M., "Prevalence of primary and revision total hip and knee arthroplasty in the United States from 1990 through 2002,” J. Bone Joint Surgery, 87:1487-97,2005.

12. Michael, H., Parvizi, J., Gilbert, N., "What's New in Hip Arthroplasty," J Bone Joint Surgery, Volume 88A, No. 9, pp. 2100-2113, September 2006.

13. Joshi, M., Advani, S., Miller, F., Santare, M., "Analysis of a Femoral Hip Prosthesis Designed to Reduce Stress Shielding," Journal of Biomechanics 2000; 33(12): 1655-62.

14. Santori, F., Rendine, M., Fredella, N., Manili, M., Santori, N., "Ultra Short Stem With Proximal Load Transfer: Clinical and Radiogrpahic Results at 4 Years Follow Up,” J. Bone Joint Surgery [BR], 88-B:SUPP I, 2006.

15. Crisofolini, L., Teutonico, A.S., "Comparative in vitro study on the long term performance of cemented hip stems: validation of a protocol to discriminate between "good" and "bad" designs," J. Biomechanics, 36, pp. 1603-1615, 2003.

16. Stolk, J., Verdonschot, N., "Finite element and experiment models of cemented hip joint reconstructions can produce similar bone and cement strains in preclinical tests," J. Biomechanics, 35, pp. 499-510, 2002.

17. Whiteside, L., McCarthy, D., White, S., "Rotational Stability of Noncemented Total Hip Femoral Components," The American Journal of Orthopedics 1996; 25(4): 276-79.

18. Hirakawa, K., Jacobs, J., Urban, R., Saito, T., "Mechanisms of Failure of Total Hip Replacements," Clin Orthop, Number 420, pp. 10-17, March 2004.

19. Geesink, R., "Osteoconductive coatings for total joint arthroplasty," Clin Orthop, Number 395, pp. 53-65, 2002.

20. Geesink, R., de Groot, K., "Chemical implant fixation using hydroxyl-apatite coatings," Clin Orthop. Number 225, pp. 147-170, 1987.

21. Soballe K., Brockstedt-Rasmussen H., Stender Hansen E., et al., "Hydroxyapatite coating modifies implant membrane formation," Acta Orthop Scand, Number 63, pp. 128-140, 1992.

22. Soballe K., Hansen E., Brockstedt-Rasmussen H., et al., "Fixation of titanium and hydroxyapatite-coated implants in arthritic osteopenic bone," J Arthroplasty, No. 6, pp. 307-316, 1991. 
23. Bauer T., Geesink R., Zimmerman R., et al., "Hydroxyapatite-coated femoral stems: Histological analysis of components retrieved at autopsy," J Bone Joint Surg, No 73A, pp. 1439-1452, 1991.

24. Bauer T., Stulberg B., Ming J., et al., "Uncemented acetabular components: Histologic analysis of retrieved hydroxyapatite-coated and porous implants," J Arthroplasty, No. 8, pp. 167-177, 1993.

25. Hardy D., Frayssinet P., Guilhem A., et al., "Bonding of hydroxyapatitecoated femoral prostheses: Histopathology of specimens from four cases," J Bone Joint Surg., No. 73B, pp. 732-740, 1991.

26. Tonino A., Therin M., Doyle C., "Hydroxyapatite-coated femoral stems: Histology and histomorphometry around five components retrieved at postmortem," J Bone Joint Surg, No. 81B, pp. 148-154, 1999.

27. Tonino A., Oosterbos C., Rahmy A., et al., "Hydroxyapatite-coated acetabular components: Histology and histomorphometric analysis of six cups retrieved at autopsy between three and seven years after successful implantation," J Bone Joint Surg, No. 83A, pp. 817-826, 2001.

28. Lee, Thay., Danto, M., Kim, W., "Initial Stability Comparison of Modular Hip Implants in Synthetic Femurs," Orthopedics 1998; 21(8): 885-888.

29. Pacific Research Laboratories, Vashon, Wyoming.

30. Vishay Measurements Group, Inc., Raleigh, North Carolina.

31. National Instruments Corporation, Austin, Texas.

32. Hnat, Dr. William P., LabVIEW programming development, January 2003.

33. Block, Brian., "Construction of single leg stance testing fixture,” Structured Research Project, University of Louisville, 2001.

34. Stryker Howmedica Osteonics, Allendale, New Jersey.

35. Fries, Steven, "The effect of tapered and non-tapered fluted stems on proximal stress shielding and rotational stability in the human femur," Masters of Engineering Thesis, University of Louisville, 2003. 
X. APPENDIX 


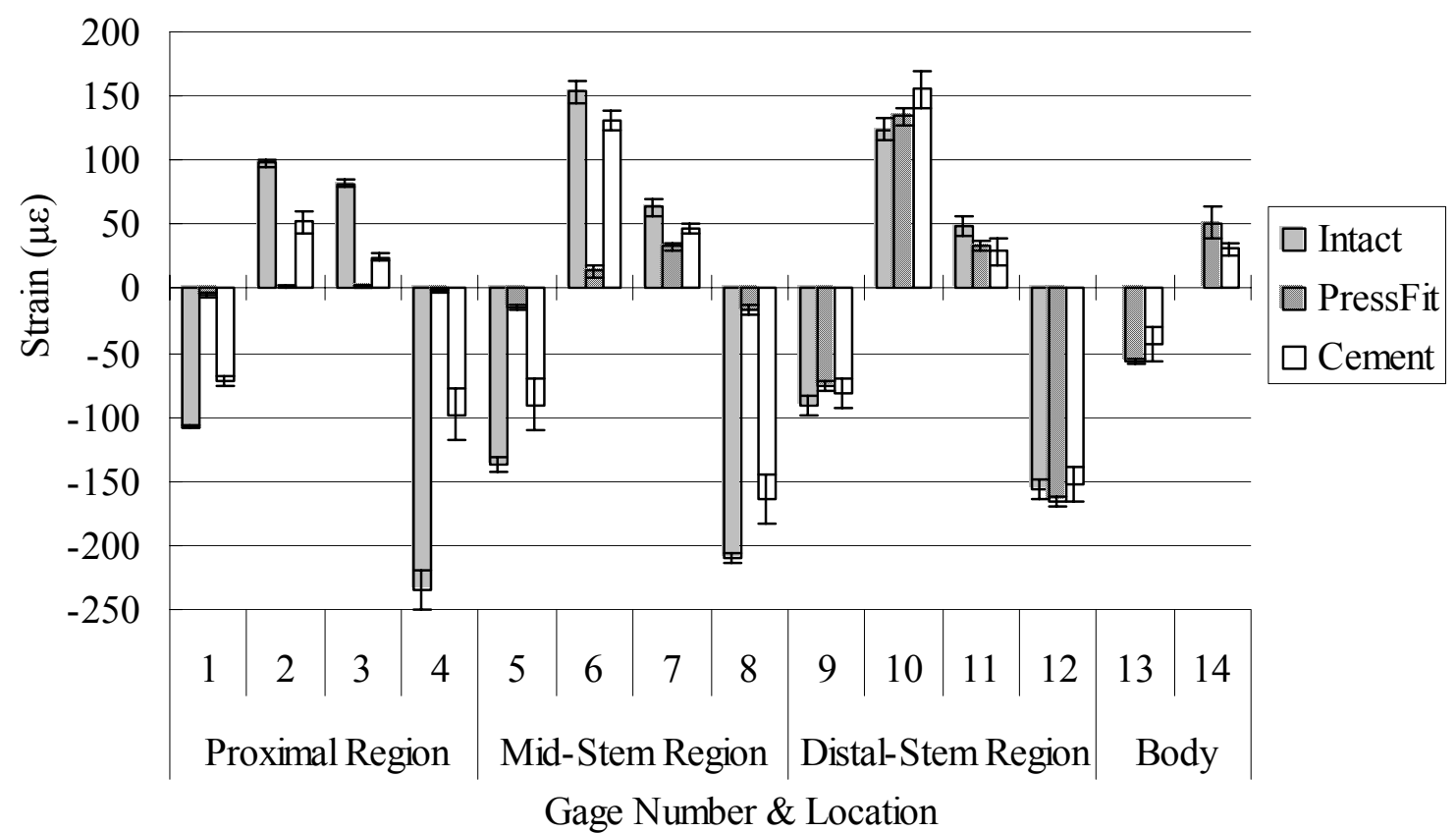

FIGURE 37. Measured intact, press fit, and cemented surface strains with a $180 \mathrm{~N}$ load for femur \#4139.

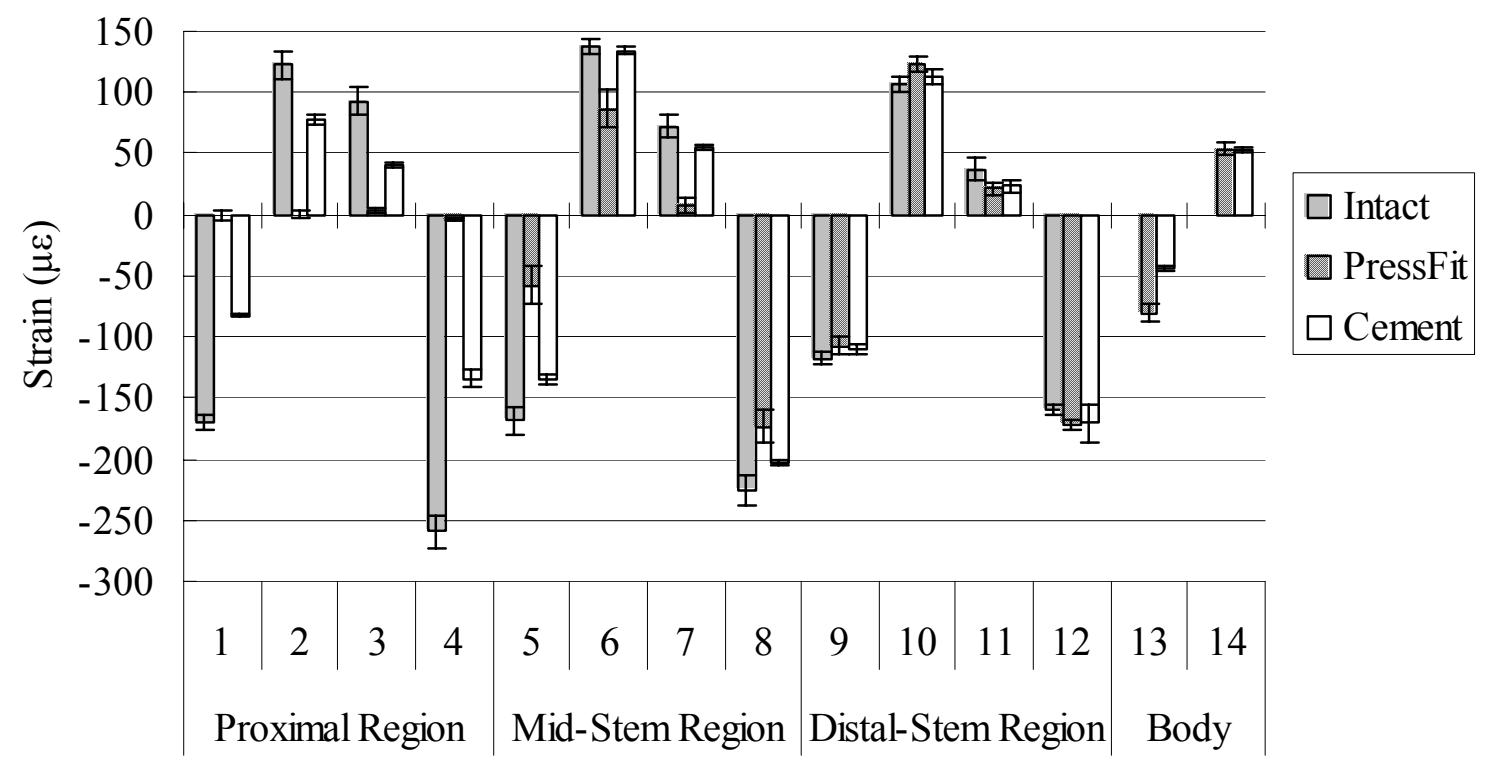

Gage Number \& Location

FIGURE 38. Measured intact, press fit, and cemented surface strains with a $180 \mathrm{~N}$ load for femur \#4140. 


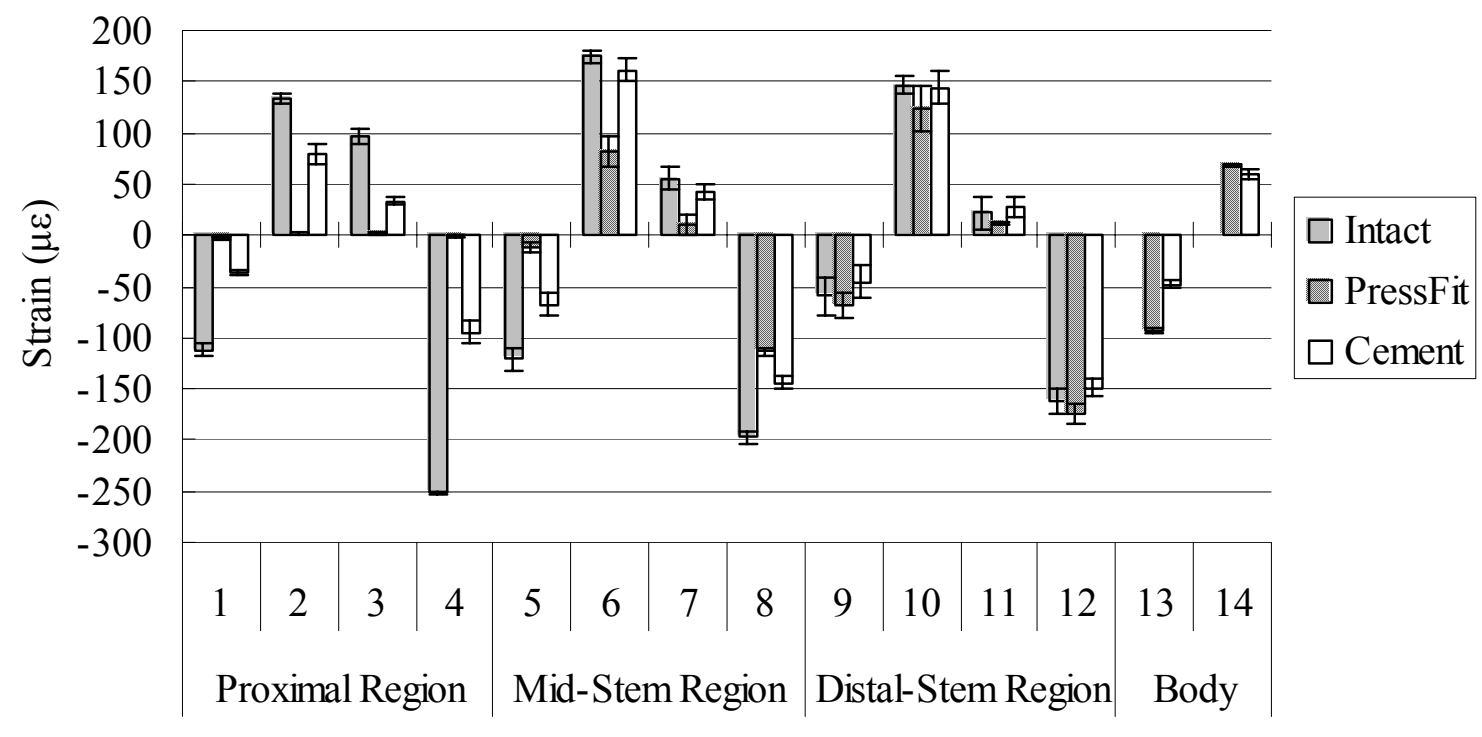

Gage Number \& Location

FIGURE 39. Measured intact, press fit, and cemented surface strains with a $180 \mathrm{~N}$ load for femur \#4141.

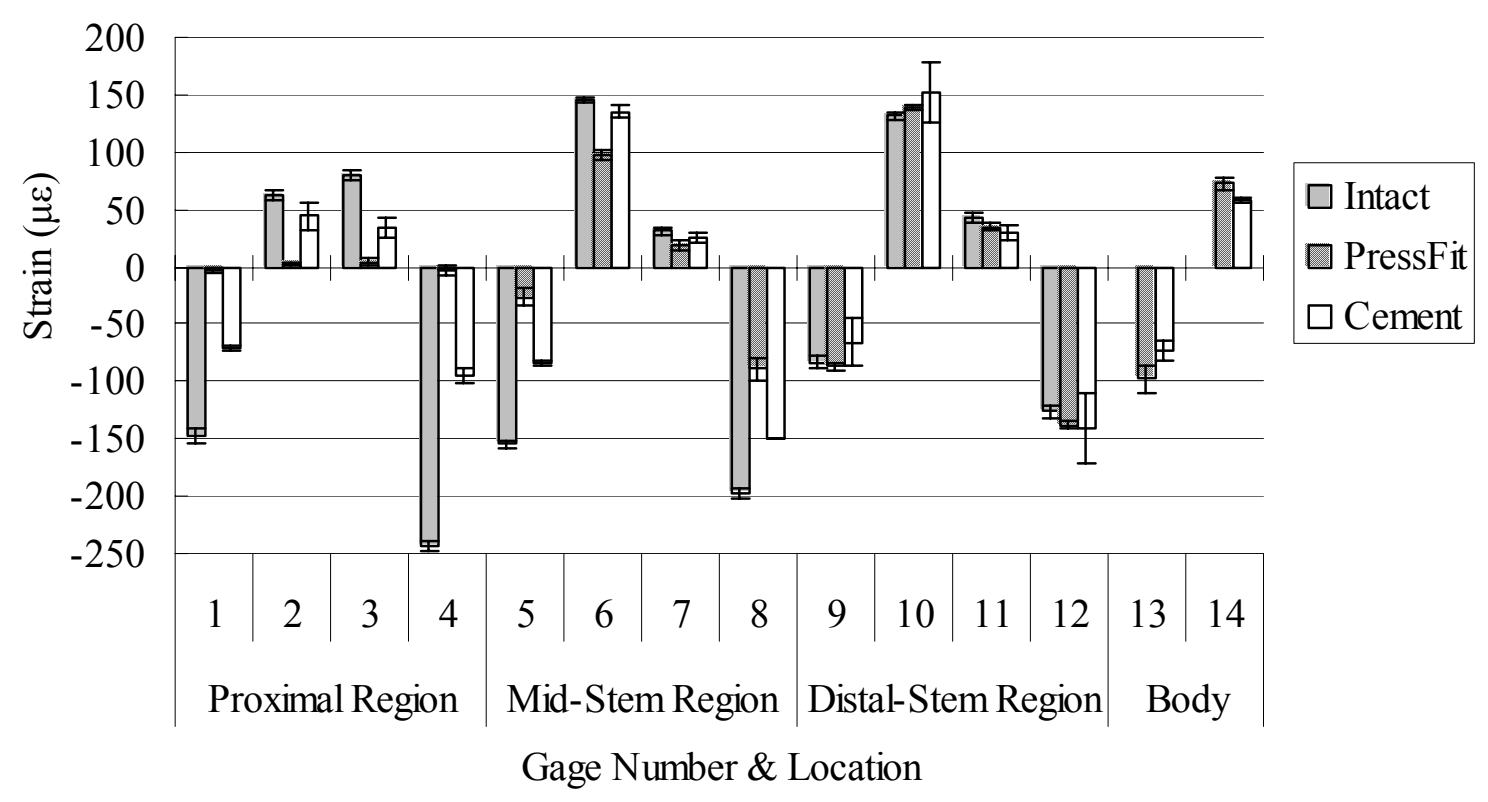

FIGURE 40. Measured intact, press fit, and cemented surface strains with a $180 \mathrm{~N}$ load for femur \#4142. 


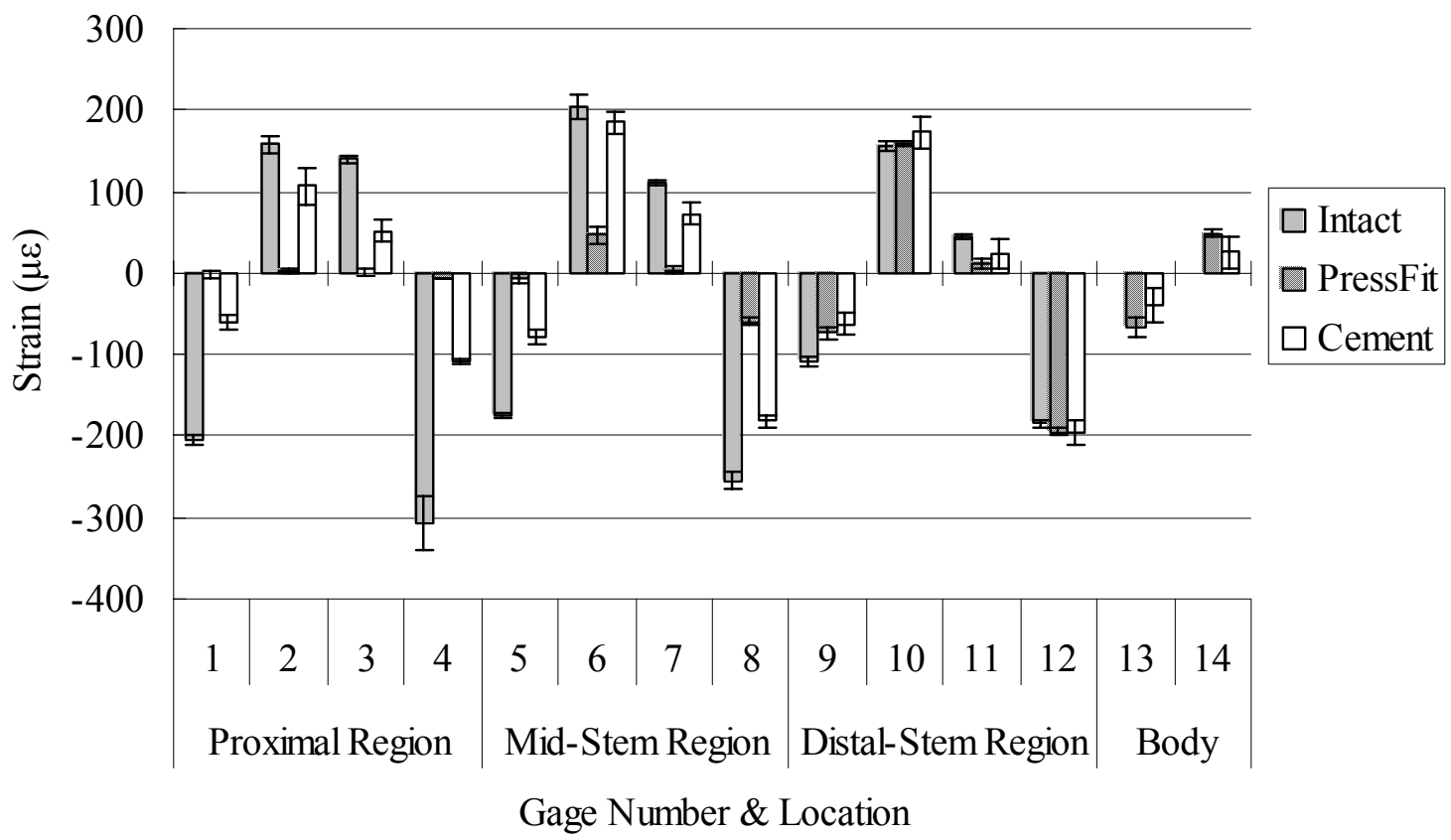

FIGURE 41. Measured intact, press fit, and cemented surface strains with a $180 \mathrm{~N}$ load for femur $\# 4470$.

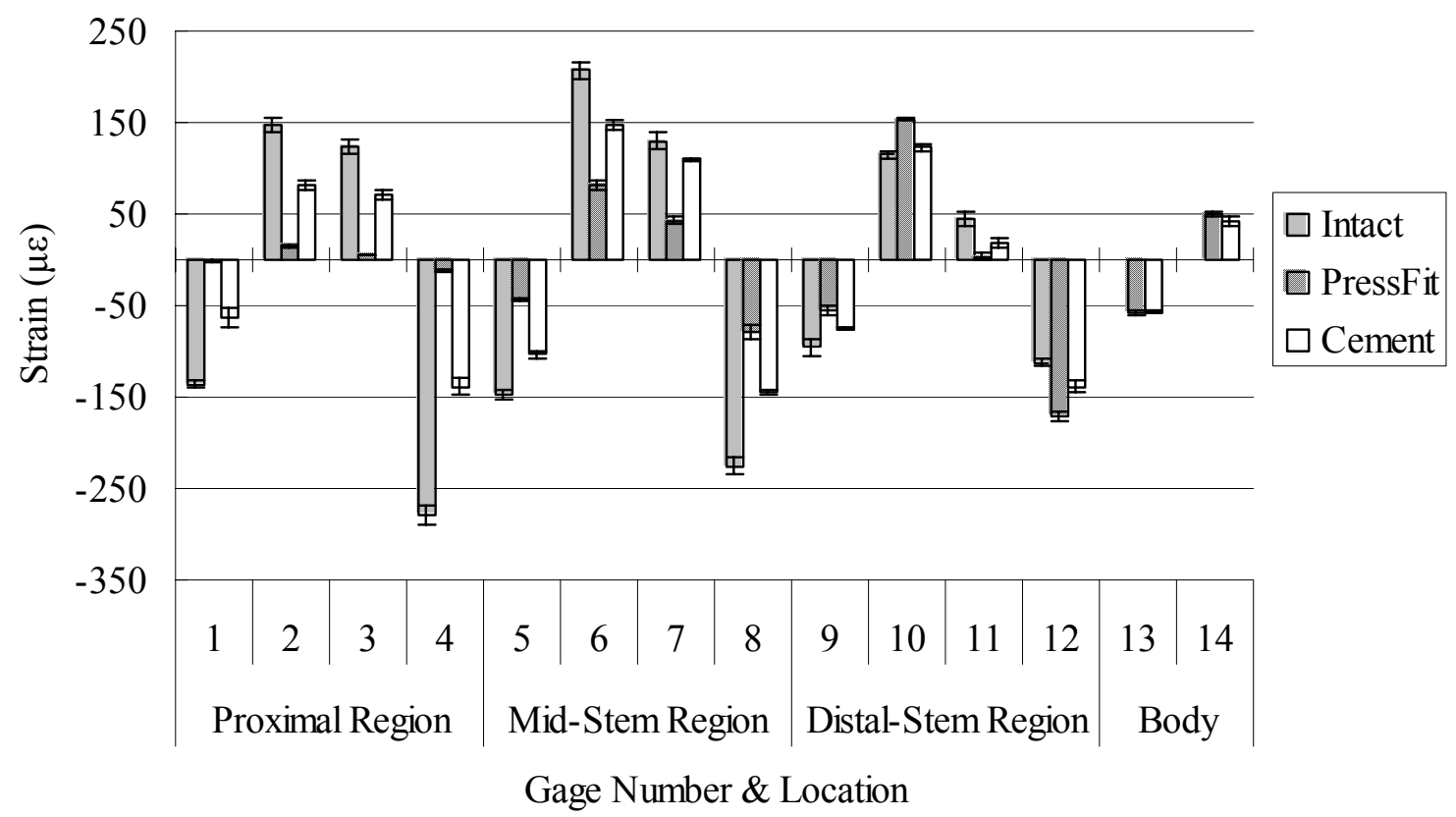

FIGURE 42. Measured intact, press fit, and cemented surface strains with a $180 \mathrm{~N}$ load for femur \#4471. 


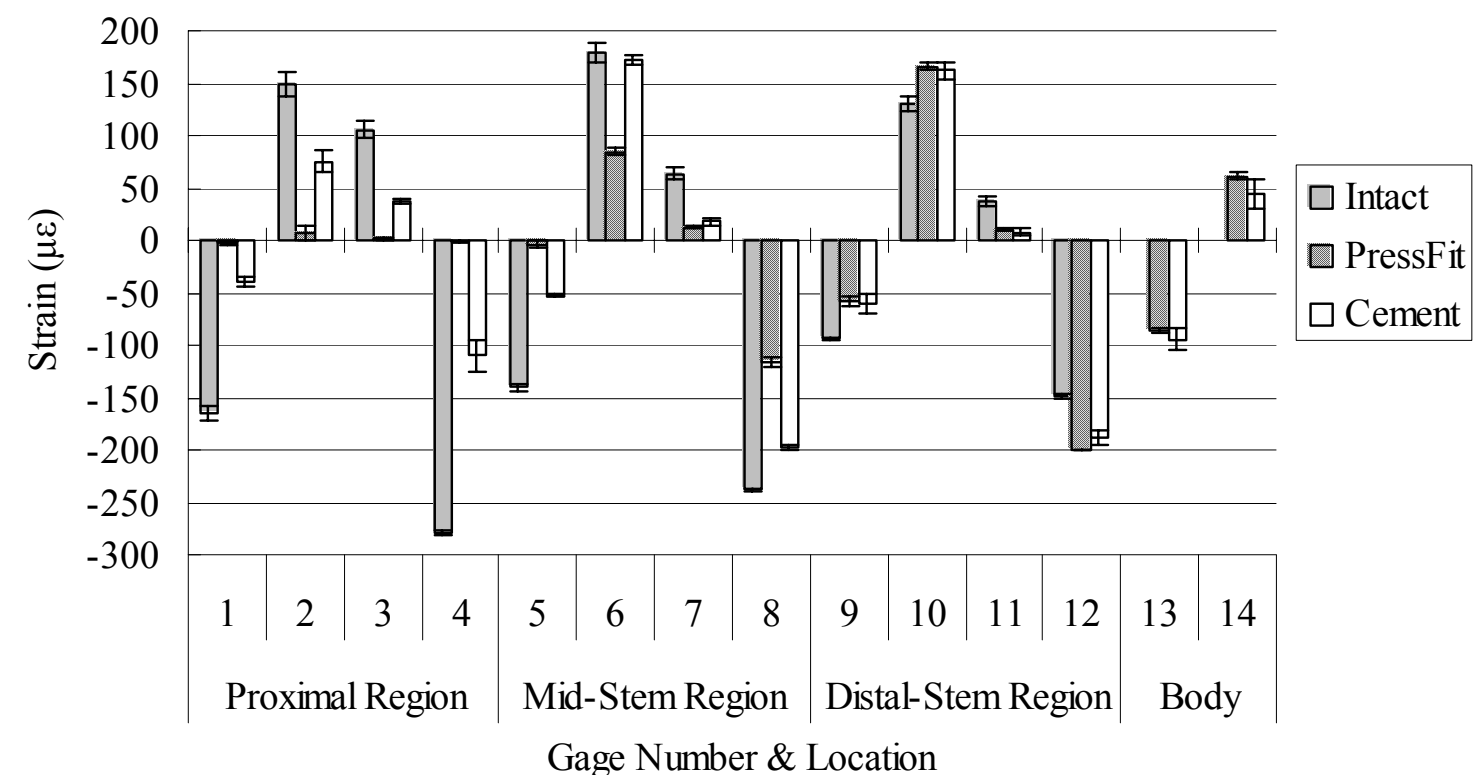

FIGURE 43. Measured intact, press fit, and cemented surface strains with a $180 \mathrm{~N}$ load for femur $\# 4472$.

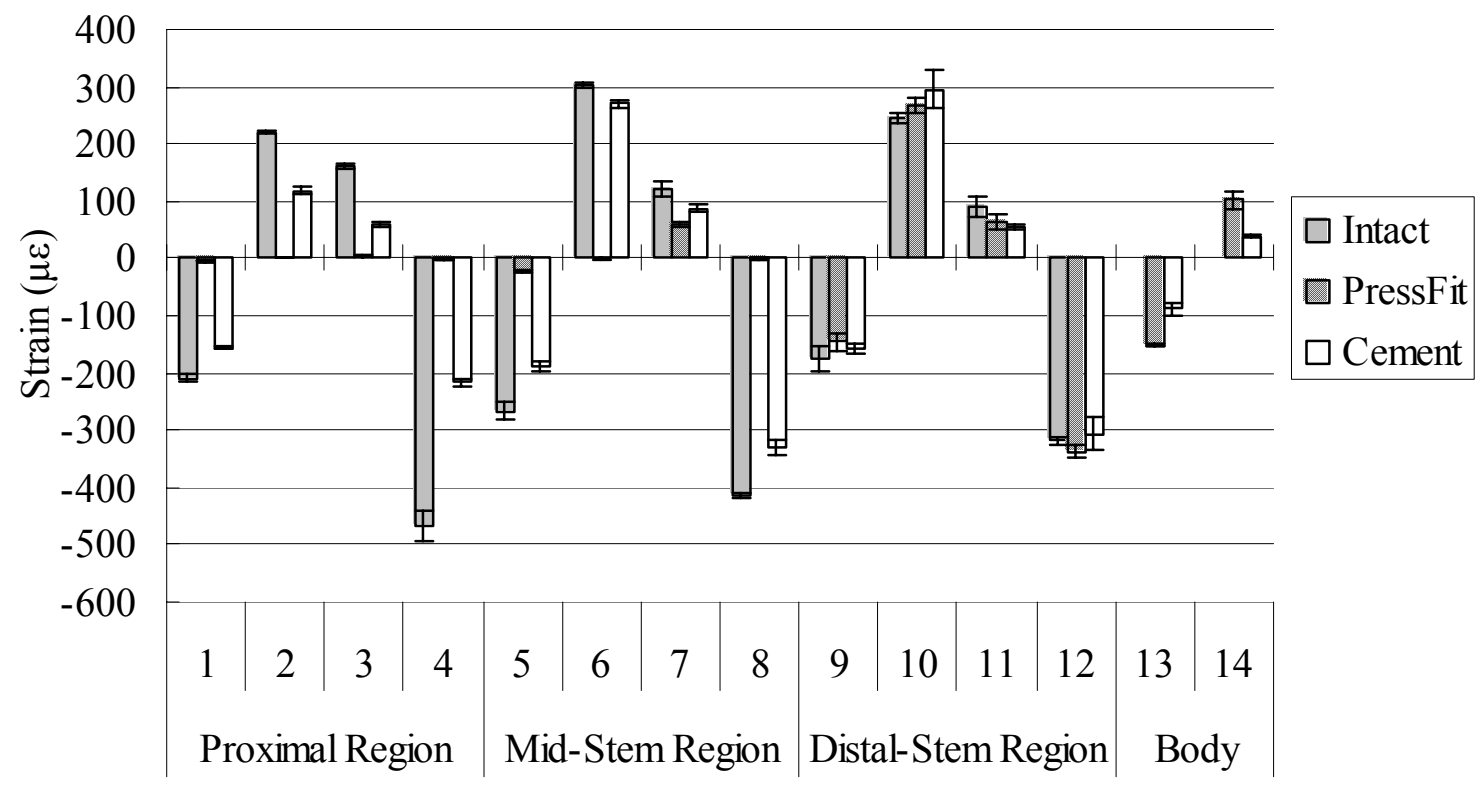

Gage Number \& Location

FIGURE 44. Measured intact, press fit, and cemented surface strains with a $360 \mathrm{~N}$ load for femur \#4139. 


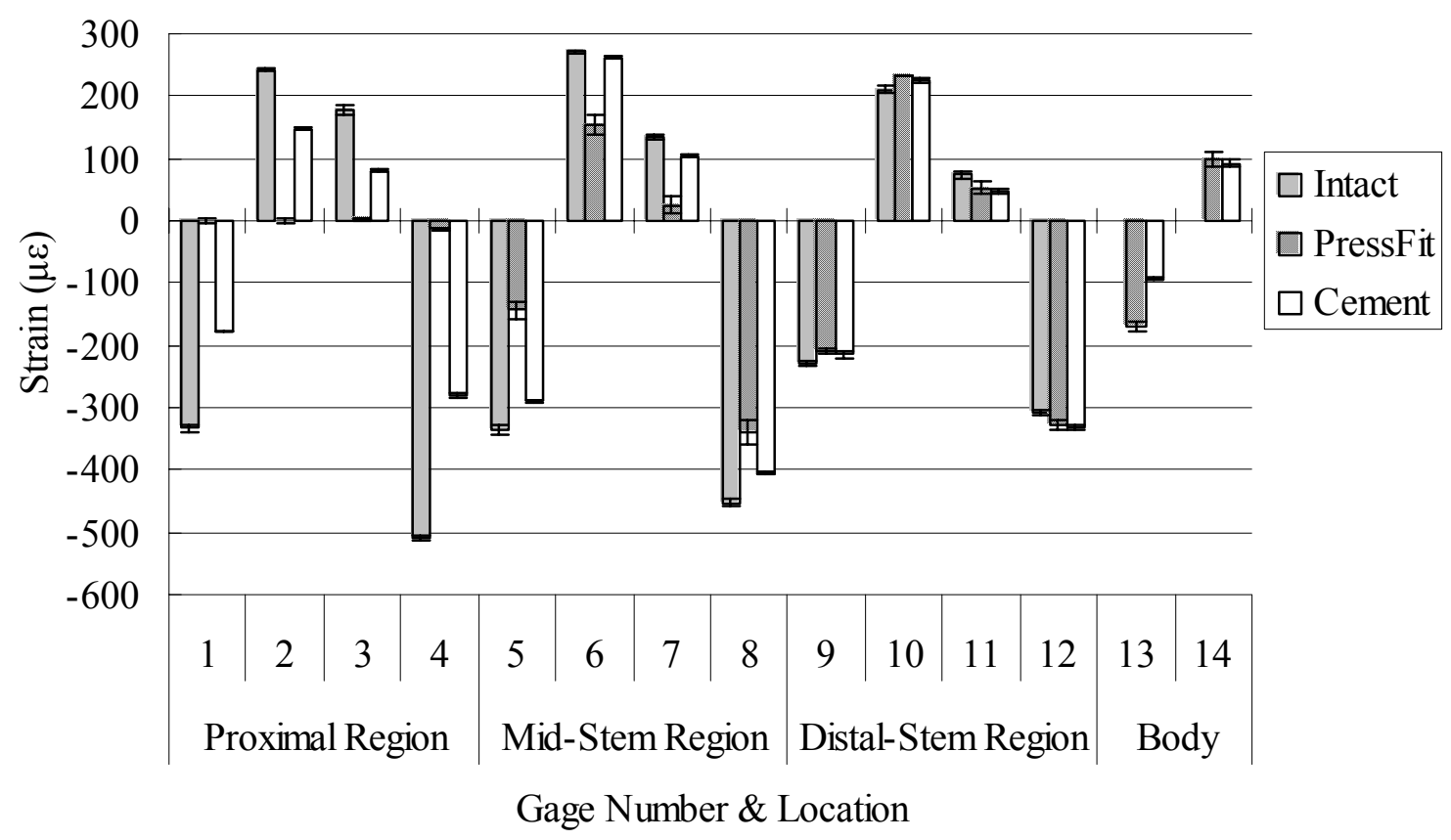

FIGURE 45. Measured intact, press fit, and cemented surface strains with a $360 \mathrm{~N}$ load for femur \#4140.

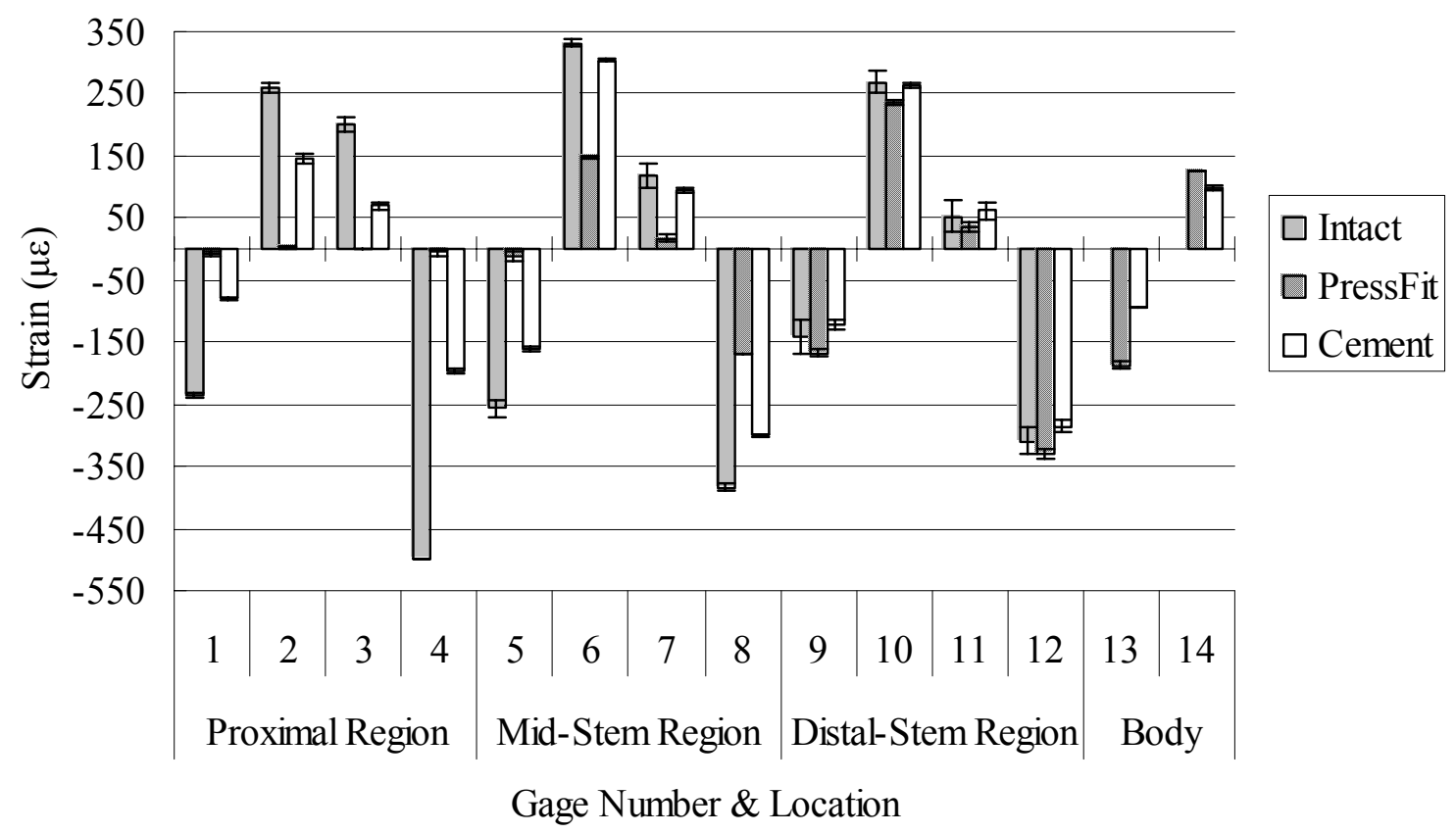

FIGURE 46. Measured intact, press fit, and cemented surface strains with a $360 \mathrm{~N}$ load for femur \#4141. 


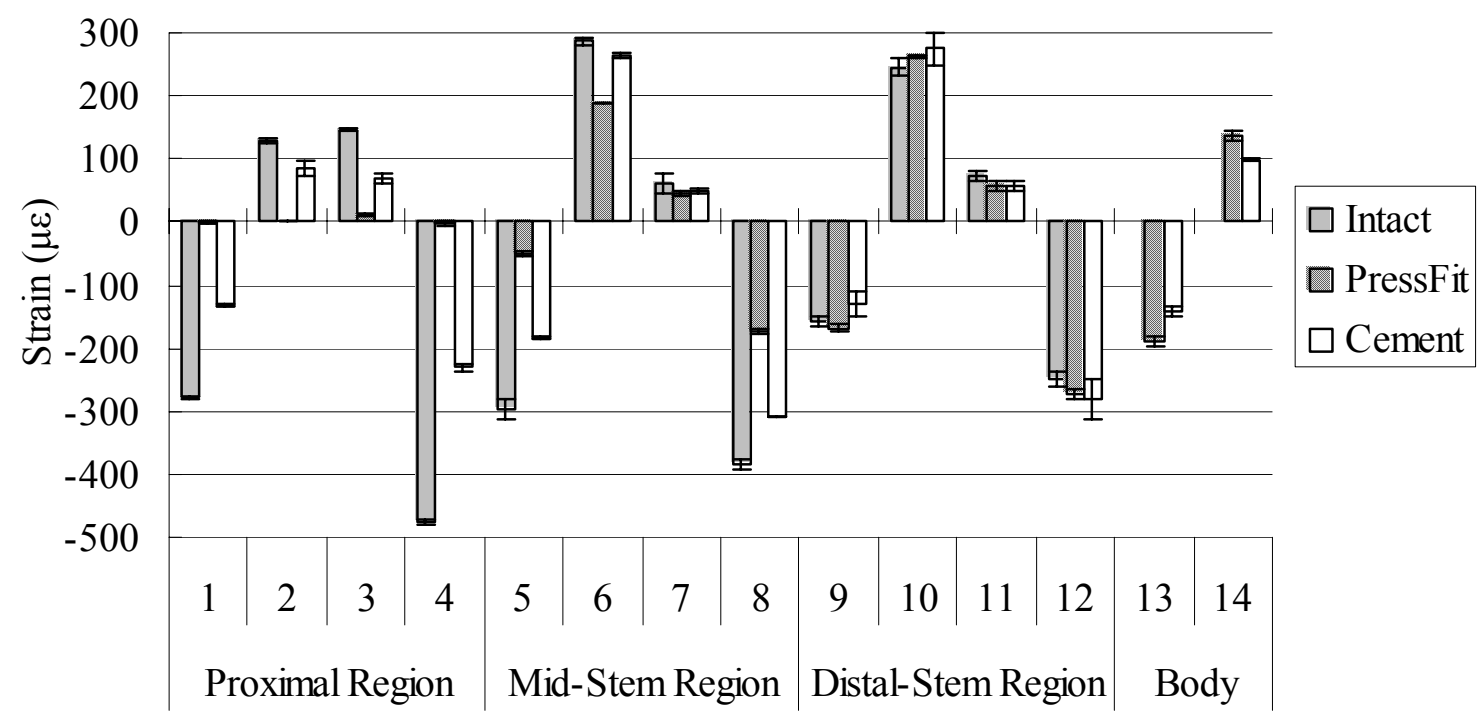

Gage Number \& Location

FIGURE 47. Measured intact, press fit, and cemented surface strains with a $360 \mathrm{~N}$ load for femur \#4142.

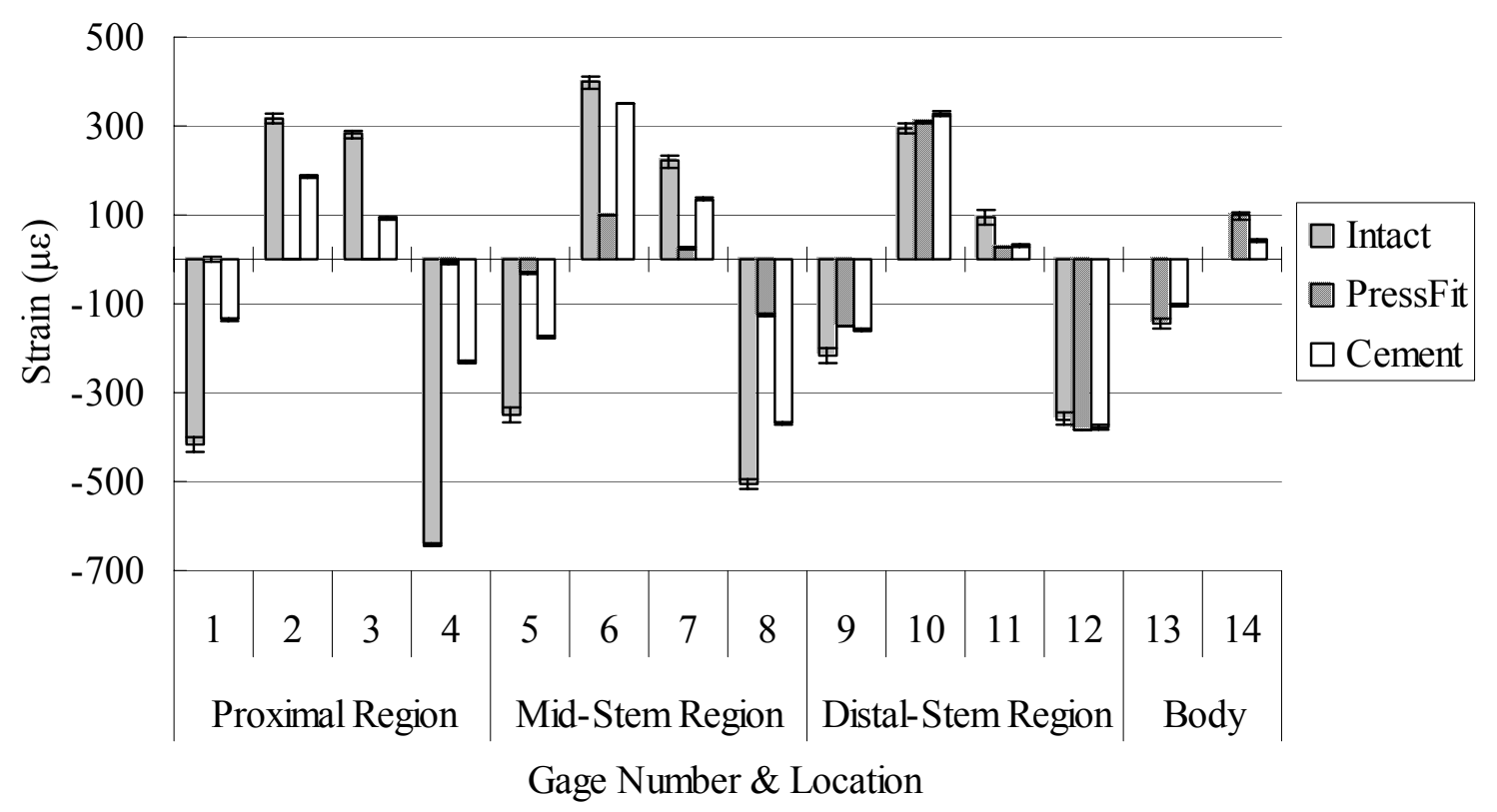

FIGURE 48. Measured intact, press fit, and cemented surface strains with a $360 \mathrm{~N}$ load for femur $\# 4470$. 


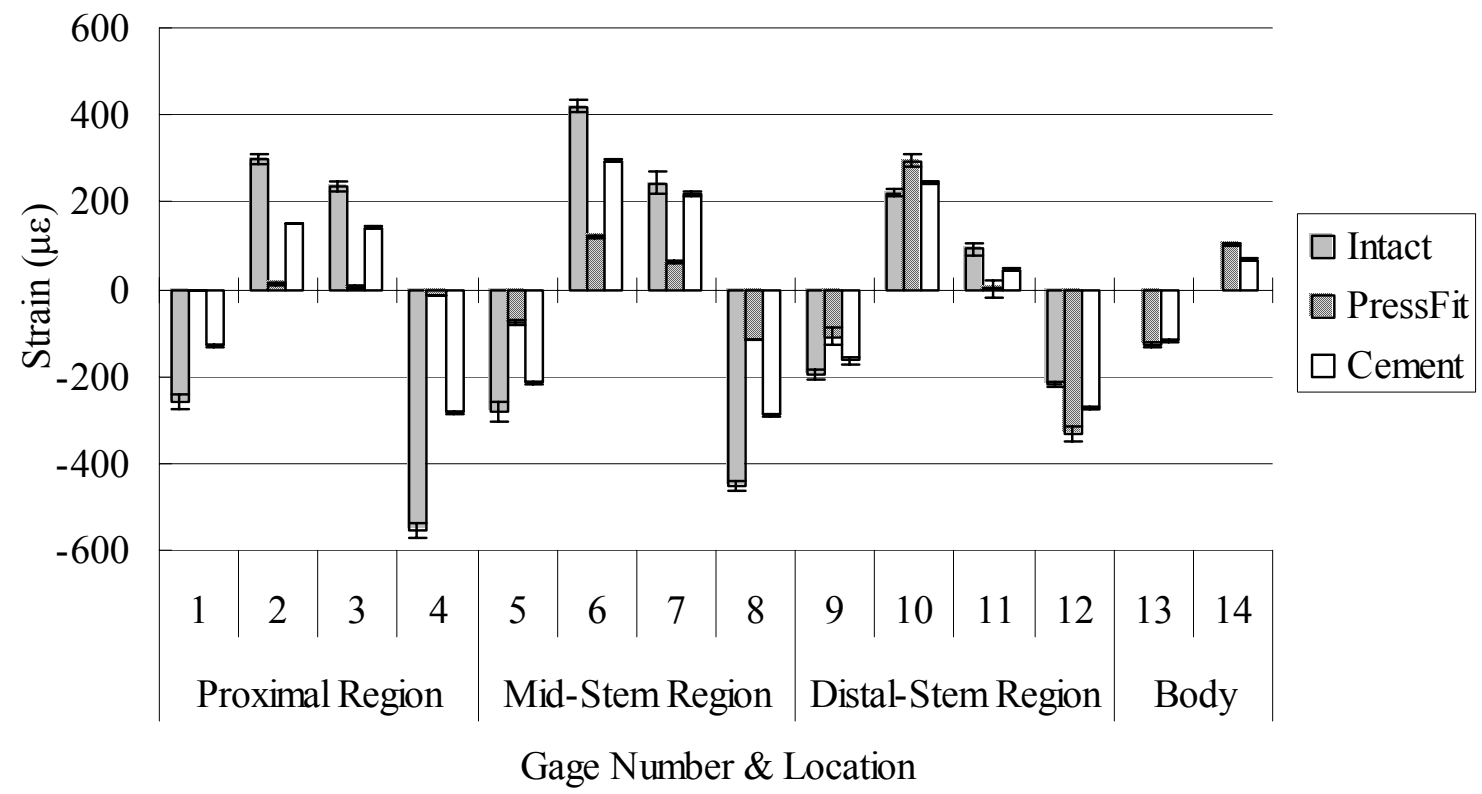

FIGURE 49. Measured intact, press fit, and cemented surface strains with a $360 \mathrm{~N}$ load for femur \#4471.

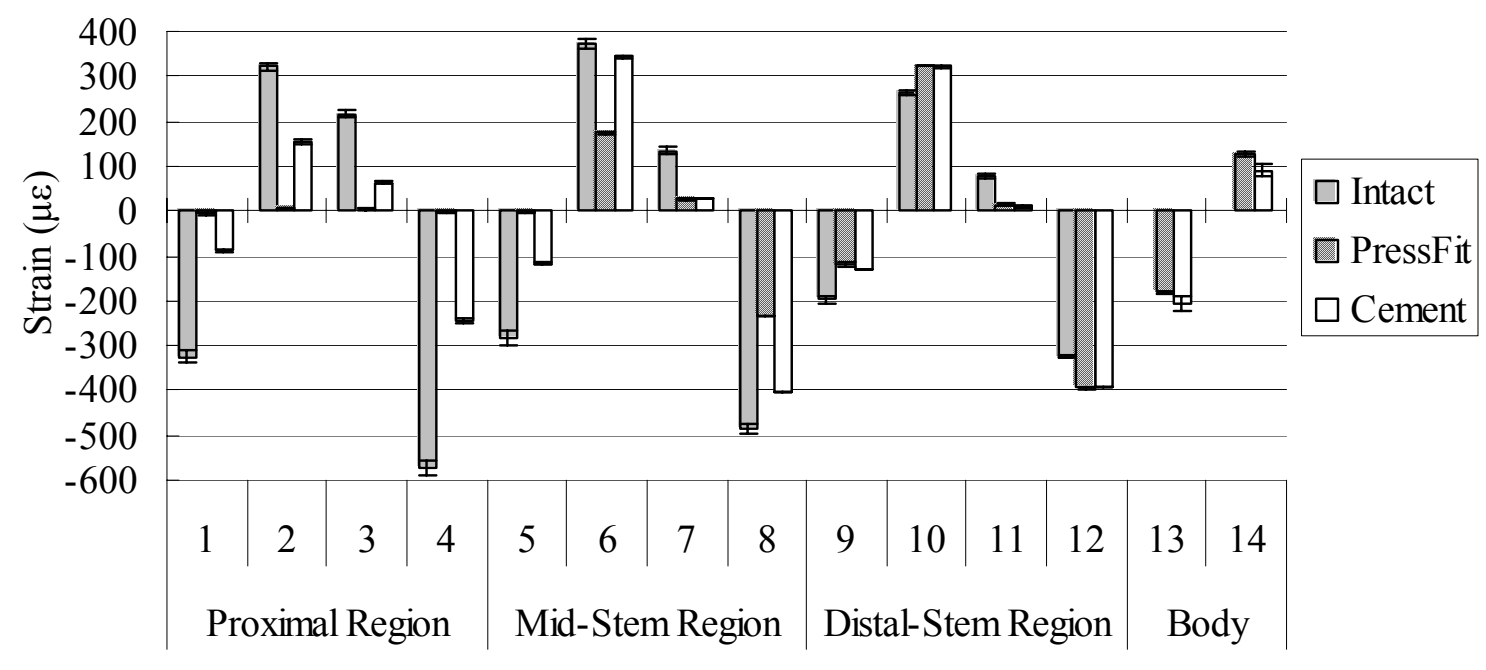

Gage Number \& Location

FIGURE 50. Measured intact, press fit, and cemented surface strains with a $360 \mathrm{~N}$ load for femur \#4472. 
TABLE XIII. Percent strain decrease between press fit and cemented loading cases on modular body.

\begin{tabular}{|c|c|c|c|c|c|c|c|c|}
\hline \multicolumn{2}{|c|}{ Gage \# and Location } & \multicolumn{7}{|c|}{ Femur \# } \\
\cline { 3 - 9 } & 4139 & 4140 & 4141 & 4142 & 4470 & 4471 & 4472 \\
\hline \hline Medial face on body & 13 & $20.4 \%$ & $47.7 \%$ & $49.5 \%$ & $51.6 \%$ & $66.6 \%$ & $16.4 \%$ & $31.0 \%$ \\
\hline Lateral face on body & 14 & $31.3 \%$ & $13.1 \%$ & $27.5 \%$ & $39.9 \%$ & $42.3 \%$ & $23.1 \%$ & $45.3 \%$ \\
\hline \multicolumn{2}{|c|}{ Overall } & $25.9 \%$ & $30.4 \%$ & $38.5 \%$ & $45.8 \%$ & $54.5 \%$ & $19.8 \%$ & $38.2 \%$ \\
\hline
\end{tabular}

TABLE XIV. Mean and standard deviation between trials under $180 \mathrm{~N}$ for femur $\# 4140$.

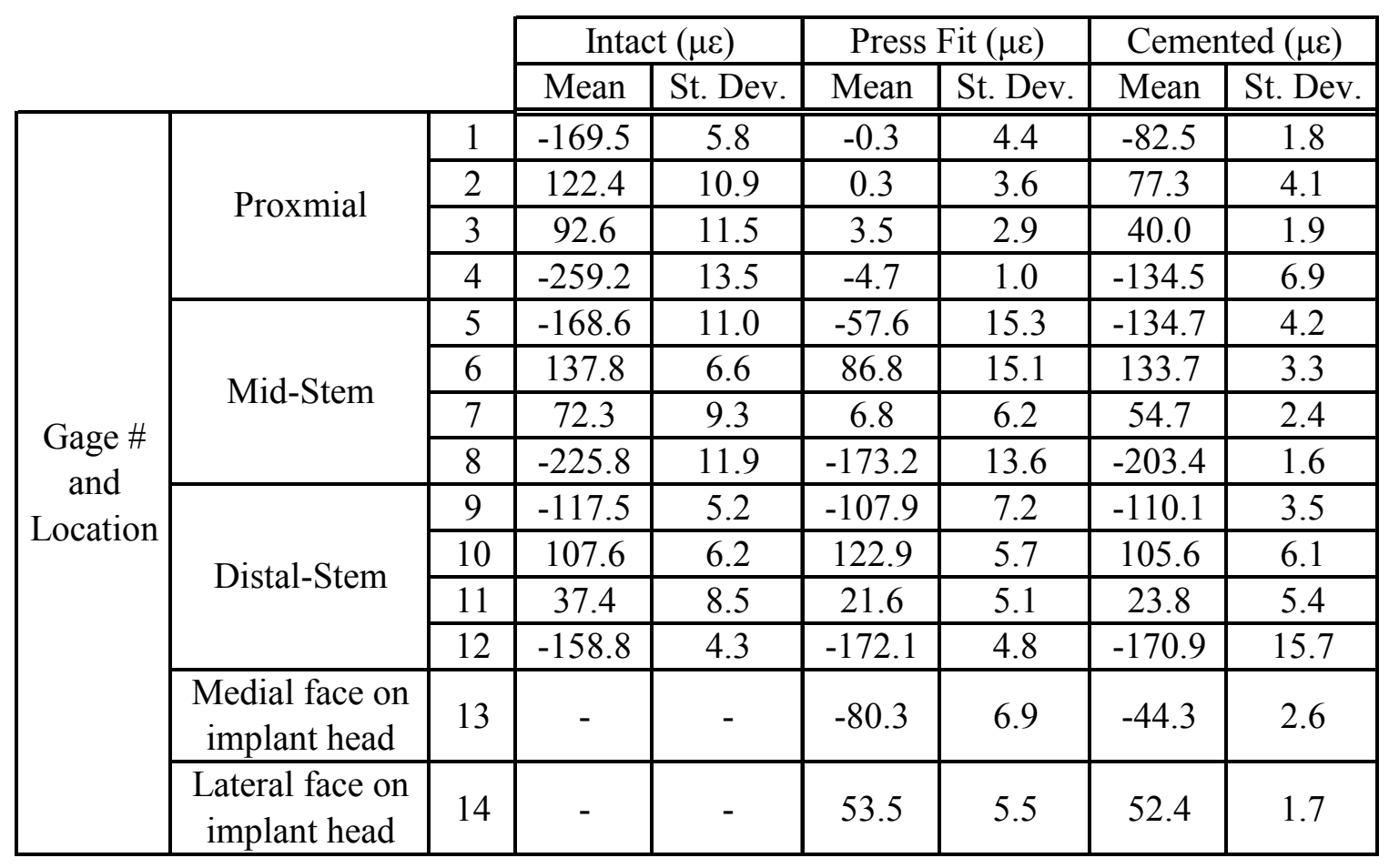


TABLE XV. Mean and standard deviation between trials under $360 \mathrm{~N}$ for femur \#4140.

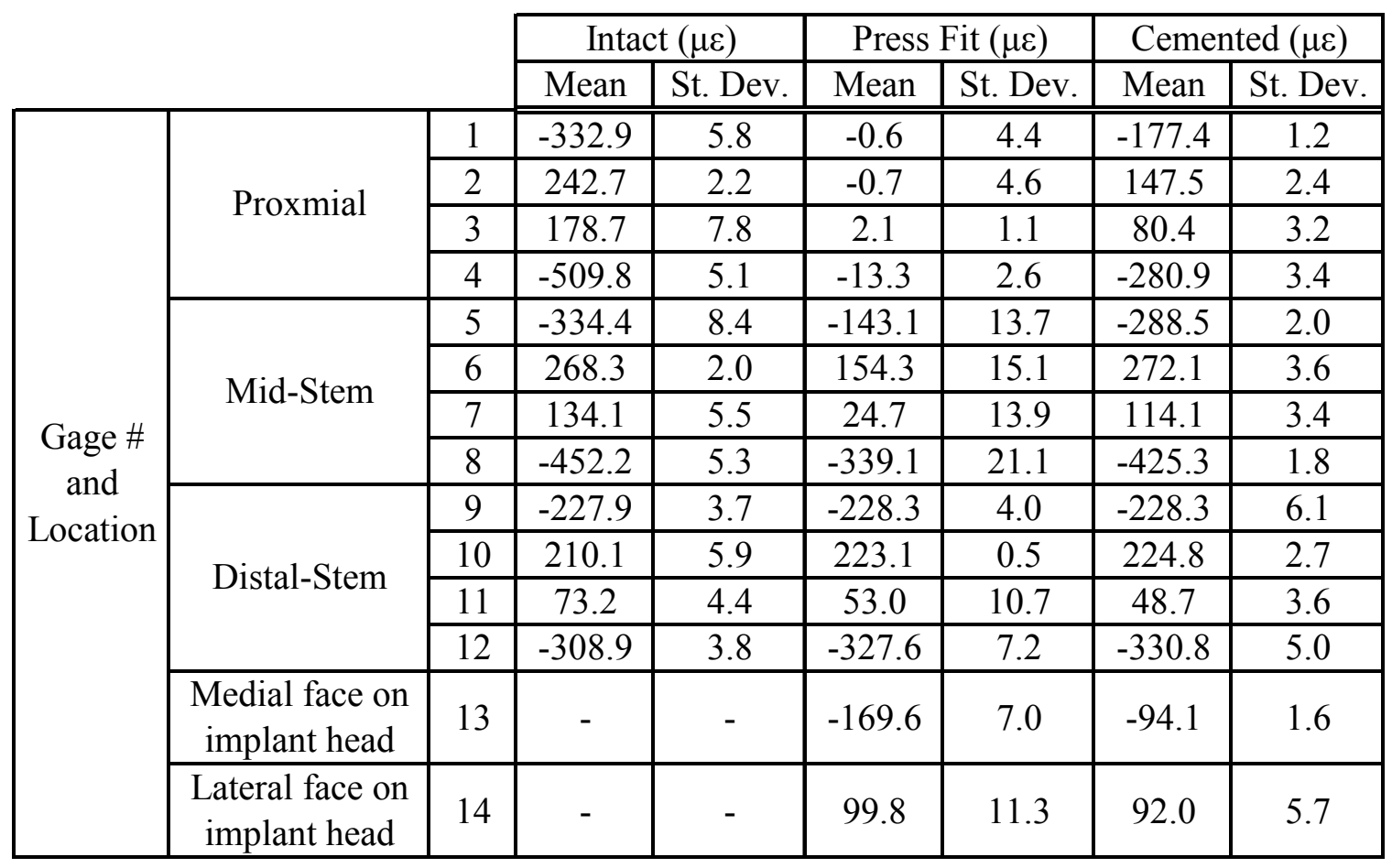

TABLE XVI. Mean and standard deviation between trials under $180 \mathrm{~N}$ for femur $\# 4141$.

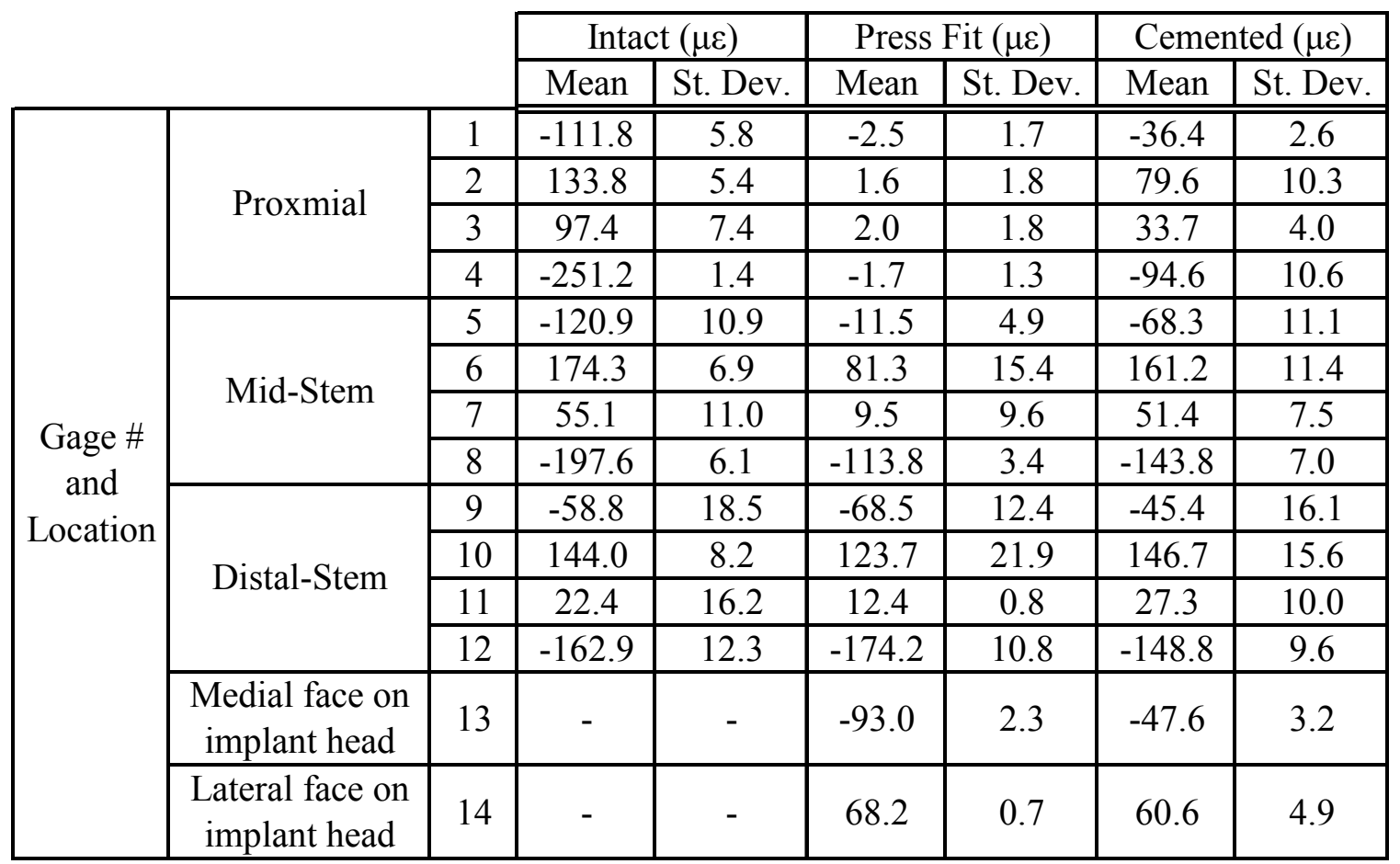


TABLE XVII. Mean and standard deviation between trials under $360 \mathrm{~N}$ for femur \#4141.

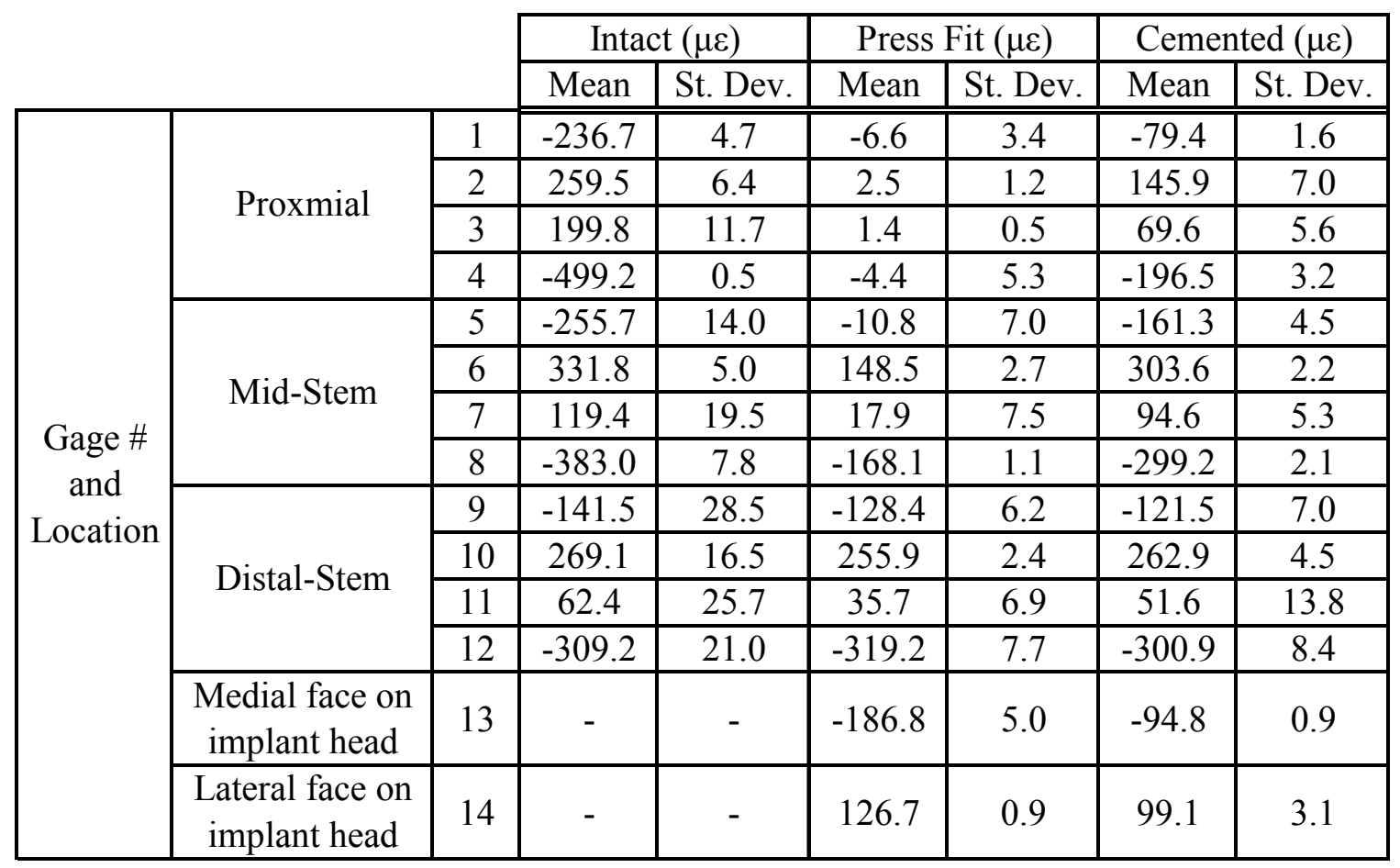


TABLE XVIII. Mean and standard deviation between trials under $180 \mathrm{~N}$ for femur \#4142.

\begin{tabular}{|c|c|c|c|c|c|c|c|c|}
\hline & \multicolumn{2}{|c|}{ Intact $(\mu \varepsilon)$} & \multicolumn{2}{|c|}{ Press Fit $(\mu \varepsilon)$} & \multicolumn{2}{|c|}{ Cemented $(\mu \varepsilon)$} \\
\hline & & & Mean & St. Dev. & Mean & St. Dev. & Mean & St. Dev \\
\hline \multirow{14}{*}{$\begin{array}{l}\text { Gage \# } \\
\text { and } \\
\text { Location }\end{array}$} & \multirow{4}{*}{ Proxmial } & 1 & -147.7 & 6.6 & -3.4 & 1.4 & -71.0 & 1.4 \\
\hline & & 2 & 61.9 & 3.8 & 3.1 & 1.1 & 44.4 & 11.9 \\
\hline & & 3 & 79.1 & 4.3 & 4.3 & 3.1 & 33.7 & 8.4 \\
\hline & & 4 & -242.7 & 4.1 & -2.8 & 4.6 & -95.4 & 6.1 \\
\hline & \multirow{4}{*}{ Mid-Stem } & 5 & -154.9 & 3.0 & -26.3 & 8.1 & -83.8 & 1.7 \\
\hline & & 6 & 145.3 & 2.3 & 97.6 & 4.6 & 135.4 & 5.5 \\
\hline & & 7 & 31.1 & 2.8 & 18.8 & 4.8 & 26.3 & 4.4 \\
\hline & & 8 & -198.3 & 4.6 & -89.4 & 9.4 & -149.7 & 0.5 \\
\hline & \multirow{4}{*}{ Distal-Stem } & 9 & $\begin{array}{c}-83.1 \\
\end{array}$ & 6.1 & -86.8 & 3.8 & $\begin{array}{l}-65.7 \\
\end{array}$ & 20.5 \\
\hline & & 10 & 131.2 & 4.0 & 131.2 & 2.4 & 151.8 & 26.2 \\
\hline & & 11 & 42.4 & 4.6 & 35.0 & 2.5 & 29.0 & 6.7 \\
\hline & & 12 & -125.9 & 5.3 & -137.8 & 3.6 & -127.7 & 30.4 \\
\hline & $\begin{array}{c}\text { Medial face on } \\
\text { implant head }\end{array}$ & 13 & - & - & -98.1 & 11.8 & -73.3 & 8.7 \\
\hline & $\begin{array}{l}\text { Lateral face on } \\
\text { implant head }\end{array}$ & 14 & - & - & 72.8 & 5.8 & 57.4 & 2.0 \\
\hline
\end{tabular}

TABLE XIX. Mean and standard deviation between trials under $360 \mathrm{~N}$ for femur \#4142.

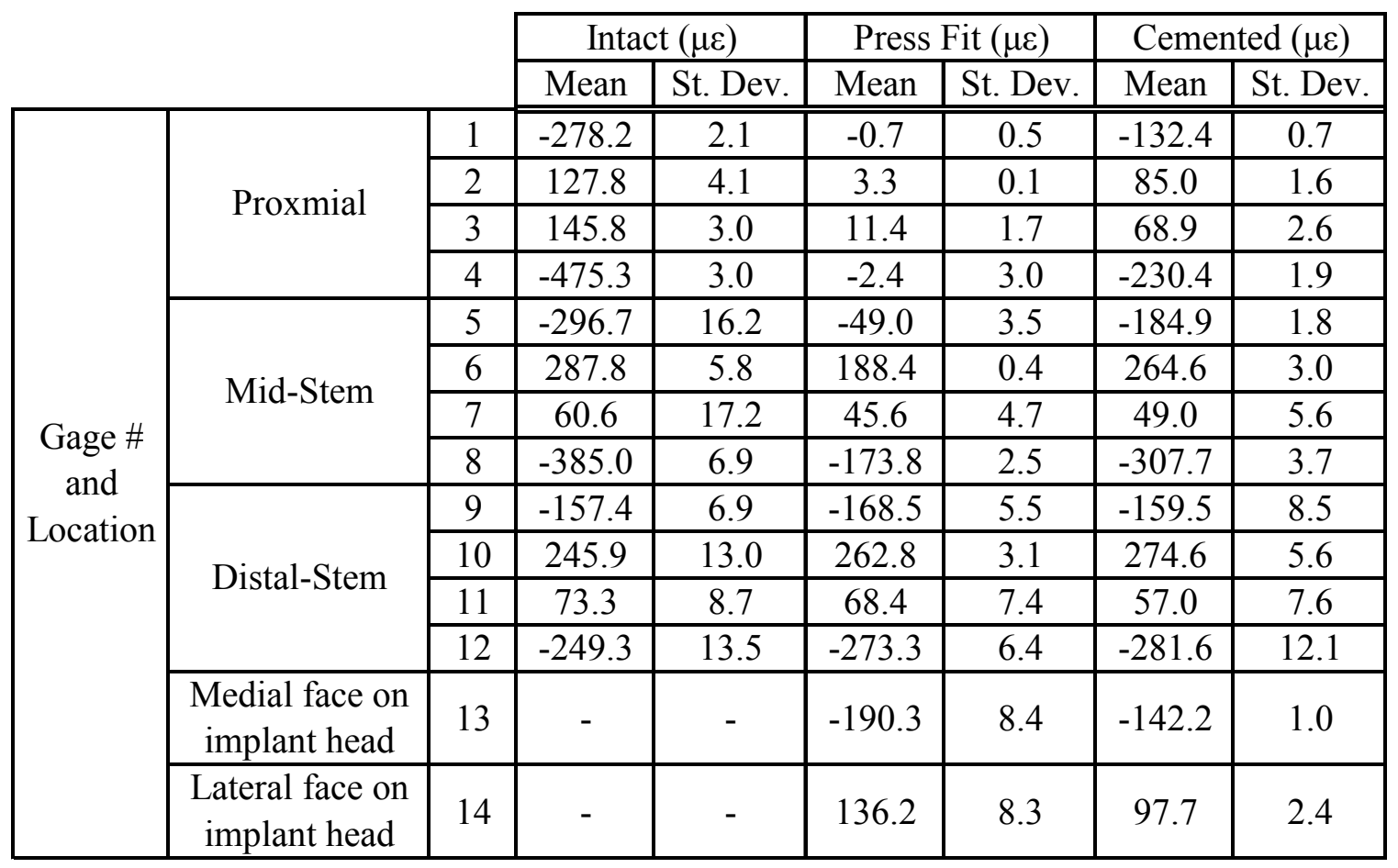


TABLE XX. Mean and standard deviation between trials under $180 \mathrm{~N}$ for femur \#4470.

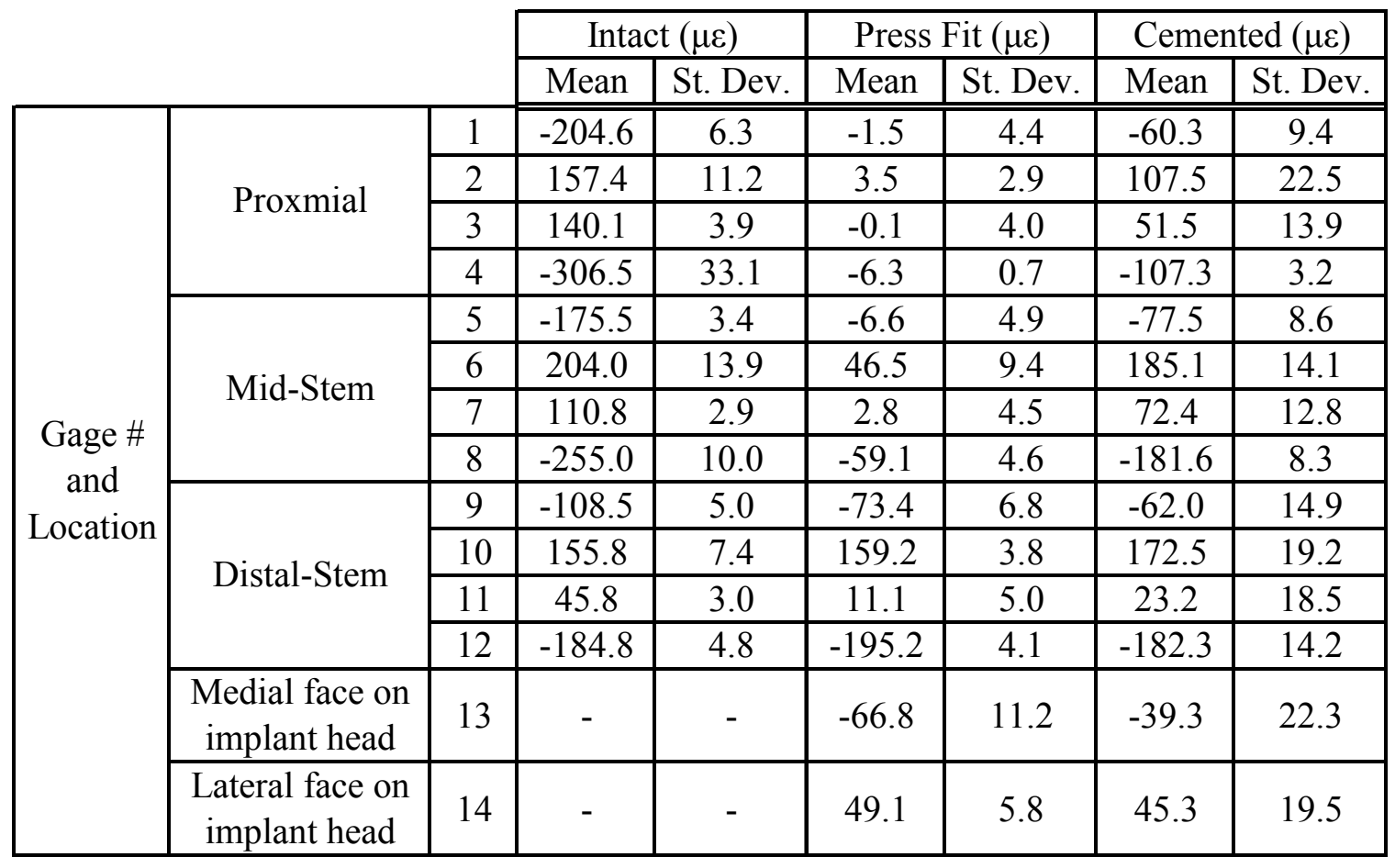

TABLE XXI. Mean and standard deviation between trials under $360 \mathrm{~N}$ for femur $\# 4470$.

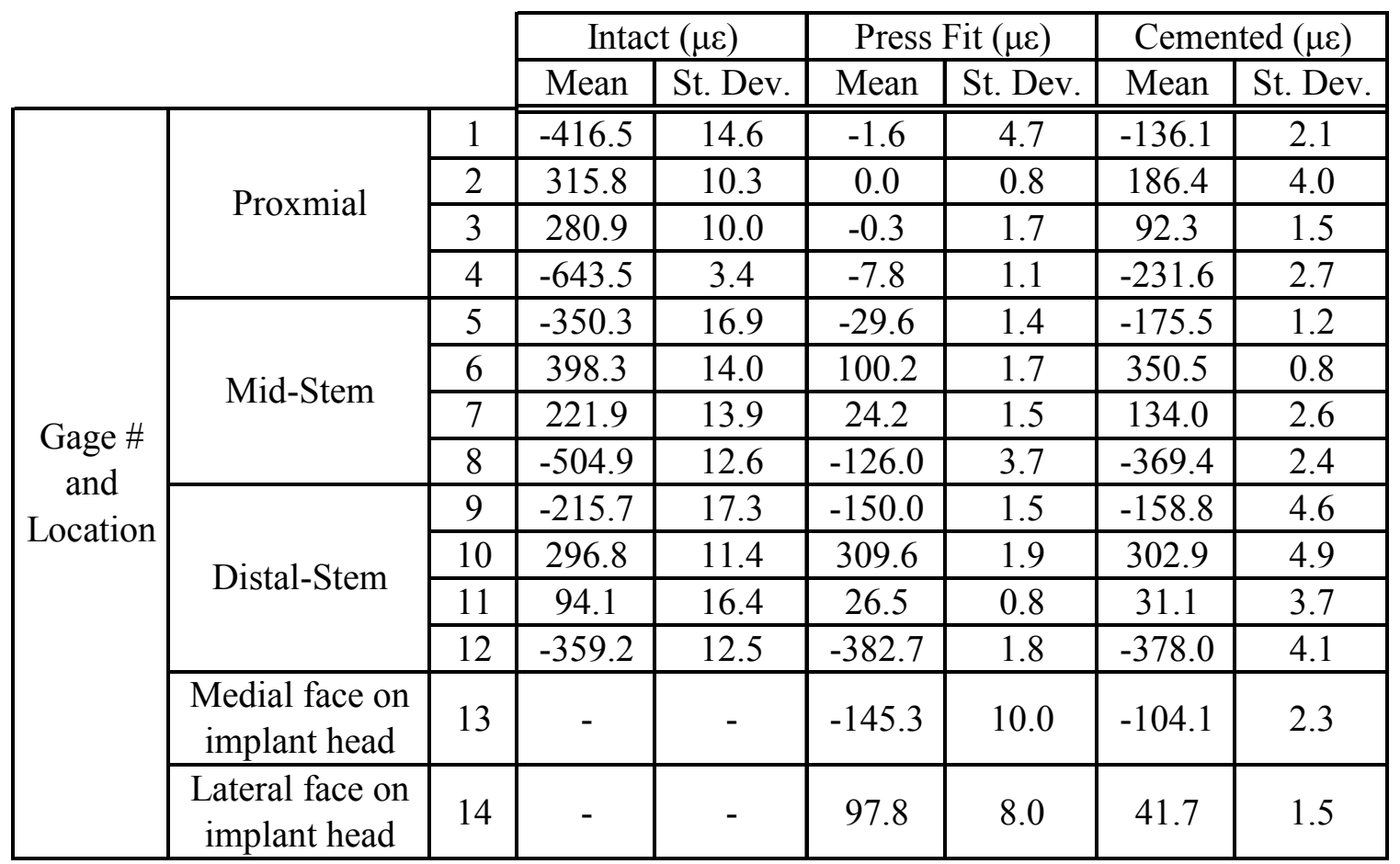


TABLE XXII. Mean and standard deviation between trials under $180 \mathrm{~N}$ for femur \#4471.

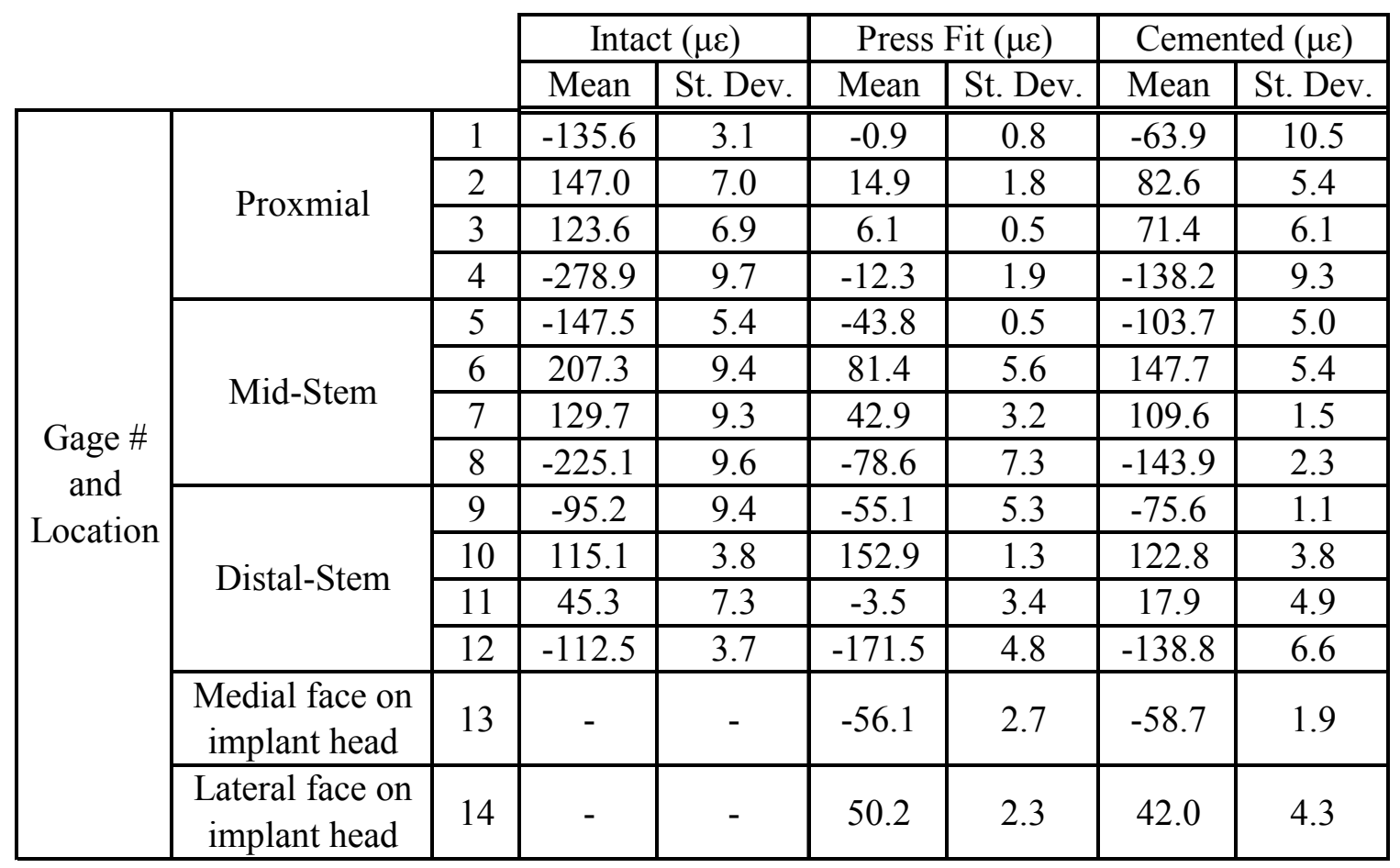


TABLE XXIII. Mean and standard deviation between trials under $360 \mathrm{~N}$ for femur \#4471.

\begin{tabular}{|c|c|c|c|c|c|c|c|c|}
\hline & \multicolumn{2}{|c|}{ Intact $(\mu \varepsilon)$} & \multicolumn{2}{|c|}{ Press Fit $(\mu \varepsilon)$} & \multicolumn{2}{|c|}{ Cemented $(\mu \varepsilon)$} \\
\hline & & & Mean & St. Dev. & Mean & St. Dev. & Mean & St. Dev. \\
\hline \multirow{14}{*}{$\begin{array}{l}\text { Gage \# } \\
\text { and } \\
\text { Location }\end{array}$} & \multirow{4}{*}{ Proxmial } & 1 & -259.2 & 16.8 & -1.3 & $\overline{00.2}$ & -129.7 & 3.1 \\
\hline & & 2 & 296.7 & 10.6 & 12.8 & 2.2 & 150.9 & 0.7 \\
\hline & & 3 & 236.4 & 13.6 & 5.5 & 1.0 & 141.9 & 2.0 \\
\hline & & 4 & -554.2 & 15.2 & -15.2 & 0.6 & -284.3 & 3.9 \\
\hline & \multirow{4}{*}{ Mid-Stem } & 5 & -279.3 & 22.2 & -76.6 & 3.6 & -213.5 & 2.7 \\
\hline & & 6 & 420.1 & 12.9 & 120.1 & 3.0 & 295.7 & 1.4 \\
\hline & & 7 & 243.7 & 24.1 & 62.3 & 1.4 & 220.3 & 4.5 \\
\hline & & 8 & -452.6 & 12.4 & -117.5 & 0.5 & -288.7 & 2.1 \\
\hline & \multirow{4}{*}{ Distal-Stem } & 9 & -197.3 & 12.8 & -109.7 & 19.4 & -164.7 & 7.4 \\
\hline & & 10 & 220.5 & 7.2 & 295.2 & 13.9 & 244.6 & 3.0 \\
\hline & & 11 & 93.5 & 14.1 & -1.0 & 18.7 & 43.9 & 2.6 \\
\hline & & 12 & -219.2 & 3.4 & -332.1 & 18.1 & -273.2 & 2.2 \\
\hline & $\begin{array}{c}\text { Medial face on } \\
\text { implant head }\end{array}$ & 13 & - & - & -127.6 & 3.5 & -118.8 & 1.2 \\
\hline & $\begin{array}{l}\text { Lateral face on } \\
\text { implant head }\end{array}$ & 14 & - & - & 102.9 & 4.5 & 67.5 & 2.5 \\
\hline
\end{tabular}


TABLE XXIV. Mean and standard deviation between trials under $180 \mathrm{~N}$ for femur \#4472.

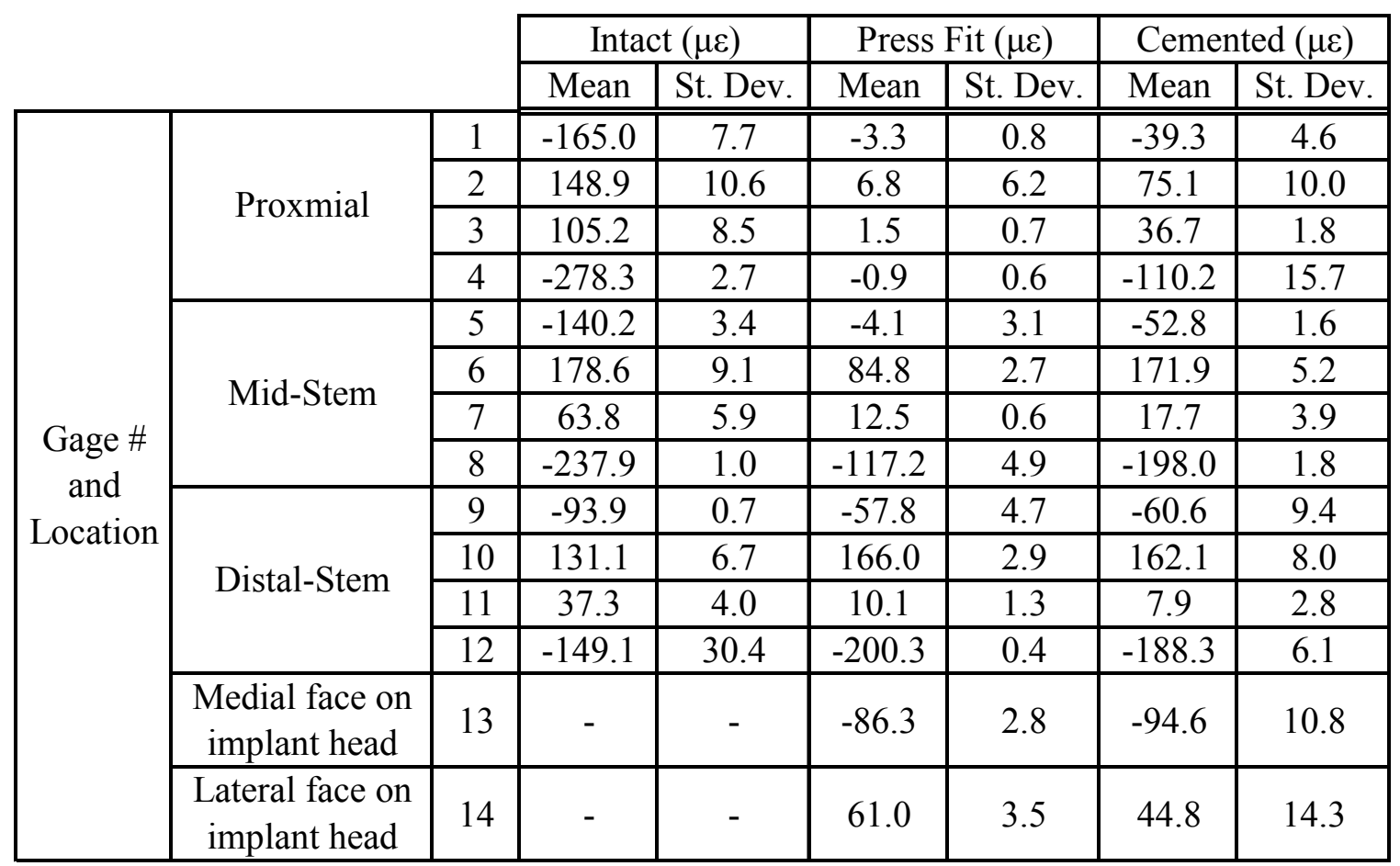


TABLE XXV. Mean and standard deviation between trials under $360 \mathrm{~N}$ for femur \#4472.

\begin{tabular}{|c|c|c|c|c|c|c|c|c|}
\hline & \multicolumn{2}{|c|}{ Intact $(\mu \varepsilon)$} & \multicolumn{2}{|c|}{ Press Fit $(\mu \varepsilon)$} & \multicolumn{2}{|c|}{ Cemented $(\mu \varepsilon)$} \\
\hline & & & Mean & $\overline{\text { St. Dev. }}$ & Mean & St. Dev. & Mean & St. Dev \\
\hline \multirow{14}{*}{$\begin{array}{l}\text { Gage \# } \\
\text { and } \\
\text { Location }\end{array}$} & \multirow{4}{*}{ Proxmial } & 1 & 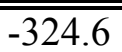 & $\begin{array}{l}13.9 \\
\end{array}$ & -4.7 & 2.8 & -88.9 & 2.9 \\
\hline & & 2 & 321.6 & 8.3 & 6.7 & 2.3 & 154.4 & 3.7 \\
\hline & & 3 & 215.4 & 8.8 & 3.3 & 0.8 & 63.8 & 1.8 \\
\hline & & 4 & -571.8 & 14.8 & -3.0 & 1.1 & -246.6 & 4.9 \\
\hline & \multirow{4}{*}{ Mid-Stem } & 5 & -281.5 & 15.4 & -3.8 & 2.0 & -116.7 & 2.4 \\
\hline & & 6 & 372.0 & 9.0 & 173.6 & 2.0 & 343.4 & 2.3 \\
\hline & & 7 & 133.9 & 7.3 & 25.8 & 2.7 & 27.5 & 0.9 \\
\hline & & 8 & -485.3 & 11.4 & -235.8 & 0.6 & -403.3 & 1.9 \\
\hline & \multirow{4}{*}{ Distal-Stem } & 9 & -197.8 & 10.1 & -119.2 & 3.7 & -129.0 & 1.6 \\
\hline & & 10 & 264.2 & 6.0 & 325.6 & 0.2 & 320.8 & 3.8 \\
\hline & & 11 & 78.5 & 4.8 & 14.7 & 4.3 & 10.4 & 1.5 \\
\hline & & 12 & -324.2 & 3.1 & -393.4 & 3.7 & -392.1 & 1.5 \\
\hline & $\begin{array}{c}\text { Medial face on } \\
\text { implant head }\end{array}$ & 13 & - & - & -180.8 & 3.0 & -207.4 & 16.2 \\
\hline & $\begin{array}{l}\text { Lateral face on } \\
\text { implant head }\end{array}$ & 14 & - & - & 126.8 & 3.5 & 91.1 & 11.4 \\
\hline
\end{tabular}


XI. VITA

Justin Conway is the son of Steve and Sharon Conway of Sandy Hook, Kentucky and the grandson of J.C. and Della Adkins of West Liberty and Virgil and Viola Conway of Mt. Sterling. Justin graduated in 2005 from the University of Louisville with a Bachelor of Science degree in Mechanical Engineering. In 2006, he obtained his Master's degree in Mechanical Engineering. He has accepted a position with Exactech, Inc. in Gainesville, FL as Product Design Engineer and will be getting married in 2006. 